Andrews University

Digital Commons @ Andrews University

\title{
The Impact of Values Clarification and Expression of Beliefs on Dysfunctional Leadership among Church Lay Leaders
}

John F. Cosgrove

Andrews University, jcf1953@gmail.com

Follow this and additional works at: https://digitalcommons.andrews.edu/dissertations

Part of the Education Commons, and the Leadership Studies Commons

\section{Recommended Citation}

Cosgrove, John F., "The Impact of Values Clarification and Expression of Beliefs on Dysfunctional Leadership among Church Lay Leaders" (2016). Dissertations. 1593.

https://digitalcommons.andrews.edu/dissertations/1593

https://dx.doi.org/10.32597/dissertations/1593

This Dissertation is brought to you for free and open access by the Graduate Research at Digital Commons @ Andrews University. It has been accepted for inclusion in Dissertations by an authorized administrator of Digital Commons@ Andrews University. For more information, please contact repository@andrews.edu. 


\begin{abstract}
THE IMPACT OF VALUES CLARIFICATION AND EXPRESSION OF BELIEFS ON DYSFUNCTIONAL LEADERSHIP AMONG CHURCH LAY LEADERS
\end{abstract}

by

John F. Cosgrove

Chair: Sylvia Gonzalez 


\title{
ABSTRACT OF GRADUATE STUDENT RESEARCH
}

\author{
Dissertation
}

Andrews University

School of Education

\section{Title: THE IMPACT OF VALUES CLARIFICATION AND EXPRESSION OF BELIEFS ON DYSFUNCTIONAL LEADERSHIP AMONG CHURCH LAY LEADERS}

Name of researcher: John F. Cosgrove

Name and degree of faculty chair: Sylvia Gonzalez, Ph.D.

Date completed: March 2016

\section{Problem}

Leaders face challenges from within themselves and from others. Dysfunctions within the leader and with their group can lessen leadership effectiveness. It appears some leaders manage these dysfunctions better than others. More needs to be understood about how these dysfunctions are best mediated and some have suggested clarification of values and beliefs can do that.

\section{Method}

This study followed a quantitative correlational research design. Data were obtained using surveys that 84 participants completed on line. Participants were selected from current lay leaders and former lay leaders of not more than three years past from 
Christ United Methodist Church of Chattanooga, Tennessee and Collegedale Community Church of Collegedale, Tennessee. The Dark Side Leadership Profile (DSLP) was used to measure the degree of codependence, compulsion, paranoia, narcissism, and passiveaggression tendencies (described as dysfunctions) while the Modeling-the-Way Leadership Practices Inventory (LPI) Self was used to measure the degree one can clarify and authentically express values and beliefs. Regression and correlation analysis was used to test for a relationship between Modeling-the-Way and each dysfunction.

\section{Results}

The results of the study indicate a moderate degree of each of the dysfunctions existing among the participants however higher dysfunctional scores were evident with compulsion and codependence while lower scores, but still in the moderate range, were measured in passive-aggression scores. The results also indicated a consistently high degree of clarification and expression of values and beliefs among the participants.

A statistically significant inverse relationship was discovered between Modelingthe-Way LPI Self scores and the DSLP scores measuring each dysfunction with the exception of codependence among lay leaders in Collegedale Community Church. With that exception these results indicate that the higher one scored on the Modeling-the-Way LPI Self, a measure used to show the degree one has discovered and authentically expressed values and beliefs, the lower one scored on the DSLP inventory, the measuring for dysfunction. Results also indicated that the major component of Modeling-the-Way that asks the constituent "for feedback on how my [the leader's] actions affect others performance" impacted significantly every dysfunction with the exception of codependence. 


\section{Conclusions}

The purpose of the study was to explore if the discovery and authentic expression of a leader's values and beliefs may lower a leader's tendencies toward these dysfunctions. The results of the study indicate that the more lay leaders in these congregations discover and authentically express their values to their constituents the lower the levels of dysfunctional tendencies, with the exception of codependence in Collegedale Community Church. A review of the literature validates the results obtained. It is therefore suggested that the more one discovers and authentically expresses values and beliefs, the less dysfunction will be reported and the more effective a leader will be perceived to be. 
Andrews University

School of Education

\title{
THE IMPACT OF VALUES CLARIFICATION AND EXPRESSION OF BELIEFS ON DYSFUNCTIONAL LEADERSHIP AMONG CHURCH LAY LEADERS
}

\author{
A Dissertation \\ Presented in Partial Fulfillment \\ of the Requirements for the Degree \\ Doctor of Philosophy
}

by

John F. Cosgrove

March 2016 
(C) Copyright by John F. Cosgrove 2016

All Rights Reserved 
THE IMPACT OF VALUES CLARIFICATION AND EXPRESSION OF BELIEFS ON DYSFUNCTIONAL LEADERSHIP

AMONG CHURCH LAY LEADERS

\author{
A dissertation \\ presented in partial fulfillment \\ of the requirements for the degree \\ Doctor of Philosophy
}

\author{
by
}

John F. Cosgrove

APPROVAL BY THE COMMITTEE:

Chair: Sylvia Gonzalez

Member: Jay Brand

Member: Duane Covrig

External:
Dean, School of Education

Robson Marinho

Robson Marinho 


\section{TABLE OF CONTENTS}

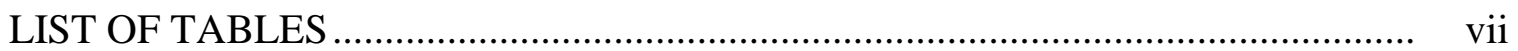

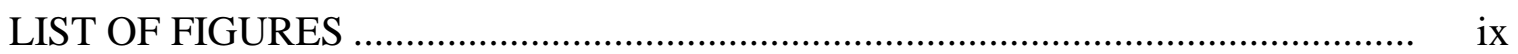

\section{Chapter}

1. INTRODUCTION .................................................................................

Background to the Study .........................................................................

Statement of the Problem........................................................................ 4

Purpose of the Study ................................................................................. 4

Research Question .......................................................................... 4

Hypothesis....................................................................................... 6

Conceptual Framework ……………………………………………..... 6

General Methodology ........................................................................... 8

Rationale ……...................................................................... 9

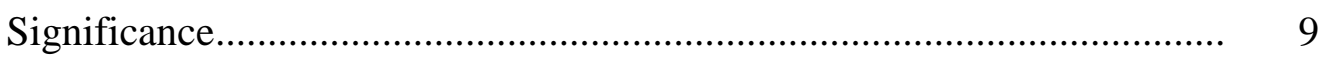

Definition of Terms.......................................................................... 10

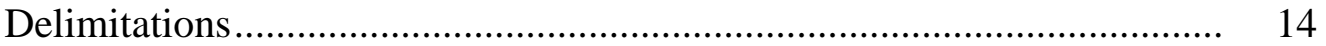

Organization of the Study ...................................................................... 14

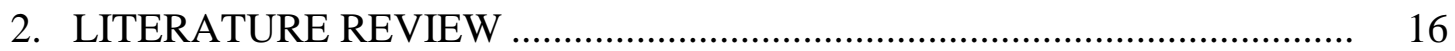

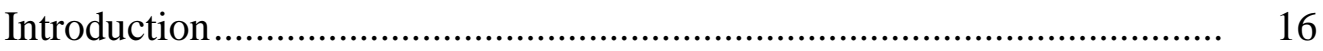

Values and Beliefs in Leadership ........................................................... 15

Modeling-the-Way ……………………...................................... 17

Empirical Study Connecting Values to Effective

Leadership in the Profit Sector ..................................................... 22

Empirical Study Connecting Values to Effective

Leadership in the Nonprofit Sector to Include

Church................................................................................ 24

Values and Beliefs in the Seventh-day Adventist

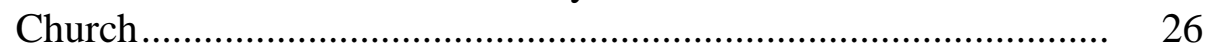

Values and Beliefs in the Methodist Church ...................................... 28

Effective Leadership .......................................................................... 29

Traits of Effective Leadership ......................................................... 31

Inspire a Shared Vision ............................................................. 33

Challenge the Process .................................................................. 34

Enable Others to Act............................................................... 36 
Encourage the Heart...................................................................... 38

Effective Leadership in a Changing Environment ............................... $\quad 39$

Effective Leadership and the Group ................................................. 42

Measuring Effective Leadership ........................................................ 44

Ineffective Leadership and Leader Dysfunctions ..................................... 45

Ineffective Leadership and the Church …………….......................... 49

The Compulsive Leader ................................................................. 50

The Codependent Leader ................................................................. 51

The Narcissistic Leader.................................................................... 52

The Paranoid Leader ...................................................................... 54

The Passive-aggressive Leader ......................................................... 54

Lay Leadership in Churches and Community ........................................... 56

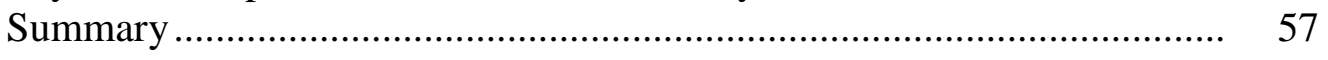

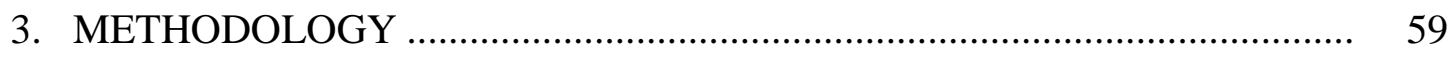

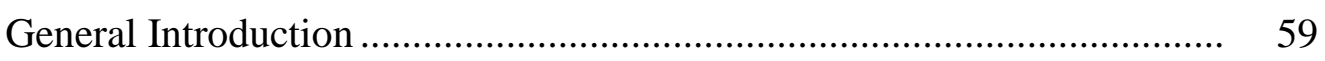

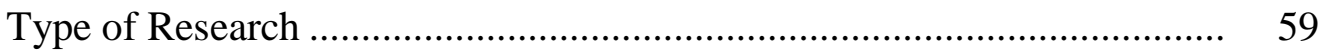

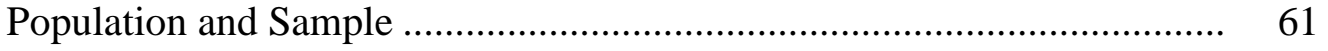

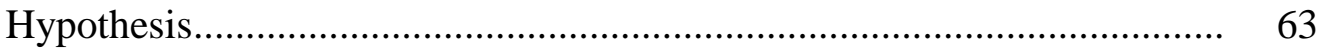

Definition of Variables ......................................................................... 64

Instrumentation, Reliability, and Validity …………………………........ 66

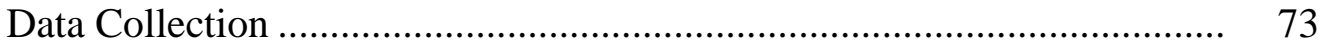

Permission to Conduct Study and Ethical

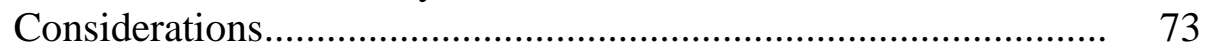

Administrating the Data-Collection Process.......................................... 74

Data Analysis ..................................................................................... 77

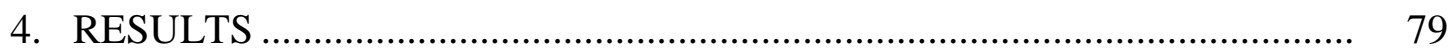

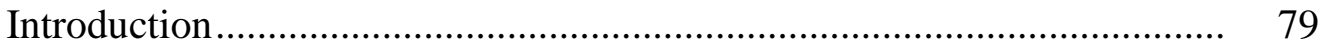

Demographics of the Sample …………................................................ 80

Statistical Assumptions for the Variables ................................................... 83

Test of Hypothesis ............................................................................... 86

Inferential Statistics, Specific Hypothesis, and

Regression Analysis..................................................................... 88

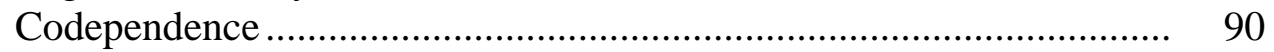

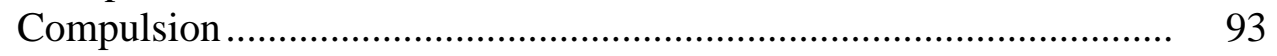

Narcissism........................................................................ 95

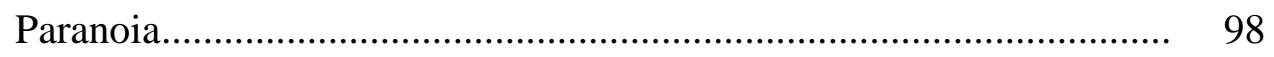

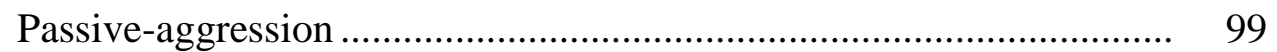

Summary of Regression Analysis for Components ............................. 103

Alternative Explanations........................................................................ 104

Conclusions and Findings ..................................................................... 106

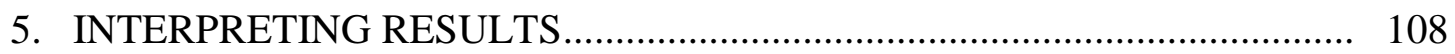




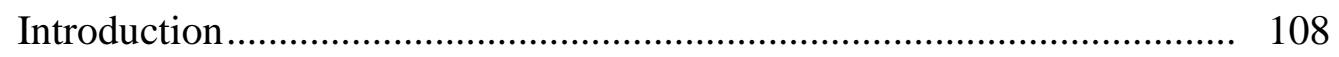

Background of the Study ................................................................. 108

Statement of the Problem................................................................. 111

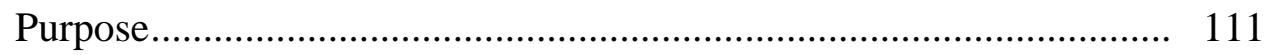

Research Questions ................................................................... 112

Research Design and Procedures ............................................................ 113

Population and Sample ....................................................................... 114

Summary of Findings..................................................................... 117

Descriptive Statistics..................................................................... 117

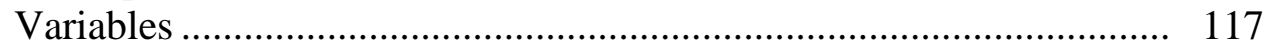

Primary Findings..................................................................... 119

Discussion ......................................................................... 120

Codependence ................................................................... 122

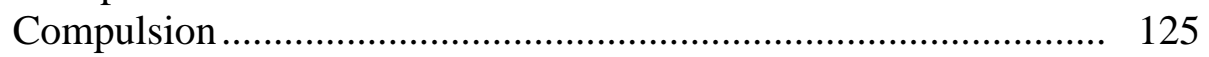

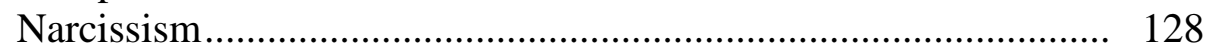

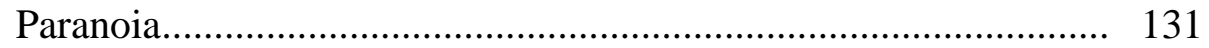

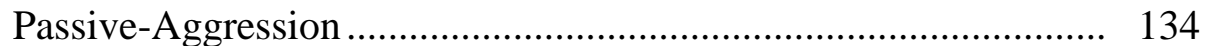

Concluding Discussion ............................................................ 137

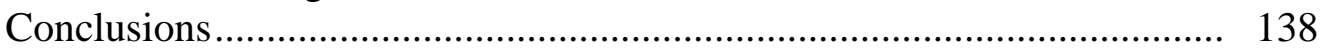

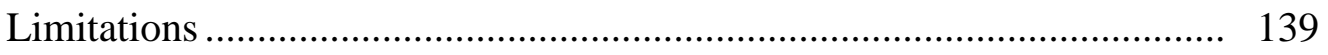

Recommendations for Practice ........................................................... 140

Recommendations for Further Research............................................... 141

Appendix

A. DARK SIDE LEADERSHIP PROFILE ...................................................... 144

B. MODELING-THE-WAY LPI—SELF INVENTORY .................................... 149

C. LETTER of AUTHORIZATION FROM METHODIST

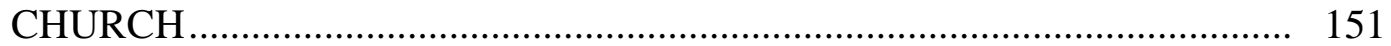

D. LETTER OF AUTHORIZATION FROM COLLEGEDALE COMMUNITY CHURCH................................................................ 153

E. EMAIL INVITATION TO PARTICIPATE ................................................ 155

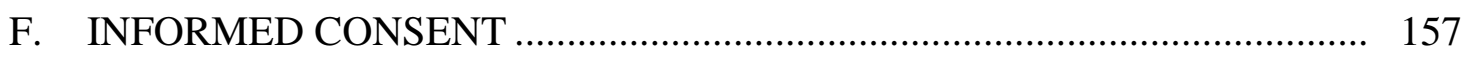

G. HISTOGRAMS TESTING FOR NORMALCY …...................................... 160

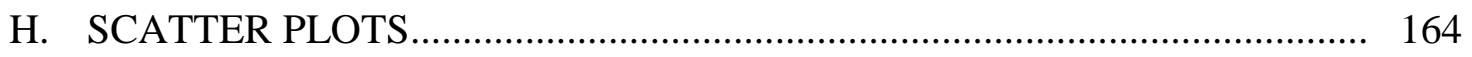

I. GENDER CORRELATION TABLES …………….................................... 169

J. DSLP MEAN SCORES BY DEMOGRAPHIC CATEGORY ….................... 171 
REFERENCE LIST

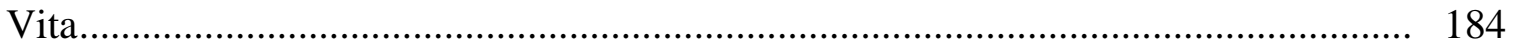




\section{LIST OF TABLES}

1. Study Population and Response to Participation …….................................. 62

2. Dysfunctional Variables and Modeling-the-Way Variable ............................... 65

3. DSLP Reliability Analysis .......................................................................... 72

4. Cronbach Alpha Score for Reliability Among Participants ............................... 73

5. Gender Frequencies ...................................................................... 80

6. Denominational Frequencies ………………......................................... 80

7. Tenure as Church Members ………………………................................. 81

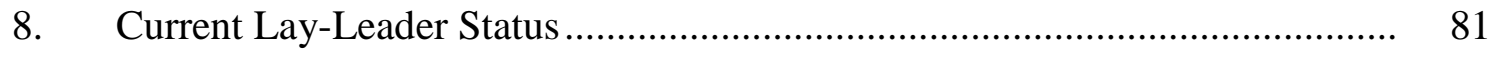

9. Tenure as a Lay Leaders …………………………................................. 82

10. Average Scores for Dysfunctions by Location and Gender............................. 82

11. Average Scores for Modeling-the-Way ........................................................... 83

12. Variables of the Study With Description of Skewness ..................................... 85

13. Homogeneity of Variance Between Congregations.......................................... 87

14. Homogeneity of Variance Between Males and Females .................................. 87

15. Pearson's Correlation Between Modeling-the-Way and Each Dysfunction .................................................................................. 89

16. Model Summary of Modeling-the-Way Relationship to Compulsive Dysfunction in Collegedale Community Church.

17. Summary of Regression Analysis for the Components of Modeling-the-Way and Codependence Dysfunction in Collegedale Community Church 
18. Model Summary of Modeling-the-Way Relationship to

Codependence Dysfunction in Christ United Methodist

Church.....

19. Summary of Regression Analysis for the Components of

Modeling-the-Way and Codependence Dysfunction in

Christ United Methodist Church....

20. Model Summary of Modeling-the-Way Relationship to

Compulsion Dysfunction

21. Summary of Regression Analysis for the Components of

Modeling-the-Way and Compulsion Dysfunction.

22. Model Summary of Modeling-the-Way Relationship to

Narcissism Dysfunction

23. Summary of Regression Analysis for the Components of

Modeling-the-Way and Narcissism Dysfunction.

24. Model Summary of Modeling-the-Way Relationship to

Paranoia Dysfunction.

25. Summary of Regression Analysis for the Components of

Modeling-the-Way and Codependence Dysfunction in

Christ United Methodist Church.

26. Model Summary of Modeling-the-Way Relationship to

Passive-aggression Dysfunction

27. Summary of Regression Analysis for the Components of

Modeling-the-Way and Passive-aggression Dysfunction

28. Summary of Regression Analysis Standard Error and Beta

Coefficients for Modeling-the-Way Components and

Dysfunctions 


\section{LIST OF FIGURES}

1. Research Approach ............................................................................... $\quad 75$

2. Modeling-the-Way Versus Tenure as a Lay Leader ......................................... 105

3. Modeling-the-Way Versus Tenure as a Church Member ................................ 106 


\section{CHAPTER 1}

\section{INTRODUCTION}

\section{Background of the Study}

Kouzes and Posner (2012a) discovered that the most admired leaders behave and make decisions based on "personal guiding principles" and "deeply held beliefs" (p. 4445). The authors further described these admired leaders as effective and credible leaders and argued that "to become a credible leader, you first have to comprehend fully deeply held beliefs - the values, standards, ethics, and ideals - that drive you" (p. 45) and that effective leaders speak out "on matters of values and conscience" (p. 44).

Kouzes and Posner (2012a) argue that "credibility is the foundation of leadership" (p. 37). Hughes, Ginnett, and Curphy (2006) argue that credibility is a factor of competency and trust and that "leaders with high levels of credibility are seen as trustworthy; they have a strong sense of right and wrong, stand up and speak up for what they believe in" (p. 525). Kouzes and Posner (2012a) argue that people trust leaders that can articulate their beliefs and values and thus can be credible.

In recent decades some have characterized many leaders as having limited or skewed values and beliefs to the point of creating a leadership "values crisis" (Morin, 1995, p. 10). Morin describes leaders with limited or skewed values as "people without rudders, without vision and with values that have very little value at all” (p. 10). The author further posits that if values can be simply defined as "those things that are 
important to a person or institution" (Morin, 1995, p. 10) in the absence of strongly supported moral values, "increasing greed and diminishing trust" (p. 10) are the guiding values. It is the absence of or failure to abide by a well justified and morally supported set of values that have caused many leaders to lose credibility, putting organizations and nations at risk (George \& Sims, 2007; Gilkeson, 2007; Hughes, Ginnett, \& Curphy, 2012; Rosenzweig, 2007; Sorkin, 2009).

Evidence suggests that the nonprofit sector and specifically the church may be experiencing a similar values and leadership crisis (Gilkeson, 2007; McIntosh \& Rima, 2007; Mead, 2008; Sarantopoulos, 2008). McIntosh and Rima (1997) conducted research addressing church leadership involving scandal and immoral behavior. They identified five dysfunctions as negatively impacting a leader's credibility. These dysfunctions are compulsion, narcissism, paranoia, codependence, and passive-aggression. Some researchers posit that the leadership crisis in churches may be due to those leadership dysfunctions (Boyd, 2007; McIntosh \& Rima, 2007). These dysfunctions in leaders may produce behavior consistent with self-promotion, greed, and immoral actions (George \& Sims, 2007; Kellerman, 2012; McIntosh \& Rima, 2007).

McIntosh and Rima (2007) argue that all leaders have dysfunctions that, if not recognized and managed, can negatively impact leadership effectiveness. The author posits that recognizing and being intentional about addressing dysfunctional leadership traits may be important to effective leadership. It has been further posited that leaders who have defined and authentically expressed their values and beliefs may lessen the impact of personal dysfunctions they may possess thus improving on their ability to gain credibility and influence followers (Boyd, 2007: Kouzes \& Posner, 2012a). 
McIntosh and Rima (2007) posit that all leaders are plagued with some of five separate dysfunctions and this argument extends to church lay leadership. The five dysfunctions described by McIntosh and Rima include compulsion, narcissism, paranoia, codependence, and passive-aggression.

On the other hand Kouzes and Posner (2012a) argue when extraordinary things happen in organizations, leaders engage in, what they call, "the five practices of exemplary leadership" (p. 15). These five practices include model the way, inspire a shared vision, challenge the process, enable others to act, and encourage the heart. The first of these exemplary practices is Modeling-the-Way and it is this practice that is the focus of this study. Literature will show that for a leader to be effective they must believe in something and be able to articulate these beliefs. Modeling-the-Way implies that the leader has discovered their core values and can clearly articulate what those values are. It may be helpful to explore how discovering and authentically articulating values, represented in Modeling-the-Way, may impact dysfunctions that negatively affect leadership effectiveness.

The two specific congregations that were studied were Christ United Methodist Church (CUM) and Collegedale Community Seventh-day Adventist Church (CCC). CUM was founded in 1958, has undergone numerous building projects and currently has 1500 members that attend worship each week. The head pastor has been in the position for nine years. He is 51 years old, married, and has two children and three grandchildren. CCC was founded in 1985, has also undergone numerous building projects and currently has 1100 members that attend worship each week. The head pastor has been in the position for 13 years. He is 60 years old, married, and has three children and six 
grandchildren. The churches are located 8.5 miles apart. The head pastors of each church have never met nor have any members of the governing bodies of each church had any affiliation or relationship in any capacity.

\section{Statement of the Problem}

Leaders face challenges from within themselves and from others. Dysfunctions within the leader and with their group can lessen leadership effectiveness. It appears some leaders manage these dysfunctions better than others. More needs to be understood about how these dysfunctions are best mediated and some have suggested clarification of values and beliefs can do that.

\section{Purpose of the Study}

This study explores if a relationship exists between personal dysfunctions associated with church lay leaders and the degree to which they have discovered and authentically expressed their values and beliefs among lay leaders in two different congregations, Christ United Methodist Church and Collegedale Community Seventhday Adventist Church, both located in the same community.

\section{Research Question}

This research was guided by the following question: What is the relationship between defining and authentically expressing values as defined by Modeling-the-Way and measured by Kouzes and Posner's (2012a) Leadership Practice Inventory (LPI) Self and the five personal dysfunctions, as measured by McIntosh and Rima's (2007) Dark Side Leadership Profile (DSLP), among church lay leaders in two specific congregations? 
There were also five sub questions:

1. Does a relationship exist between Modeling-the-Way, as measured by Kouzes and Posner's (2012a) LPI Self and the dysfunction of codependence as described by McIntosh and Rima's (2007) DSLP inventory among church lay leaders in two specific congregations?

2. Does a relationship exist between Modeling-the-Way, as measured by Kouzes and Posner's (2012a) LPI Self and the dysfunction of compulsion as described by McIntosh and Rima's (2007) DSLP inventory among church lay leaders in two specific congregations?

3. Does a relationship exist between Modeling-the-Way, as measured by Kouzes and Posner's (2012a) LPI Self and the dysfunction of narcissism as described by McIntosh and Rima's (2007) DSLP inventory among church lay leaders in two specific congregations?

4. Does a relationship exist between Modeling-the-Way, as measured by Kouzes and Posner's (2012a) LPI Self and the dysfunction of paranoia as described by McIntosh and Rima's (2007) DSLP inventory among church lay leaders in two specific congregations?

5. Does a relationship exist between Modeling-the-Way, as measured by Kouzes and Posner's (2012a) LPI Self and the dysfunction of passive-aggression as described by McIntosh and Rima's (2007) DSLP inventory among church lay leaders in two specific congregations? 


\section{Hypothesis}

The following null hypothesis guided this study:

$\mathrm{H} 1_{\mathrm{o}}$ : There is no correlation between the Modeling-the-Way scores, as measured by Kouzes and Posner's (2012a) LPI Self, and the dysfunctional leadership traits (codependence, compulsion, narcissism, paranoia, and passive-aggression) scores, as measured by McIntosh and Rima's (2007) DSLP inventory, for lay leaders in two congregations in Tennessee.

\section{Conceptual Framework}

In the field of leadership and leadership development scholars have attempted to define effective leadership. They have presented leadership theories and practices to help explain effectiveness. In this regard, Hughes et al. (2012) devote the following descriptions as skills associated with effective leadership: learning from experience, effective communication, listening, being assertive, able to provide constructive feedback, effectively manage stress, technical competence, building effective relationships, setting goals, and managing conflict to name a few. Northouse (2004) examined the following variables in describing how leaders influence followers: influence, perceptions, communicating a vision, motivations, empathy, social skills, and self-awareness.

On the other hand, scholars have also made efforts to describe or predict personal dysfunctions associated with ineffective leadership. In an attempt to predict dysfunctional leadership traits, Daboub, Rasheed, Priem, and Gray (1995) examined age, length of service, functional background, MBA education, military service, and homogeneity/ heterogeneity. They concluded that the older one was, the more educated they were, and 
the more military experience they had the weaker the relationship between personal dysfunctions and corporate illegal activity. Martin (2009), Rosenweig (2007), and Wolf (2010) attribute leadership dysfunction as a leader's inability to be flexible and recognize changing cultures and thus shift strategies and tactics effectively. Some of these studies defined leaders using only general descriptions and definitions representing good and dysfunctional leadership. Many lacked statistical evidence suggesting ways to lessen the negative impact of behaviors associated with dysfunctional leadership traits. Boyd (2007) provided empirical evidence that values clarification and expression of beliefs lowered the scores associated with a dysfunctional trait of leadership within clergy. His study measured the LPI Self's score as it relates to codependence among church clergy, but not including lay leaders or a fuller version of dysfunctions.

This study examined whether there is a relationship between the clarification of values and expression of beliefs with aspects of dysfunctional leadership. The clarification of values and expression of beliefs was quantitatively measured using Kouzes and Posner's (2012a) LPI Self. The dysfunctional traits of leadership were quantitatively measured using the DSLP by McIntosh and Rima (2007).

McIntosh and Rima (2007) examined five scales of dysfunctional leadership: compulsion, codependence, narcissism, paranoia, and passive-aggression. The authors argue that everyone has the five dysfunctions in our personalities. The authors state:

The key that will determine whether we experience success or tragic failure is the degree to which we become acquainted with our dark side [dysfunctions] and put in place the defenses that will prevent it from running rampant and trampling our ability to lead effectively. (p. 99) 
McIntosh and Rima (2007) developed inventories that measure to what extent these dysfunctional traits (termed 'dark side' by the authors) has infected the individual leader.

This study was also guided by Kouzes and Posner's (2012a) work to measure effective leadership using the LPI Self. The LPI Self measures leadership effectiveness as it relates to the following five "exemplary practices;" model the way, inspire a shared vision, challenge the process, enable others to act, encourage the heart. According to Kouzes and Posner, followers follow leaders that believe in something and can authentically vocalize that belief. The authors argue that effective leadership must start with the clarification of values, expressing those values, and aligning personal values to become shared values. Kouzes and Posner titled this Modeling-the-Way and argued that exemplary leadership must start with the attributes it represents.

\section{General Methodology}

This study followed a quantitative research design. Data were obtained using surveys that participants completed on line. Participants were selected from Christ United Methodist Church of Chattanooga and Collegedale Community Seventh-day Adventist Church of Collegedale. All current lay leaders, and former lay leaders not in a leadership position for three years or less, were solicited to participate in the survey. Demographic variables are not a construct used in this study, however data were collected to describe the sample, including gender, and tenure as a member and lay leader in the church, and denomination recognizing its possible value for further studies. Since the study sought to discover a possible relationship a correlation design was used that included a Pearson's $r$ correlation test and a simple linear regression analysis. 


\section{Rationale}

It has been suggested that all leaders, to include church leaders, have dysfunctions that may limit their effectiveness as leaders (McIntosh \& Rima, 2007; Palmer, 1994). It has thus been posited that the more we do to lessen these dysfunctions the more effective a leader may be (George \& Sims, 2007; Northouse, 2013; Phillips, 1992). Kouzes and Posner (2012a) have suggested five practices of exemplary leadership, the first is Modeling-the-Way, which promotes the importance of one having discovered personal values and beliefs and authentically expressed them to their constituents. This research investigates if there is a relationship between the level of dysfunction that may inhibit a leader from being more effective and the level one has discovered and authentically articulated personal values and beliefs.

Research has been conducted investigating how to improve church leadership with some research supporting the argument that lessening dysfunctions may improve church leadership (Boyd, 2007; Sarantopoulos, 2008). However, this conducted research investigated only church clergy and only one dysfunction, codependence, invariably leaving opportunities for more study. It was the intent of my study to extend the field of research to include church lay leadership and to discover if a relationship might exist between five distinct dysfunctions and the extent one has discovered and authentically expressed personal values.

\section{Significance}

The purpose of this study was to determine if there is a relationship between clarification of values and expression of beliefs and dysfunctional leadership traits among church lay leaders. This may help church leaders, including clergy, to better understand 
their lay leader constituents and with this better understanding be more intentional about lay leadership development and selection. This aspiration reaches greater significance if one agrees with Hybels (2002) when he states:

I believe to the core of my being that local church leadership have the potential to be the most influential force on planet earth. If they "get it," and get on with it, churches can become the redemptive centers that Jesus intended them to be. (p. 12)

Hybels (2002) extends this belief by arguing that a more effective lay leader constituency may spill over into society at large thus having the potential to improve leadership throughout all sectors of society.

\section{Definition of Terms}

The following terms were used throughout this study:

Codependent Leader -For this work we will accept a broader definition of

Codependence:

An emotional psychological, and behavioral condition that develops as a result of an individual's prolonged exposure to, and practice of, asset of oppressive rulesrules that prevent the open expression of feelings as well as the direct discussion of personal and interpersonal problems. (Beattie, 1987, p. 32)

In churches this leader places the social system and structure ahead of himself or herself or the over-arching purpose of the church. This oppressive trait prevents the open expression of feelings as well as direct discussions of organizational or personal problems (McIntosh \& Rima, 2007).

Compulsive Leader - In a leadership context, and for the purpose of this study, compulsion is described as "the need to maintain absolute order" (McIntosh \& Rima, 2007, p. 105). McIntosh and Rima extend this definition by describing the compulsive leader's personality as one that demands the same order in his/her organizational life as a 
leader as he/she does in personal life. Since this leaders sees the performance of the organization as a direct personal reflection of self-worth the compulsive leader is very controlling, needs constant reassurance and approval of authority, is often referred to as workaholics, and will deflect responsibility if something goes wrong.

Core Values - Core values are directly related to judgment that causes appropriate or inappropriate behavior (Johnson, 2012). They are the guiding principles that frame practices and norms that lead to acceptable standards of behavior. Rokeach (1979) refers to values as an enduring belief. Kouzes and Posner (2012a) refer to values as the "hereand-now beliefs about how things should be accomplished" (p. 48).

Dark Leadership—McKlesky (2012) describes leaders associated with dark leadership as "leaders who emphasize their personal vision at the expense of the organization's health, demonstrate poor general management capabilities, and possess poor interpersonal skills, engender dark leadership outcomes" (p. 36). McIntosh and Rima (2007) describe leaders associated with dark leadership as those leaders who have "inner urges, compulsions, and dysfunctions of [our] personality that often go unexamined or remain unknown to us until we experience an emotional explosion" (p. 28). McKlesky's (2012) definition captures the self-serving intent of dark leadership while McIntosh and Rima (2007) highlight dysfunctions associated with dark leadership. Both descriptions are relevant for this study however this study uses this term sparingly in that the intent is not to subordinate any class of people or give a discriminatory appearance. 
Denominations - Structures in which the church exists acknowledging the same ecclesiastical authority (Bruinsma, 2009). Denomination represents an overarching organization to which a church belongs or is affiliated with (Boyd, 2007).

Effective Leadership - Some would define effective leadership as the degree to which the leader's group achieves organizational goals and successfully performs its mission (Baumgartner, 1990). Hughes et al. (2012) defines leadership as "the process of influencing an organized group toward achieving its goal" (p. 35), implying effectiveness must include follower contributions and situational assessment. Burns (1978) maintains that effective leadership must include improving the lives of those being lead. This study includes all of these descriptions of effective leadership to include goal achievement, situational assessment, and improving the lives of the constituent.

Leader-A person who "has an unusual degree of power to project on other people his or her shadow, or his or her light" (Palmer, 1994, p. 3). One of the three elements used to describe leadership: leader, follower, and situation (Hughes et al., 2012).

Leadership-The phenomenon involving the leader, follower, and the situation. For our purposes leadership can be defined as "the process of influencing an organized group toward accomplishing its goal" (Hughes et al., 2012, p. 8).

Light Leadership-The acts of inspiring people by free will and free choice to move forward in a common purpose. This inspiration is derived from the five practices of exemplary leadership: model the way, inspire a shared vision, challenge the process, enable others to act, encourage the heart (Kouzes \& Posner, 2012a). For this study light 
leadership represents an absence of what is defined in dark leadership and also is accountable to effective leadership.

Modeling the Way-Modeling-the-Way was defined by Kouzes and Posner (2001, $2003,2004,2012 a)$ as one of the five exemplary practices of leadership. Its premise rests with the discovery, clarification and authentic expression of personal values.

Narcissistic Leader-This leader is self-absorbed with the feelings of selfimportance and thus feels all activity revolves around self. They have a strong need to be admired and need constant attention. They tend to overestimate their own abilities while refusing to recognize the accomplishments and abilities of others along with lacking empathy to others (Franklin \& Fong, 2011; McIntosh \& Rima, 2007).

Paranoid Leader-The paranoid leader is characteristically suspicious, hostile, and guarded in their relationships (Million, Grossman, Millon, Meagher, \& Ramnath, 2004; Schweitzer, 2011). Their "basic capacity for trust has somehow been destroyed" (Million et al., 2004, p. 436). This leader has a tendency to overreact and will create structures and systems to ensure they keep control. Suggestions or criticism is perceived as an effort to overthrow their position or authority (McIntosh \& Rima, 2007). Paranoid personality disorder criteria, as established by the American Psychological Association (1994), include persuasive distrust and suspiciousness of others, a preoccupation questioning the loyalty and trustworthiness of friends, a reluctance to confide in others, bears grudges, and perceives attacks on his or her character or reputation.

Passive Aggressive Leader-This leader resists demands associated with completing tasks. They have a tendency to procrastinate, be stubborn, forgetful, and intentionally inefficient (Million et al., 2004). They can be impatient and are prone to 
short outbursts expressing intense emotion. These leaders can make people feel uncomfortable and confused (McIntosh \& Rima, 2007).

\section{Delimitations}

This study focused on lay leaders in two specific congregations, one Methodist and one Seventh-day Adventist in Chattanooga, Tennessee. Further boundaries were expanded to include lay leaders three years removed. This was done due to economies of scale that impacted cost, time, and control. This boundary allowed the entire population of lay leadership to be invited to participate. The study was also limited to include lay leaders three years removed because I felt that their experience as lay leaders was recent enough to be relevant. Lastly the data were analyzed using Pearson's $r$ correlation and simple bivariate linear regression analysis. This was chosen in favor of other multivariate analysis due to its simplicity may be better understood by a wider population of reader, that the direction of the relationship (positive or negative) would be clearer, and the reason for the relationship may be better analyzed and understood by examining the standard error and beta of each Modeling-the-Way component as they related to each dysfunction.

\section{Organization of the Study}

This study is organized in the following manner: Chapter 1 provides a framework for this study and the need to study the relationship between Modeling-the-Way and the

prominent dysfunctional trait of leadership in a specific congregation; Chapter 2 provides an in-depth review of the literature as it pertains to effective leadership, so as to give the study community relevance, personal and organizational values, the described dysfunctional traits of leadership, and leadership effectiveness consistent with the 
Methodist and Adventist church; Chapter 3 describes the methodology of the study;

Chapter 4 reports the results of the study and; Chapter 5 interprets the results reported and offers recommendations for practice and further studies. 


\section{CHAPTER 2}

\section{LITERATURE REVIEW}

\section{Introduction}

This study measured the relationship of personal values and beliefs with dysfunctions that may inhibit leadership effectiveness among lay leaders in two protestant churches in Tennessee. This chapter starts with a review of literature that examines the association of values and beliefs to effective leadership in the profit and nonprofit sectors of society. The second section extends this review to other characteristics of effective leadership supported by literature. The third section reviews literature that explores aspects of ineffective leadership that has caused some to conclude we are experiencing a leadership crisis. Included is literature supporting a relationship between personal dysfunctions and ineffective leadership. The last section reviews literature framing lay leadership in the Methodist and Seventh-day Adventist denominations and reviews literature supporting the importance of lay leadership in churches and its impact on the community at large.

\section{Values and Beliefs in Leadership}

Positions of leadership may give someone a title but it is a leader's behavior that gives the leader the respect needed to be effective and it is a leader's values and beliefs that frame behavior (Kouzes \& Posner, 2012a). Johnson (2012) extends this discussion by stating: 
If a mission statement identifies our final destination, then our values serve as a moral compass to guide us on our journey. Values provide a frame of reference, helping us to set priorities and to determine right from wrong. . . . Morale values are directly related to judgments about what's appropriate or inappropriate behavior. (Johnson, 2012, p. 104)

This statement complements Rokeach (1979) and Schwartz (2012) assertion that a leader's behavior is predicated on the importance the leader places on a particular value. Thus a leader's decisions and actions can be linked to the leader's values.

Kouzes and Posner (2012a) suggest that values and beliefs of the leader are important to the leader's effectiveness and present this suggestion in their first of five exemplary leadership practices entitled Modeling-the-Way.

\section{Modeling-the-Way}

Kouzes and Posner (2002) "surveyed over 350,000 managers and non-managers across a variety of organizations, disciplines, and demographic backgrounds" (p. 2). Four values or beliefs received over $50 \%$ of the votes consistently: honesty (selected most often), forward looking (selected more than 70\%), competent, and inspiring. Each year the authors ensure ongoing empirical data with 500,000 to 750,000 responses annually that, in their words, "keep us on guard and on target in identifying the behaviors that make a difference” (Kouzes \& Posner, 2012a, p. 4). Kouzes and Posner argue that Modeling-the-Way represents some of all four of these beliefs or values. The authors state:

To become a credible leader, you first must comprehend fully the deeply held beliefs - the values, standards, ethics, and ideals - that drive you. You have to freely and honestly choose the principles you will use to guide your decisions and actions. Then you have to genuinely express yourself. You have to authentically communicate your beliefs in ways that uniquely represent who you are. (p. 45)

The principle components of Modeling-the-Way include discovering and 
authentically articulating your values and beliefs. The remainder of this section reviews literature devoted to these components.

Modeling-the-Way suggests that leaders be intentional about discovering their values and beliefs. Kouzes and Posner (2012a) state, "the first step a leader must take along the oath to becoming an exemplary leader is inward" (p. 42). This self-discovery concludes with an authentic set of principles that define, personally, how the leader behaves, makes decisions, and lives his or her life (George \& Sims, 2007; Kouzes \& Posner, 2012a). Kouzes and Posner (2012a) concluded from their study that advertising personal core values, in the leaders own words, was significant in the effectiveness of the leader. Finally the authors suggest, through collaboration, that the values of constituents are considered and organizational values are framed and both sets of values are honestly shared.

George and Sims (2007), in their book True North: Discover Your Authentic Leadership, interviewed 125 leaders and concluded that leaders put self-awareness as "central to becoming authentic leaders" (p. 76). This self-awareness is central to discovering our values and requires an intentional effort of personal self-reflection (George \& Sims, 2007; Johnson, 2012; Kouzes \& Posner, 2001). Kouzes and Posner’s (2001) intentional effort of self-reflection takes the constituent through a recollection of previous experiences and challenges them to identify what was "the most meaningful, energizing, enriching, and fun" (p. 32). They then ask the constituent to reflect on what they value in how these projects or experiences were conducted. Kouzes and Posner then ask the constituent to imagine the legacy they hope to have left to the participants as a result of this effort. Kouzes and Posner ask, "What are you already doing and . . . what 
should you start doing to help create this legacy?” (Kouzes \& Posner, 2001, p. 33-34).

This demands a reflection on what was done wrong or maybe how a leader ethically misbehaved. This may require the leader "to go within and make a spiritual journey" (Palmer, 1994, p. 2). Palmer, in referring to discovering what we value, places, what they call 'inner work', as critically important. Palmer states:

It would be wonderful if the phrase "inner work" could become a central theme in our schools, in our businesses, and in our churches - if we could help people understand that the phrase really means something. The activities that constitute "inner work" are as real and as important as any outer project or task-activities like journaling, reflective reading, spiritual friendship, and meditation. We must come to understand that if we skimp on inner work, our outer work will be as diminished as well. (p. 10)

Palmer (1994) reminds us that this inner work is deeply personal but not necessarily private. Effective leadership encourages us not to be afraid of confronting our mistakes or behaviors that we may not be proud of. It is part of inner work that can move us to discovering our core values that frame our behaviors (George \& Sims, 2007; Kouzes \& Posner, 2012a; Palmer, 1994).

Discovering personal beliefs and values, though very personal, may involve enlisting others for help and thus getting feedback from associates you trust (Buford, 2008; Drucker, 1999). Johnson (2012) encourages individuals to share individual responses to the following questions to co-workers:

1. What core values (values that you would hold regardless of whether they were rewarded) do you personally bring to your work?

2. What core values would you tell your children that you hold at work and that you hope they will hold as working adults?

3. If you were to start a new organization in a different line of work, what 
core values would you build into the new organization regardless of the industry?

(Johnson, 2012, pp. 334-335).

The author argues that this reflection followed by ensuing discussions may play a pivotal role in discovering personal core values. This process of personal discovery with the group is part of what Kouzes and Posner (2012a) describe as giving your values a "voice."

Once the leader has explored his/her inner self and can define "what you care about, what defines you, and what makes you what you are" (Kouzes \& Posner, 2012a, p. 46), the leader will have discovered his/her values. Once discovered, the authors posit that effective leaders express their values and beliefs authentically.

People want leaders that believe in values that are truthful and important and, in turn, can express these values and beliefs with authenticity (Francis, 2012; Kouzes \& Posner, 2012a). George and Sims (2007) in their study of 125 executives discovered that many organizations were shifting away from management by objectives to leading by values. This study suggested that leadership effectiveness is positively supported when leaders have an established set of core values and can authentically advertise them to other members of the organization. This authenticity argues that a trueness to one's self is essential to effective leadership (George \& Sims, 2007; Northouse, 2013). Specifically, George and Sims (2007) discovered that authentic leaders demonstrated 5 basic characteristics:

1. Pursuing purpose with passion

2. Practicing discovered values

3. Leading with the heart 
4. Establishing connectedness with relationships

5. Demonstrating self-discipline (George and Sims, 2007).

"Establishing connectedness with relationships" is partially defined as the sharing of personal values. Of note, except for "demonstrating self-discipline," Kouzes and Posner's (2012a) Modeling-the-Way is aligned with George and Sims's (2007) five characteristics of authentic leadership.

Effective leadership is not only about the leader's values. It is also about everyone in the organizations sharing personal values. Kouzes and Posner (2012a) state:

Your constituents will be significantly more engaged in a place where they believe they can be true to their beliefs. Although clarifying your values is essential, understanding the values of others and building alignment around values that everyone can share are equally critical. (p. 57)

Affirming shared values constitutes the "uncovering, reinforcing, and holding one another accountable to what 'we' value" (Kouzes \& Posner, 2012a, p. 58). George and Sims (2007) discovered in their study that authentic leaders are genuinely interested in others and are intentional about knowing the values of constituents so as to frame values that everyone can share. Drucker (1999), in his article Managing Oneself, emphasized the importance of shared values when he stated, "To work in an organization whose value system is unacceptable or incompatible with one's own condemns a person both to frustration and to nonperformance" (p. 23). If leadership is about influencing others toward a common goal and the performance of the constituent is essential to accomplishing the goal, then the alignment of values and the affirmation of those values are important to effective leadership (Drucker, 1999; Hughes et al., 2012; Kellerman, 2012; Kouzes \& Posner, 2012a). This is particularly important if one agrees with Kellerman (2012) when she suggests that change is constant and that it is our values that 
keep behaviors framed and centered in the chaotic environment that change can bring.

Change has always been with us. However there are those that argue that lately, whether it is due to the turmoil caused by volatile economic conditions, rapid technological advances, turbulent international competition and circumstances, upstart institutional investors, and/or continually shifting political and economic conditions, the pace of change is unprecedented and even constant (Kellerman, 2012; O’Toole, 1996). There are those that argue that in the midst of constant chaotic change exists a need to “create internal strategic unity within a chaotic external environment" (O’Toole, 1996, p. xvii). To this end it has been accepted by some that effective leadership demands leaders that have strong and shared personal and group (or organizational) values to unite them behind a basic theme of behaviors consistent with effectively leading in today's turbulent and increasingly decentralized environment (Kellerman, 2012; Kouzes \& Posner, 2012a; Northouse, 2013; O’Toole, 1996).

\section{Empirical Study Connecting Values to Effective Leadership in the Profit Sector}

In the for-profit sector, Mancheno-Smoak, Endres, Polak, and Athanasaw (2009) conducted a study that surveyed Human Resources executives/managers from each of the Fortune 500 companies. This study cited Avolio, Bass, and Jung (1999) to present empirical evidence that transformational leadership is positively associated with job satisfaction, employee commitment, trust, job performance, and fewer turnover intentions, all associated with positive work related behaviors and important to being effective. Mancheno-Smoak et al. (2009) used Kouzes and Posner's (1997) LPI Self, Dorfman and Howell's (1988) Cultural Dimensions Questionnaire, and the Abridged Job Description Index developed by P. Smith, Kendall, and Hulin in 1969. The study 
concluded, from the data garnered from the LPI Self that a significant correlation exists between work related cultural values of the individual and transformational leadership behaviors. The implications from these results support the notion that the intentional discovery of individual values and the authentic expression of these values within the organization, the components of Modeling-the-Way, support transformational leadership behaviors.

Shoemaker (2003), in a study examining successful sales people, used Kouzes and Posner's (2012a) LPI Self to explore if there was a correlation between Kouzes and Posner's measure of effective leadership among sales managers and the success of individual sales people as measured by revenue generated. This research supported the argument that sales managers who modeled a set of advertised values had more successful sales team members as measured by sales results than leaders who scored lower on advertising and modeling values. In relating Modeling-the-Way and values to behavior, Shoemaker (2003) states:

Modeling the Way implies that sales managers should consistently model the expected behavior. If a sales person is expected to provide superior customer service, then the sales manager must consistently support all sales people in providing superior customer service. Salespeople observe the sale manager as a group to establish group norms. (p. 23)

Likewise, Groves and LaRocca (2012) conducted a study to measure a leader's personal values, the follower's beliefs in corporate social responsibility, and leadership performance outcomes. The study included 110 managers and 472 of their direct reports. The study discovered a strong correlation between effectiveness and the leader's openness to change, self-transcendence, and recognition of the collective values of the followers. These are values, argued by the authors, as having a relationship with effective transformational leaders. 
Four hundred Brazilian executives were studied by Bruno and Lay (2008) to evaluate the personal values profile with leadership effectiveness. The study discovered a strong relationship between personnel values balance (flexibility, teamwork, and sharing ideas) and leadership effectiveness.

\section{Empirical Studies Connecting Values to Effective Leadership in the Nonprofit Sector to Include Church}

Similar to the for-profit-sector literature that supports well defined and articulated shared values being important to effective leadership, this review discovered literature that supports the same argument in the nonprofit sector. Sarantopoulis (2008) conducted a quantitative correlation study between values and leadership style that included 988 nonprofit leaders from Essex County, Massachusetts. The study suggested that a moderate yet conclusive correlation existed between leader behavior that modeled and practiced a set of values with leader behavior that practiced a more transformational style of leadership.

Baloglu (2012) conducted a study to examine if a relationship existed between value based leadership and distributed leadership among educators. Distributed leadership considers people working together to pool their initiatives and expertise so that the outcome is greater than the sum of their individual actions. This study included 225 primary school teachers and their response to their principal's behavior. The findings supported a positive correlation between distributed leadership and value-based leadership. For the purposes of this study values-based leadership included surveys that measured teamwork, support, vision, and supervision. 
Boeckmann and Dickinson (2001) conducted a similar study that included 500 superintendents from 17 different states. The researchers argued that if an educator wants certain values played out in students, he/she needs to ensure those values are being played out in the leader. This study explored if superintendents who model the values they hope to inspire in others will be more successful than those who did not practice these values, but agreed to their importance, on a day-to-day basis. This study showed that superintendents that practiced the values of integrity, fairness, and behaving ethically promoted more successful students than those superintendents who were measured as not practicing these values on a day-to-day basis. In addition, Boeckmann and Dickinson (2001) state, "Those responsible for preparation programs should ensure that prospective leaders have sufficient understanding of the nature of teaching and learning and the links between beliefs, values, and practice" (p. 1).

Similar studies have been conducted within the church. Anderson (2009) studied attitudes, values, and beliefs of congregants and clergy toward church planting, also referred to as church outreach. The study concluded that pastors who failed to impart their beliefs, values, and attitudes toward church planting to their congregants, or pastors who had noticeable different beliefs, attitudes and values than their congregants were less effective than those pastors who did advertise, practice, and align their beliefs, values, and attitudes with congregants.

Boyd (2007) studied 3500 pastors from across the country to determine if there was a correlation between pastors' score from Kouzes and Posner's (2012a) six questions addressing Modeling-the-Way and the portion of McIntosh and Rima's (2007) DLSP inventory that measured codependence as a dysfunction. The study concluded that a high 
correlation existed between a high Modeling-the-Way score and a low DLSP score that measured codependence. This implied that pastors who advertised and practiced their beliefs and values were less codependent. Boyd (2007) further posited that organizational values and individual values (core characteristics) both carry implications for behavior and are thus important to explore. Boyd stated, "Hence, one could conclude that organizational or societal values and norms surrounding a religious leader play just as much of an active part in shaping a religious leaders behavior as core characteristics." (p. 140)

It was Boyd's (2007) study that served as the beginning blue print for this study in that the author explored a relationship between Modeling-the-Way using the LPI Self and the dysfunction codependence using the DSLP among clergy, as opposed to including other dysfunctions and lay leadership as in this study.

The next two sections are not intended to be an exhaustive review of leadership values and beliefs in the church or denominations. Rather the section's intent is to gain familiarization to literature relevant to the denominations being examined in the context of this study

\section{Values and Beliefs in the Seventh-day Adventist Church}

Much of the early values and beliefs of Adventists can be traced back to the writings and speeches of Ellen White (Gonzalez, 2009). Gonzalez, in his article Ellen White's Views on Church Order: The Early Years 1849-1854, states:

Her role in dealing with particular situations of some Sabbatarian congregations was important because through it she laid fundamental principles on ecclesiastical order that would be essential to the Advent movement as a whole. In these views we can find the theological reasoning of some Adventists ordering practices that have continued into present times. (p. 72) 
These fundamental principles included church leadership. Ellen White, in addressing a congregation in Jackson, Michigan, regarding the meaning of leadership and framing core values among early Sabbatarian Adventists, stated, "I saw that those who profess to be teachers should be patterns of piety, meekness, and great humility, possessing a love, kind spirit, winning souls to Jesus, and the truth of the Bible." (White, as cited by Gonzalez, 2009, p. 65)

Gonzalez (2009) argues that the reference to teachers is a direct reference to leadership. She further declared that "spirituality, judgment, and experience" (p. 70) were the three necessary qualifications to those wanting to be leaders in the church.

White, along with other Adventist pioneers, came from a Methodist background (Bruinsma, 2009; Gonzalez, 2009). This can be seen in the pragmatic approach to church organization and leadership, in particular, "the role of camp meetings that were so characteristic of U.S. frontier Methodism ... that soon also became a common practice in the Adventist world" (Bruinsma, 2009, p. 137). Order in meetings and church structure also appears to apply to leaders and contributed to the framing of leadership and values in the Adventist church. White called on church leaders for a higher degree of order within the church and themselves. The value of services being more Christ centered demanded that leaders display degrees of humility and a greater advocacy for a team approach to worship, rather than individual leadership, emerged (Gonzalez, 2009). She advocated that leaders should be "perfectly united in their views of the Bible" (p. 63). She asked leaders to make joint decisions when confronted with new ideas thus placing a joint effort ahead of individualism making their position a totally selfless proposition. She extended these humble and selfless traits when describing the responsibilities of a teacher is to teach, 
with no concern for learning themselves and with leaders to minister, with no regard for being ministered to (Gonzalez, 2009; Knight, 2006).

The Seventh-day Adventist community can see a similar character today. Robert Pierson, the second longest presiding president of the General Conference of Seventh-day Adventists, summarized the attributes of an effective leader in today's Adventist community. In this summarization Pierson (1996) states that a true Christian leader is a spiritual person who has a personal vision, is humble, has patience, well studied in scripture, is kind, and has a proper sense of responsibility and purpose. He further argues that a true Christian leader has courage, is a person of integrity, and is loyal to God, the Church, and its members. These values are consistent with the religious leader qualifications that emphasize the importance of "a good reputation" as critical to leadership effectiveness in the Adventist church (General Conference, 2000); however,

this manual extends the description of these values to include "moral fitness," "religious fitness," "respect and deference," and "cooperates with others" (pp. 43-46).

\section{Value and Beliefs in the Methodist Church}

In Hucks' (2003) research, entitled John Wesley and the Eighteenth Century Methodist Movement: A Model for Effective Leadership, the author argues that "to understand the Methodist heritage, it is necessary to catch the spirit of Wesley, the man and his message" (Heitzenrater, 1995, p. 317 as cited by Hucks, 2003, p. 1). It is thus relevant for this study to examine the values represented by John Wesley.

Using Wesley as the model, Hucks (2003) argues integrity, public redemption, boldness, and organization as values associated with effective leadership. The author continues to argue that transformational leadership as described by Kouzes and Posner 
(2003), and cited by Bass (1990), could be a written tribute to Wesley. Methodist leadership philosophy includes attributes attributing to transformational leadership. Hucks (2003) argues that Wesley exemplified, what Kouzes and Posners (2012a) describe as, the five practices of exemplary leadership previously reviewed in this study: challenge the process, inspire a vision, enable others to act, model the way, and encourage the heart. Hucks (2003) states:

Wesley challenged the process, in his case spiritual and ecclesiastical processes of the established Church of England. He inspired vision to the degree that thousands embraced his vision in his lifetime. He enabled others to act by his willingness to share and train leadership. He modeled the way through his practice and of spiritual discipline and for his love and respect for people. He encouraged the hearts of multitudes in his day and still encourages the hearts of those who study him. (p. 37)

Of note, Wesley's intentional philosophy of developing leadership in the church has extended itself to the modern Methodist Church to include respect for those different than us, openness, selfless service, and spreading the Good News and it is these values that are associated with effective leadership in the United Methodist Church (United Methodist Publishing House, 2012).

\section{Effective Leadership}

In this section I will review, in general terms, an evolution of leadership in terms of effective leadership. This introduction will be followed by subsections that review literature pertaining to traits of effective leadership, Kouzes and Posner's remaining four practices of exemplary leadership, effective leadership in a changing environment, and

effective leadership in a group. The final subsection will review literature that pertains to measuring effective leadership. 
Kellerman (2012), in framing the history of leadership and providing a road map for its evolution, states, "More than anything else it is about the devolution of powerfrom those on top to those down below" (p. 3). Kellerman posits that we have lived through a history where effective leadership was characterized as those that were strong and courageous satisfying the common people's passion for authority and their yearning for order, dominance, and perfection. Through time the follower's desire for authority did not change but the composition of the leadership effectiveness did. Leaders were perceived to have stepped out of the ranks of the common man into the realm of hero leader. Martin Luther King Jr., Nelson Mandela, Gandhi, and even, in context, Adolph Hitler serve as examples. These were common people put in place by common people because of the people's need for order and authority in situations of crisis (Baumgartner, 1990; Kellerman, 2012).

The United States has been founded on the premise that the follower, motivated by feeling of being disenfranchised, would rise up and assume more power. The American Revolution was the result of the oppressive acts by England on the colonies resulting in the revolutionary war and U.S. independence (Rozbicki, 2011). The plight of minorities in the U.S. serves as another example of the less powerful follower rising up to redefine effective leadership in society. In the 1960s and 1970s the U.S. experienced turbulence throughout society where leaders became less effective and lost power. This power was never really recaptured. The country was marked by protests, the resignation of a president, and significant unrest on the civil rights front (Kellerman, 2012). One could argue that a new concept of leadership was emerging in the midst of leadership that was not acceptable or effective to the follower. In the midst of crisis, where effective 
leadership was void, the lay leader emerged to fill the void. The lay leader is a person who evolves into accepting leadership responsibilities because the values and beliefs that effect behavior are acceptable to the constituents (George \& Sims, 2007).

Hybels (2002), in his book, Courageous Leadership, argues that the leaders of the future will be developed within the church. He continues to argue that we need to make a greater effort in the development of lay leadership. He contends that the most effective crisis leadership that we experienced during Hurricane Katrina and the disaster on September 11, 2001 came from church leaders that stepped forward and voluntarily led during crisis.

This study begins with the notion that the development of effective leaders in the nonprofit sector will spill over into society. More specifically, that the development of effective leaders within our churches will impact other aspects of society outside of the church (Hybels, 2002). In Collins' (2005) book, Good to Great in the Social Sector, the author argues that our future leaders will come from the social sector. Both Collins (2005) and Hybels (2002) argue that effective leadership could emerge from the nonprofit sector of society and potentially spill over into all sectors of society and positively affect the landscape of leadership in our country.

Judge, Piccolo, and Kosalka (2009) state in their article, The Bright and Dark Side of Leadership Traits: A Review and Theoretical Extension of the Leader Trait Paradigm, "It is fair to surmise that whenever there is social activity, a social structure develops, and one (perhaps the) defining characteristic of that structure is the emergence of a leader or leaders" (p. 855). The author implies that what allows a leader to emerge are leadership traits that make the leader effective. 


\section{Traits of Effective Leadership}

To explore effective leadership and leadership traits, Kouzes and Posner (2012a) "spent more than three decades together researching, consulting, teaching, and writing about what leaders do and how everyone can learn to be a better leader" (p. 2). The authors argue that Five Practices of Exemplary Leadership impacts leadership effectiveness across all sectors of society and across all industries. They further argue that these practices hold no racial, religious, ethnic, or cultural borders. If "making extraordinary things happen in organizations" (Kouzes \& Posner, 2012a, p. 15) is important to effective leadership, then the authors argue that the five exemplary traits to effective leadership are relevant. To this end Kouzes and Posner's five exemplary practices (traits), starting with Modeling-the-Way, are as follows:

1. Modeling-the-Way

2. Inspire a Shared Vision

3. Challenge the Process

4. Enable Others to Act

5. Encourage the Heart.

Though Kouzes and Posner (2012a) have chosen to highlight these five practices as important traits to effective leadership, with Modeling-the-Way being a major construct of this study, before reviewing the remaining four this research has revealed other similar lists that represents traits of effective leadership. Judge et al. (2009) argue eight traits that they label as "bright side of bright traits" (p. 866). They include conscientiousness, extraversion, agreeableness, emotional stability, openness to expertise, core self-evaluation, intelligence, and charisma. 
Fullan (2008), in his book The Six Secrets of Change, agrees with Kellerman (2012) that change is a constant in leadership and that effective leadership rests in "how grounded and insightful your theorizing is" (p. 2). To that end Fullan argues the following six secrets of change as a theory to effective leadership: love your employees, connect peers to purpose, capacity building prevails, learning is the work, transparency rules, and systems learn.

\section{Inspire a Shared Vision}

Kouzes and Posner (2012a) argue that "leaders are dreamers. Leaders are idealists" (p. 105). Kouzes and Posner (2012b) further postulate that a vision must be clarified and is a reflection of one's own intimate beliefs. The authors state:

Leaders look forward to the future. They hold in their minds ideas and visions of what can be. They have a sense for what is uniquely possible if everyone works together for a common purpose. Leaders are positive about the future, and they passionately believe that people can make a difference. (p. 100)

Through reflecting on the past themes, patterns and beliefs you define why you care about something, why you are passionate, and why it is significant (Buford, 2008; Kouzes \& Posner, 2012b). This core self-reflection is referred by Judge et al. (2009) as the "bright side of bright traits" (p. 866) and is argued by the authors as being a critical trait of effective leadership. Effective leadership implies, through reflection, a leader's authentic effort to realize "your sense of meaning and purpose" (Kouzes \& Posner, 2012b, p. 113). The importance of discovering a purpose of significance and the passion associated with such a purpose was the heart of Buford's (2008) book Halftime. He argued that in developing a passion for the future one must discover their significant purpose. Kouzes and Posner (2012a) argue that this discovery is important to effective leadership for it gives passion and reason as to why a leader does what a leader does. 
Kouzes and Posner (2012a) acknowledge that "the vision can't only belong to the leader. It's shared" (p. 104). And it involves inspiring a shared vision. Northouse (2013) terms this as "attention to common goals" (p. 6). Fullan (2008) calls this "connecting peers with purpose" (p. 41) and argues this as being one of the six secrets of leading effectively in changing environments. Kouzes and Posner (2012b) include followers as important to effective leadership when discussing a shared vision. The importance of shared vision is also argued by Turak (2013) in his book, Business Secrets of the Trappist Monks. The author describes his personal experience living and working with the Trappist Monks as they transitioned one successful business after another (egg, mushroom, fertilizer, and forestry businesses). Turak states:

The secret to Mepkin Abbey's success is that the monks are not in the egg, mushroom, fertilizer, or forestry business. Like great archers they aim past all the targets. They are in the business of serving God by serving one another and their neighbor. They are spiritual people who happen to run businesses (p. 63).

The monks shared an over-arching purpose that collectively focused their efforts. Collins (2005), in his book Good to Great in the Social Sector, continues the relevance of over-arching purpose and shared vision to effective leadership in the nonprofit sector. In explaining his fourth issue for effectiveness, The Hedgehog Concept, which encourages rethinking the economics of the organization without a profit motive, the author asks, "What are you deeply passionate about?" (p. 19). Collins defines passion as "understanding what your organization stands for (its core values) and why it exists (its mission or core purpose)" (p. 19). It is the rallying point for followers and leader alike to focus and challenge the status quo to something greater, hence Challenge the Process.

\section{Challenge the Process}


Kouzes and Posner (2012a) argue that effective leadership will seize the initiative, force things to happen, encourage initiative, and challenge the process. The author argues that effective leadership does more than react to change, rather effective leadership recognizes the need for change and makes change happen while encouraging the same initiative in others. Kouzes and Posner state:

Challenge is the opportunity for greatness. People do their best when there's the chance to change the way things are. Maintaining the status quo simply breeds mediocrity. Leaders seek and accept challenging opportunities to test their abilities. They motivate others as well to exceed their self-perceived limits. They seize initiative and make something meaningful happen. Leaders treat every assignment as an adventure. (Kouzes \& Posner, 2012a, p. 156)

Effective leadership understands that change is a constant (Kellerman, 2012).

Effective leaders need to put themselves in a position to impact cultures that are in a constant state of change making them ready for innovation (Gupta, 2011). Fullan (2008), in discussing change, argues that organizations failing to learn will fail to change. Bell (2000), in his article, The Mentor as a Partner, states:

There is one group of employees, however, who sing in the midst of turmoil. Thriving on discord, this group turns dissonance into harmony. They are the perpetual learners in the organization.... Learners are not only happier employees, but they are less likely to disconnect or depart in the face of change and confusion. Increasing the number of singers isn't likely to quell chaos; massive change is here to stay. Nor does calm come through adding more training programs or expanding the tuition reimbursement policy. It entails fundamentally altering the role of leaders from corporate parents to compassionate partner. It involves having all leaders add learning coach and mentor to their repertoire. (p. 2)

The author argues that if constant change is here to stay then constant learning is a critical component to success. If effective leadership understands change and innovation are constant then learning is also constant implying that effective leadership means effective coaching and mentoring as a critical component to being an effective leader (Bell, 2000; Fullan, 2008; Gupta, 2011; Kellerman, 2012). 
Judge et al. (2009) in describing the bright side traits to effective leadership included openness to experience and intelligence as critical traits to effective leadership. Openness to experience corresponds directly to "openness to organizational change" (p. 866). Negotiating change is also associated with intelligence, for change occurs as solutions to complex problems requiring an intuition and creativity associated with an intelligent leader.

The nonprofit community is not immune from the challenges incurred from constant change and the leadership it takes to effectively negotiate the changes.

Decreased government funding, outsourcing, and a challenged economy all contribute to negotiating change as essential to effectively leading in the nonprofit space (Austin, Regan, Gothard, \& Carnochan, 2013; Rubio, Birkenmaier, \& Berg-Weger, 2000; Schmid, 2013).

In referring to the nonprofit sector, Collins (2005) defines great as an "organization ... that delivers superior performance and makes a distinctive impact over a long period of time" (p. 5) arguing that effective leadership needs to change with the challenges of time if they are to be great. Churches are included in this population requiring effective leaders to negotiate change. One only needs to observe how church leaders respond to crisis and the change that this implies, on short notice, if they are to realize their purpose and be effective (Hybels, 2002).

\section{Enable Others to Act}

Kouzes and Posner's (2012a) research supported the argument that leadership effectiveness is predicated on the notion that the leader cannot do it alone, they need 
partners to make extraordinary things happen. The effective leader, as a member of the team, needs to enable others act. Kouzes and Posner state:

Leaders invest in creating trustworthy relationships. They build spirited and cohesive teams, teams that feel like family. They actively involve others in planning and give them the discretion to make their own decisions. Leaders make others feel like owners, not hired hands (p. 214).

This is consistent with leadership effectiveness as described by Judge et al. (2009) in the bright side of bright traits, agreeableness. Though the authors admit that empirical evidence implies a weak correlation between agreeableness and leadership effectiveness (Judge, Bono, \& Gerhardt, 2002), there is evidence to support that an agreeable leader will be more inclusive, more likely to support cooperation among team members, have a genuine concern for the well-being of others, and is interested in the followers job satisfaction and professional development (Bass, 1985; Dhar \& Mishra, 2001; Judge et al., 2009).

Fullan (2008) in discussing change describes the importance of leadership effectiveness as "enabling employees to learn continuously and to find meaning in their work and in their relationship to coworkers and to the company as a whole" (p. 12). Fullan further argues that enabling others implies a direct commitment to the follower's development giving them the skills and confidence to act effectively. This is further observed by Isadore Sharpe, the CEO of the Best Western hotel chain, in being the principle architect behind the hotels success. A principle trait of his effectiveness was how he enabled all employees. An example was his decision to have no customer service department. Instead, he made every employee not just a member of the department but in charge of the department enabling every employee to make decisions when serving customers (Martin, 2007). 
Enabling others is a critical component to effective leadership in a diffused power structure represented in the nonprofit leadership community. Collins (2005) further reminds us that in the nonprofit sector forcing things on people does not work, rather people need to be provided with the information and then be enabled to make changes at their own discretion. This is consistent with the church leadership environment particularly during crisis. Hybels (2002) argues that church lay leaders, a focus of this study, work in a diverse power base and as such need to be enabled to make decisions quickly to be effective not only in the daily work of the church but during crisis situations.

\section{Encourage the Heart}

Kouzes and Posner (2012a) explain encouraging from the heart by describing the effective leader as one who takes great pride in the team's accomplishments and looks for opportunity to tell the rest of the organization what the team has achieved. They extend this explanation by stating, "Leaders give heart by visibly recognizing people's contributions to the common vision. With a thank-you note, a smile, and public praise, the leader lets others know how much they mean to the organization" (p. 276).

Kouzes and Posner (2012a) further explain that "exemplary leaders elicit high performance because they strongly believe in the abilities of their constituents to achieve even the most challenging goals" (p. 276). This effective leader knows the performance of group members and is very sensitive to publicly praising and rewarding followers (Dhar \& Mishra, 2001). This leader effectively encourages followers toward fulfilling the organizational mission, adhering to the organizational values, and inspires commitment 
from all team members (Dhar \& Mishra, 2001; Judge et al., 2009; Kouzes \& Posner, 2012a).

Leadership traits associated with "encourage the heart" and its association to effective leadership in the nonprofit sector is also supported by literature. In this sector leadership effectiveness emphasizes the importance of developing deep levels of commitment and satisfaction (Dhar \& Mishra, 2001). Charisma is specifically associated with encouraging followers with empirical studies supporting an association with this Encourage-the-Heart trait and performance in the nonprofit sector (Dhar \& Mishra, 2001; Judge et al., 2009).

In the discussion on effective leadership there has been one common thread that seems to connect all the traits of effective leadership_values (Johnson, 2002; Judge et al., 2009; Kouzes \& Posner, 2012a). Kouzes and Posner (2012a) describe how leaders mobilize others to do extraordinary things is about "practices leaders use to transform values into actions, visions into realities, obstacles into innovations, separateness into solidarity, and risks into rewards" (p. 2). However, Kouzes and Posner emphasize that it first starts with the leader clarifying and expressing personal values and belief hence the first exemplary practice (trait) listed is Modeling-the-Way.

\section{Effective Leadership in a Changing Environment}

Given our recent advances in technology it is argued that situations will be changing constantly and a leader's effectiveness will be measured on the leader's ability to adapt to a constantly changing environment (Fullan, 2008; Kellerman, 2012). It is thus relevant for this study to explore leadership effectiveness in a constantly changing environment. 
Judge et al. (2009) extends this argument when he states:

Leadership effectiveness may depend on context. As adaptive and coordinative problems grow, the premium placed on leadership grows, too. There is little need for prudent, bold, flexible leadership when the collective faces little conflict from within or without, when resources are abundant, and the environment is quiescent. When a harsh winter comes, when a predator or competing collective encroaches, or when business conditions change, leadership may not only be important, it may be the sole path to successful adaptation and survival. (p. 858)

Hersey and Blanchard's Situational Leadership Model attempts to explain why effective leadership behavior varies between two behavioral dimensions (relationship and task) and the changing situation (Bass, 1985; Hersey \& Blanchard, 1969). The theory explains the interrelationships between the follower's readiness and the leader's behavior. Hersey and Blanchard (1969) labeled these behavioral dimensions "relationship" and "task." The "task behavior" focuses on task accomplishment with the leader focusing on what is to be done and how, when, and where it will be done which is consistent with the objective dimension of leadership effectiveness (Judge et al., 2009). Hersey and Blanchard (1974) define task behaviors as an orientation to task behaviors with the leader being very specific as to what the follower is to do to include how, when, and where it is to be done. Hughes et al. (2012) define task behaviors (objective behaviors) "as the extent to which the leader spells out the responsibilities of an individual or group" (p. 368). Hersey and Blanchard (1974) define relationship (subjective behaviors) as leadership behaviors that indicate emotional support, communication, facilitation, and interpersonal relations. Hughes et al. (2012) defines relationship behaviors as to how much "the leader engages in two way communication" (p. 368). The group's maturity is defined as its capacity to set high but attainable goals, its willingness and ability to accept responsibility, and it's educational and experience level (Hersey, Blanchard, \& Johnson, 1996; Hughes et al., 2012). 
This maturation is also consistent with follower readiness, which implies the follower's "ability and willingness to accomplish a particular task" (Hughes et al., 2012, p. 370). This Life Cycle of Leadership (Hersey \& Blanchard, 1969) brings the group from a situation demanding an objective evaluation for leadership effectiveness, to a mixture of subjective and objective evaluations for leadership effectiveness, to the most mature group level implying the most effective leadership involves little involvement from the leader - just stay out of this group's way and let them work effectively (Hughes et al., 2012; Wheeler \& Csoka, 1975). However, the last stage, or fourth quadrant, implies no change is taking place, which Kellerman (2012) argues, given our recent technological advances, is a thing of the past. In Baumgartner's (1990) dissertation, which focuses on Christian leadership, the author argues that "If approaches ignore ... Stogdill's conclusions about the situational aspects of leadership effectiveness, they are doomed to be inadequate models of Christian leadership" (p. 5).

Dinh and Lord (2012), in their study entitled Implications for Dispositional and Process Viewed Traits for Individual Difference Research in Leadership, explored leadership effectiveness and situational methodology. This research argues that the greater the self-complexity the more flexible the leader, implying that flexibility is important for effective leadership in changing situations. The author continues to argue that self-complexity increases with experience, purpose, and defined values. This position continues to validate Buford's (2008), Drucker's (1999), and Boyd's (2007) argument for the importance of purpose and values as it relates to effective leadership.

As discussed, effective leadership in developing organizations is confronted with an environment of constant change (Kellerman, 2012). Cummings and Worley (2009) 
state that "helping members gain the competence needed to change and improve the organization continually" (p. 27) is essential to being effective. Leaders need to put themselves in a position to impact cultures that are in a constant state of change making them ready for innovation (Gupta, 2011). Kouzes and Posner (2012a) state, "Times change, problems change, technology change, and people change. Leadership endures" (Kouzes \& Posner, 2012a, p. 1). The authors continue to argue that "leadership is a relationship between leaders and followers" (p. 5) and that this relationship is founded on "shared values [that] are the ground rules for making decisions and taking action" (p. 61). Environments of constant change require a framing of behavior, as represented by shared values, that not only keeps everyone focused on the overarching mission but establishes a standard of behavior for an organization (Collins, 2000; Fiorina, 2006; Hughes et al., 2012; Turak, 2013). This is the critical reason for affirming shared values for it is the shared values that frame behavior in a changing environment (Fiorina, 2006; Kouzes \& Posner, 2012a).

\section{Effective Leadership and the Group}

Leadership effectiveness is directly associated with the relationship the leader has with the group he or she is leading as well as the context. Pierro, Cicero, and Higgins (2009) conducted a study that established a high correlation between relationship the group has with the leader and effectiveness. It is further recognized that no member of a social order is in a better position to impact how a group functions as the leader (van Knippenberg, 2011). It would stand to reason that leadership effectiveness may be better informed if the characteristics of the leader as a group member are explored (Hogg, 2001; van Knippenberg, 2011). This would forward a better understanding of the group at large 
in that people, to a degree, define themselves in terms of the collective attributes of the group of which they are a member (Hogg, 2001; Pierro et al., 2009).

The effectiveness of the leader is directly associated with recognizing the identity implications associated with group membership (Judge et al., 2009; van Knippenberg, 2011). As follower identity with the group increases, effectiveness also increases (Hogg, 2001; Pierro et al., 2009). If the leader is in the best position to impact how a group functions as discussed earlier (van Knippenberg, 2011), then one can argue that effectiveness of the leader is how well the leader represents the beliefs and values of the groups and behaves accordingly. This forms trust between the leader and follower, trust being partially defined as the leader's commitment to the group (Pierro et al., 2009; van Knippenberg, 2011) and, in part, an aspect of credible leadership (Hughes et al., 2012) previously discussed. Van Kippenberg (2011), studied group prototypically and leadership effectiveness. The author concluded:

while all other things being equal leader group prototypically may have a main effect on leadership effectiveness, the relationship between leader group prototypically and leadership effectiveness is also moderated by social identification: the higher the identification, the stronger the relationship between prototypically and effectiveness. (p. 1080)

Van Kippenberg (2011) reminds us that social identification "captures the extent to which an individual defines the self in terms of a particular group membership" (p. 1079). The higher the group identity the more the individuals see "we" rather than "I." Judge et al. (2009) clarify this point by giving the example of a highly conscientious leader with followers that are not conscientious. Leadership effectiveness is highly linked to group effectiveness. Judge et al. argue that in this example it would be difficult to be effective with an unconscientious group despite the conscientiousness of the leader. 
A popular model that measures leadership effectiveness is the Managerial Grid by Blake and Mouton (Baumgartner, 1990; Blake \& Mouton, 1969). This theory argues that a leader's ability to adapt a style of behavior focused on the task or the relationship to group members affects leadership effectiveness. Baumgartner (1990) and Blake and Mouton (1969) argue that the 'team' approach is the most effective with a high emphasis on task and a high emphasis on relationship. However, as Baumgartner (1990) points out, this theory fails to recognize changing situations and the different styles those situations may demand for the greatest leadership effectiveness.

There are many examples where the absence of or failure to adhere to affirmed group values have derailed organizations (Kellerman, 2012; McIntosh \& Rima, 2007). The most recent example was the financial crisis where the absence of shared values was a major reason given for derailing major financial firms (Smith, 2008; Sorkin, 2009). There are also examples of affirmed group values that contributed to the success of the organization. One such example can be represented by "The Golden Rule" being established as a value for the Best Western Hotel chain. That, with other shared values, led the turn-around, under the leadership of their CEO, Isadore Sharpe, of the Best Western Hotel chain (Martin, 2007). Once again what comes through clear in the literature is the need for moral values clearly stated and exemplified by the leader to the group.

\section{Measuring Effective Leadership}

Given this widespread emphasis on the many aspects of effective leadership it is understandable that various researchers have developed subjective and objective ways to 
measure leadership effectiveness. This section provides a general review of literature suggesting both approaches ending with Kouzes and Posner's (2012a) LPI Self.

If the leader's group achieves its goals and performs successfully using objective measurement (profit growth, sales increase, market share, return on investment [ROI], productivity, etc.) the leader's effectiveness is measured objectively (Baumgartner, 1990; Judge et al., 2009). However leadership effectiveness has been measured mostly subjectively through subjective ratings and evaluations thus subordinating the group's contribution to the organizational mission (Baumgartner, 1990; Judge et al., 2009). Subjective measurements of leadership effectiveness are predictably contaminated with the biases of the raters (Judge et al., 2009). However, objective measurements of leadership effectiveness have its own problems. Objective leadership measurement can be badly contaminated with extraneous influences that impact the interpretation of the results (House, Spangler, \& Woycke, 1991). This warns those researching effective leadership to protect the transparency of results.

This research aligns itself with the socioanalytical theory (Hogan, 1983, 1996). This theory states:

Effective leadership requires more than competing (e.g. setting ambitious goals, and ensuring the goals are met) and cooperating (e.g., enlisting the support and commitment of the followers): it also requires ... inspiring followers to strive towards a purpose that has meaning and the promise of fulfillment. (Judge et al., 2009 , p. 861)

This implies that both objective and subjective measurements of leadership effectiveness are relevant and the need of follower purpose and fulfillment are also required. These aspects of effective leadership are represented by Kouzes and Posner's (2012a) exemplary leadership trait Modeling-the-Way and can be measured with the LPI Self. The literature thus supports leadership effectiveness being components of 
accomplishing the organizational goals and tasks (objective) and achieving acceptable relationships with the follower (subjective).

\section{Ineffective Leadership and Leader Dysfunctions}

My review has thus far focused on leadership effectiveness - its importance, many aspects, and even how it is measured. I now review ineffective or dysfunctional leadership. I do this because if we can understand the nature of ineffective leadership we can be intentional about limiting their effect thereby allowing effective traits of leadership to have greater impact (Kellerman, 2012; McIntosh \& Rima, 2007; Phillips, 1992).

George and Sims (2007) argue that, “An enormous vacuum in leadership exists today_in business, politics, government, education, religion, and nonprofit organizations" (p. xxiv). They continue to become even more specific in describing what they term as a leadership crisis in the for-profit sector when they state: "When problems surfaced at Enron, WorldCom, Arthur Anderson, Tyco, and dozens of other companies, the severity of the leadership crisis became painfully apparent, creating a widespread erosion of trust in business leaders" (p. xxv).

Over the last several decades leaders and scholars alike have written about the degradation of leadership in the for profit sector (Beattie, 1987; Bennis, 1989; Conger, 1990; Fiorina, 2006; Kellerman, 2012; McKlesky, 2012; Sorkin, 2009). Of late some notable scholars and authors have brought attention to what they term as a crisis. Notably Kellerman (2012) in her reflection of over thirty years in the leadership industry states:

Instead of making our leaders more effective and ethical, it seems at least to have the opposite effect - it seems to have made things worse. American government and business are suffering from a near breakdown in their capacity creatively and 
collaboratively to effect policies to address the most pressing of the nation's problems. Levels of trust in and approval of leaders are at all-time lows (p. xix).

This erosion of trust among corporate leaders has been argued to be caused by an overwhelming desire to achieve personal financial gain, corporate social status or recognition, and/or motives that are self -serving or gratifying (George \& Sims, 2007; Johnson, 2007; Kellerman, 2012; Rosenzweig, 2007). It may be argued that these motives are characteristics of leaders that have allowed dysfunctional aspects of themselves, to include narcissism, hubris, social dominance, passive-aggressive, and/or to override their influence on behavior and decisions (Judge et al., Million et al., 2004).

Torrenzano (2008) specifically credits the leadership failures to government officials as well. For example the last four of the previous seven Illinois governors have gone to prison with the latest imprisoned governor presently serving a 14-year sentence for numerous corruption charges to include trying to sell or trade Barrack Obama's old Senate seat for personal gain (ABC, 2013). One could conclude that the governors felt that their position and power were above the law, a view consistent with narcissistic tendencies (another dysfunction) (Bennis, 1989; McIntosh \& Rima, 2007; McKlesky, 2012). Recent history has produced two impeached (one ended in resignation) presidents for immoral acts and failing to tell the truth along with numerous accounts of other government leaders failing the moral trust of their constituents (Kellerman, 2012; McIntosh \& Rima, 2007).

Phillips (1992), in his book Lincoln on Leadership: Executive Strategies for Tough Times, provides his readers with an example of lessening the impact of leadership dysfunction. Abraham Lincoln was aware of dysfunctional aspects to his leadership and took intentional actions to lessen its impact. Lincoln was confronted with difficult 
situations that inflicted cruel criticism on him and his family. This criticism, along with other challenges, would infuriate the president to the point that if his temper were not controlled it could sabotage his effective leadership. Being aware of this dysfunction Lincoln would write a lengthy letter to the offending party. He would keep the letter, reading it periodically, until the anger subsided, and then throw the letter away. The point is not to eradicate the dysfunction in our inner self, rather it is to recognize its existence and do something about it (McIntosh \& Rima, 2007; Palmer, 1994).

The nonprofit community apparently has experienced similar leadership challenges (Collins, 2005). It is not difficult to find specific examples of leadership fraud, embezzlement and corruption in the nonprofit sector (Savage, Dunkin, \& Ford, 2004). Further examination revealed leaders spending organizational resources on personal entertainment, vacations, and expenses that did not support the organizational mission (Wiehl, 2004). Mead (2008) reported that at the turn of the century public confidence in nonprofits dropped from $90 \%$ in 2001 to $60 \%$ in 2002 as a result of the mishandling of funds. One could argue that this behavior so damaging to public confidence was a product of a number of dysfunctional tendencies to include narcissism and social dominance (Judge et al., 2009; Million et al., 2004).

Researchers have argued that church leadership may be in a favorable position to arrest what some have termed a leadership crisis (Collins, 2005; Hybels, 2002); however, that is not meant to imply that church leadership has not been also negatively impacted by a possible degradation in leadership (Baumgartner, 1990; Boyd, 2007; McIntosh \& Rima, 2007). In referring to a possible leadership crisis among church clergy McIntosh and Rima (2007) state: 
At the core of the problem is personal ambition and the insidious desire to have or possess something that is not able to be possessed - namely success. We believe in a culture obsessed with both having and success. And this desire has infiltrated the ranks of Christian leaders as it has every other strata of American culture. (p. 19)

McIntosh and Rima (2007) specifically attribute compulsion, narcissism, paranoia, codependence, and passive-aggression, as prominent dysfunctions associated with clergy leadership_all constructs of this research.

\section{Ineffective Leadership and the Church}

In response to the consistent moral failures of church leaders, as cited in their study, McIntosh and Rima (1997) explored the dark, or ineffective, side of leadership. The authors define the dysfunctions, which they call "dark side," as "a natural result of human development. It is the inner urges, compulsions, and dysfunctions of our personality that often go unexamined or remain unknown to us until we experience an emotional explosion" (p. 28). Conger (1990), in his article The Dark Side of Leadership, describes dark leadership as "losing touch with reality" or leadership that "become vehicles for purely personal gain” (p. 1).

All leaders have a dark, or dysfunctional side; yet, many are very effective leaders (McIntosh \& Rima, 2007; Palmer, 1994). McIntosh and Rima (2007) remind us that "the term 'dark side' may conjure up negative images; [however] our dark side is not intrinsically evil. It is simply a part of being human” (p. 155). Palmer (1994) defines a leader in terms of "shadow" and "light" when he states:

A leader is a person who has unusual degree of power to project on other people his or her shadow, or his or her light. A leader is a person who has an unusual degree of power to create the conditions under which other people must live and move and have their being, conditions that can either be illuminating as heaven or as shadowy as hell. A leader must take special responsibility for what's going on 
inside his or her own self, inside his or her consciousness, lest the lack of leadership create more harm than good. (p. 3)

Taking responsibility for "what's going on inside" implies great personal reflection to discover the dysfunction (darkness) that exists in all of us and then to take measures to mitigate its effect (Judge et al., 2009; McIntosh \& Rima, 2007; Palmer, 1994). Palmer (1994) describes this as "inner work" and argues that this inner work is as real as outer work and, in fact, the outer work (or the work that is typically measured cognitively), is impacted directly to the reflection and self-discovery of leadership dysfunctions that exist inside. Judge et al. (2009) describe this as core self-evaluation, which "captures one's bottom line self-assessment" (p. 866). Taking action to lessen the dysfunction is what separates effective leadership from ineffective leadership (Boyd, 2007; Kouzes \& Posner, 2012a, McIntosh \& Rima, 2007; Palmer, 1994).

McIntosh and Rima (1997) explored the dysfunctional side of church leadership. The authors present five types of dysfunctional traits of dysfunctional leadership in the church: the compulsive leader, the narcissistic leader, the paranoid leader, the codependent leader, and the passive-aggressive leader. I recognize that there may be other dysfunctional leadership traits that negatively affect church leadership (Franklin \& Fong, 2011). For example, Judge et al. (2009) argued narcissism, hubris, social dominance, and Machiavellianism as characteristics of ineffective leaders. However, for the purpose of this work, I will explore only the five traits of dysfunctional leadership, presented by McIntosh and Rima (2007).

\section{The Compulsive Leader}

Compulsiveness is McIntosh and Rima's (2007) first dysfunctional leadership trait. The compulsive leader demands control and order at all cost, tends to be very status 
conscious, and possesses a strong need to make decisions (McIntosh \& Rima, 2007;

Toates \& Coschug-Toates, 2005). This leader is challenged with deep insecurities "about their own identity, their own worth" (Palmer, 1994, p. 7). This leader can become impatient with the progress of the task or the pace that the organization is accomplishing their mission and become more hands-on or more controlling often times alienating other members of the team or direct reports (Conger, 1990). Compulsive symptoms include repetitive behaviors (e.g. hand washing, ordering, checking) or mental acts aimed at preventing or reducing stress or preventing some dreaded event or situation however these mental acts are not connected in a realistic way to the event or situation (Franklin \& Fong, 2011).

Studies have suggested that clergy are prone to elevated compulsive measures (Hepworth, Simonds, \& Marsh, 2010; Plante \& Apodaca, 2011). Hepworth et al. (2010) defined scrupulosity as a manifestation of compulsive disorders in a religious context and was the construct of her research. Though her grounded theory analysis included eleven catholic priests as the participants, evidence suggested that the disorder existed also among lay church members. This is consistent with the findings of McIntosh and Rima (2007). The church leader who must oversee the bulletins, select the songs, insist on what people wear, consistently criticize and critique, and strive for perfectionism is exercising dysfunctional leadership according to this study. The compulsive leader claims to do this in the name of God but actually does it to meet the leader's unhealthy needs. The compulsive church leader, in the pursuit of perfection, sees any flaws or imperfections as a personal reflection on themselves. They have a tendency toward violent and sudden 
outbursts, immediately followed by apologies and reconciliation to again get control of the situation.

\section{The Codependent Leader}

Codependence is McIntosh and Rima's (2007) fourth dysfunctional leadership trait. The author describes codependence as more of a generic trait or behavior that can be a component of many different personality disorders. Beattie (1987), in her book Codependent No More: How To Stop Controlling Others and Start Caring for Yourself, defines Codependence as follows:

An emotional psychological, and behavioral condition that develops as a result of an individual's prolonged exposure to, and practice of, asset of oppressive rulesrules that prevent the open expression of feelings as well as the direct discussion of personal and interpersonal problems. (p. 32)

Conger (1990) argues that co-dependency problems can occur when group members "delude themselves into agreement with the leader or dominant other" (p. 7). This agreement often distorts effective decision making for the cohesion of the group and the relationships with each other have a higher priority than accomplishing the task at hand.

In Boyd's study (2007) the codependent spiritual leader is more interested in relationships than being a leader. This study, along with other empirical research (Schweitzer, 2011), informed the reader that codependence should be a concern of church leadership and strategies need to be developed to lessen its degree among church leaders. Some examples of codependent behaviors from church leaders include the avoidance of taking action when inappropriate behavior occurs, taking responsibility for inappropriate behavior though someone else should be responsible, and an out of control schedule, in 
that they are trying to please everyone by placing unreasonable demands on themselves. (McIntosh \& Rima, 1997).

\section{The Narcissistic Leader}

Narcissism is McIntosh and Rima's (2007) second dysfunctional leadership trait. McKlesky (2012) argues that "narcissism lies at the heart of dark leadership" (p. 38). The narcissistic leader believes that everything revolves around them. This self-absorbed tendency is compensated by intense ambition, fantasies, feelings of inferiority, and overdependence on external admiration and acclaim (Bennis, 1989). This leader has an overinflated sense of importance, a need for constant attention and admiration from those they lead or to whom they report and often lack empathy for others, are self-absorbed, believe in entitlement, and have a superficial view of self (Franklin \& Fong, 2011; McIntosh \& Rima, 1997). This leader has a tendency to exaggerate personal deeds thus misrepresenting their own accomplishments and often taking credit for other people's efforts (Conger, 1990).

This individual has a need to regulate, or one could argue, inflate feelings of selfworth through narcissistic behaviors. These behaviors are centered on desires that are focused on self-gratification and satisfaction (Brown, 1997). The narcissistic leader deals with anxiety, conflict, and emotional distress using denial; their unacceptable behavior is rationalized as acceptable; they believe in entitlement thus implying a right to exploit others (Brown, 1997; McIntosh \& Rima, 2007). A narcissistic personality disorder is fitting if behaviors match five of the nine characteristics of a narcissist: exaggerated selfimportance, preoccupied with fantasies of success, belief that he or she is special, needs excessive admiration, sense of entitlement, exploits others for self-achievement, lack of 
empathy, envious, and displays an arrogant attitude (American Psychological Association [APA], 2000).

Rosenwieg (2007), in his book The Halo Effect, describes circumstances where leaders were isolated from their staff and advisors and were thus put in situations where they were separated from the reality exemplifying narcissistic leadership. These circumstances were brought on by the leaders need for recognition and the belief that they were special or, more competent and all-knowing than others. Whether it was the power of their position or their perceived history of always being right this narcissistic attitude has proven fatal to leaders and even the institutions they lead (W. Smith, 2008; Sorkin 2009).

Narcissism can cause unhealthy and abnormal conflict in churches, particularly if the pastor is not responsive in the ways of a narcissistic individual when he or she seeks out pastoral care or counseling (Schweitzer, 2011). Plass (2002), in his dissertation conducted an empirical assessment of narcissism in theological students, endeavored to measure the narcissism in people being trained for full time Christian service. This study concluded that the level of narcissism among these potential church leaders was high; however, the study failed to discern the level of pathological narcissism from narcissism that tend toward creativity and fulfilling ministry. A church leader whose motive for delivering a sermon is recognition, or, leading a church into a costly project so they would feel good about themselves, or believe that the church would suffer if they left are narcissistic examples in a church setting (McIntosh \& Rima, 2007) and are examples of pathological narcissism. According to this study these narcissistic traits exist, to some degree, among church leaders. 
Paranoia is McIntosh and Rima's (2007) third dysfunctional leadership trait. There are many references in literature that describe leaders with paranoid tendencies. The paranoid leader is afraid of anyone that has the remotest chance of undermining his leadership position. They are characteristically suspicious, hostile, and guarded in their relationships (Million et al., 2004; Schweitzer, 2011). Their "basic capacity for trust has somehow been destroyed" (Million et al., 2004, p. 436). Paranoid personality disorder criteria, as established by the APA (1994), include persuasive distrust and suspiciousness of others, a preoccupation questioning the loyalty and trustworthiness of friends, a reluctance to confide in others, bears grudges, and perceives attacks on his or her character or reputation.

Studies have concluded we all have some paranoid tendencies (McIntosh \& Rima, 2007; Schweitzer, 2011). This includes church leaders. Veenker (2000), in his dissertation study, concluded the following when reporting results about paranoia among pastors:

We have traced the development of paranoia in the life of King Saul, and surveyed some of the more common manifestations of paranoia in today's pastors. We have seen how paranoia is related to anxiety, protecting the self-concept with a "false" self and the defense mechanism of projection, and how paranoia is related to depression. (p. 121)

A pastor who prevents an associate pastor from delivering a sermon for fear that the congregation will like him better, or, preventing the church governing body to meet without them being present are examples of paranoia in the church (McIntosh \& Rima, 1997). Again, this is consistent with Palmer's (1994) description of "shadow" in that paranoia stems from personal insecurities. 


\section{The Passive-aggressive Leader}

The last dysfunctional trait that McIntosh and Rima (2007) described is passiveaggression. McIntosh and Rima (1997) describe the passive-aggressive leader has a tendency to resist demands or perform tasks; they have an intense fear of failure, and are

prone to short outbursts showing extreme emotion. They are naturally indecisive caused by trying to seek out every detail before making a decision. This inefficiency is often intentional and is accompanied by procrastination, stubbornness, and forgetfulness (Million et al., 2004).

McIntosh and Rima (1997) posit that passive-aggressive psychological disorders exist to some degree in all of us and should be a concern of church leadership. Empirical studies have confirmed its construct, that it can be reliably assessed, and be differentiated from other psychological disorders (Hopwood et al., 2009).

In ministry these leaders find it difficult to set goals, constantly complain about not having enough support from the church, and have a tendency to become impatient or irritable when things do not go their way during council or congregational meetings. These leaders are actually quite pleasant as long as the status quo is maintained. However as soon as initiatives to progress forward or make changes surface, the irrational behaviors of the passive-aggressive leader will surface (McIntosh \& Rima, 2007).

\section{Lay Leadership in Churches and Community}

Hybels (2002) argues that our local churches are uniquely equipped to address the leadership challenge. After inspecting the destruction and death at the World Trade Centers after September 11, 2001, Hybels states: “The church has an utterly unique mission to fulfill on planet Earth, and that the future of our society depends, largely, on 
whether or not church leaders understand that mission and mobilize their congregations accordingly" (p. 16). He implies that effective leadership in our local congregations will spill over into all sectors of society, thus improving our state of leadership in general.

Webster (2005), in describing what he terms the "visible" church, states:

The church is a human gathering; it engages in human activities (speech, washing, eating, and drinking); it has customs, texts, orders, and procedures and possessions, like any other visible social entity. But how does it do and have these things, and so it is what it is, by virtue of the work of the Holy Spirit. (p. 101)

This implies the need, and certainly the existence of leaders within the church.

This leadership, along with followership, have a mandate to reach out into the community (Guder, 2005).

In arguing that church leaders are uniquely prepared to lead in other sectors of society, Hybels (2002) also posits that the church has a unique opportunity today to reach out into community. Zaidman, Goldstein, and Nehemya (2009), in their study From Temples to Organizations: The Introduction and Packaging of Spirituality, conducted research based on a study of Israeli spiritual consultants and their interaction with local organizations. This spirituality recognizes that people have "inner lives, [and] an assumption that employees desire to find work meaningful and a commitment by the company to serve as a context or community for spiritual growth" (p. 598).

This inner reflection represented in spirituality has been recognized as an important aspect to successful leadership encouraging leaders to turn to their inner self and to work from the heart, not just logic (Buford, 2008, Kouzes \& Posner, 2012a; McIntosh \& Rima, 2007; Palmer, 1994; Zaidman et al., 2009). This spirituality inspires interconnectedness with people, is effective during times of challenge and unrest, encourages teamwork that is important to effective leadership, is nurtured in the church 
and serves as a conduit into all sectors of society (Collins, 2005; Hybels, 2002; Stubbs, 2011; Zaidman et al., 2009). This spirituality also inspires constant reminders of our overarching purpose both individually and organizationally, that serves a greater good in our community and also can contribute to organizational successful (Buford, 2008;

Stubbs, 2011; Turak, 2013).

Unfortunately all leaders, to include church lay leaders, can experience challenges that may surface dysfunctions. McIntosh and Rima (2007) state: "There comes a point in all leaders' lives — if they remain in leadership long enough — when they will begin to experience the relational friction, organizational blow-ups, and personal pain that result from unidentified or unresolved inner-life issues" (McIntosh \& Rima, 2007, p. 23). These issues will inhibit one to realize their full potential as a leader, deserve study, and are thus a major construct of this work (Conger, 1990; McIntosh \& Rima, 2007).

\section{Summary}

This review explored literature pertaining to effective leadership and ineffective leadership. Investigating literature pertaining to effective leadership we reviewed the importance of a leader's values and beliefs, other traits of effective leadership, and a general review of leadership in the church. Investigating ineffective leadership we reviewed dysfunctional traits that may inhibit a leader from being more effective. The next chapter frames the methodology to this study. 


\section{CHAPTER 3}

\section{METHODOLOGY}

\section{General Introduction}

This study attempted to discover if a relationship exists between the personal dysfunctions of church leaders and the discovery and expression of their values and beliefs. To accomplish this goal, leadership dysfunctions were operationally defined using McIntosh and Rima's (2007) DSLP, and the discovery and expression of beliefs were similarly represented using Kouzes and Posner (2012a) Modeling-the-Way section of the LPI Self instrument. Participants for this investigation were recruited from the lay leaders in two different congregations, Christ United Methodist Church and Collegedale Community Church (Adventist), both located in the same community. In order to provide requisite details of the research process and procedure, this chapter will explore the following areas: type of research, population and sample, hypothesis, definition of variables, instrumentation (to include reliability and validity), data collection, data analysis, and other ethical considerations.

\section{Type of Research}

Creswell (2012) states that "quantitative research problems require that you explain how one variable affects another" (p. 13). Continuing this description of quantitative research characteristics, Creswell mentions the importance of hypotheses being specific, measurable, and observable while using numeric data derived from preset 
questions and responses. This research explored whether the discovery and expression of beliefs and values, as measured in Kouzes and Posner's (2012a) Modeling-the-Way LPI Self, the independent variable, will correlate with any or all of McIntosh and Rima's (2007) five leadership dysfunctions (compulsion, narcissism, paranoia, codependence, and passive-aggression), as dependent variables, measured by McIntosh and Rima's DSLP among lay leaders within two specific church congregations. A specific research question and hypothesis about the association between these variables will be tested using inferential statistics. Therefore, a quantitative research design is appropriate for this study. Correlation describes a particular relationship between variables. This study sought to discover if a relationship exists between Modeling-the-Way and the dysfunctional leadership traits among lay leaders within two specific congregations as described before. Therefore a correlation design is appropriate.

This research used surveys to collect data. The instruments used were the LPI Self (Kouzes \& Posner, 2001) and McIntosh and Rima’s (2007) DSLP identifying-your-darkside inventories. The advantages of the survey design considered in its selection included the economy of the design, which factored in cost, time to administer, the simplicity in collecting the data and rapid turnaround time. The survey data were collected over approximately four weeks through self-administered surveys via an on-line portal. Hard copy surveys were available contingent on participants' preferences; however, all participants who completed the survey opted for on-line self-administration (Creswell, 2003). The order of survey items presented online was randomly scrambled across participants in order to reduce possible effects of survey fatigue. 


\section{Population and Sample}

This study focused on the lay leaders of Christ United Methodist Church of Chattanooga, Tennessee and Collegedale Community Church of Collegedale, Tennessee. The target population (Creswell, 2012) was the current lay leaders and lay leaders from the past three years in each respective congregation. Lay leader, for the purposes of this study, is defined as anyone in a position to influence an organized group toward a defined goal (Hughes et al., 2012) that is not being compensated for their leadership responsibilities. Paid pastors, music directors, youth leaders, missionaries, or anyone paid to perform in a leadership position within the church was not considered lay leaders for the purposes of this study. Paid church staff whose paid responsibilities do not include a position of leadership but who volunteer independent of their paid position in a lay leadership position were included in the study.

The survey was sent to everyone in the target population. Two individuals were hired to call all qualified participants to answer questions and encourage participation. A separate research assistant emailed the inventory using survey monkey, collected the inventory, and loaded the data in SPSS. This assistant ensured that confidentiality for each participant and the data provided was maintained. Because the entire population was invited to participate and the sampling process included participants from the population who were willing and available, this involved nonprobabilistic convenience sampling (Creswell, 2012). The questions on the surveys were randomly shuffled across participants to help minimize the effects of error due to survey fatigue.

Sample size is important for finding statistical significance. The population of current lay leaders in Christ United Methodist Church is 120 with an additional 12 
members having occupied leadership positions in the past three years who are currently not leaders. Thus for this population $N=132$. The population of lay leaders in the Collegedale Community Church equals 77 with an additional nine members having occupied leadership positions in the past three years who are currently not leaders. For this population, $N=86$. The response to participate is represented in Table 1 , with the total population of lay leaders being 218 , total accepting the invitation to participate being 142, and 84 responding to all questions. All surveys were completed on line, and although two participants requested a paper survey, these were never returned and thus were not included.

Table 1

Study Population and Response to Participation

\begin{tabular}{lr}
\hline Population & $N$ \\
\hline Total lay leader population & 218 \\
Total invitations & 218 \\
Total responses to survey & 142 \\
Total responses with fully completed surveys & 84 \\
Total surveys completed on line & 142 \\
Total surveys completed paper & 0 \\
Total surveys used to compile results & 142 \\
\hline
\end{tabular}

Though an effort was made to survey the entire population of lay leaders it is unrealistic to expect total participation, so statistical estimation was required. Field (2009) recommends 10 to 15 cases of data per predictor in the model. This study has five predictor variables. This suggests a minimum of 50 to 75 participants. The total population of 218 lay leaders between the two congregations was solicited to participate in this study. Using the proportional stratification sampling approach (Creswell, 2012) 
that would mean $39 \%$ of the sample should come from Collegedale Community Church and $61 \%$ of the population should come from Christ United Methodist Church.

\section{Hypothesis}

The research general question guiding this study was: Is there a relationship between leadership dysfunctions in the specific congregation and Modeling-the-Way for religious lay leaders in two specific congregations?

The research was thus guided by five sub questions:

1. Does a relationship exist between Modeling-the-Way, as measured by Kouzes and Posner's (2012a) LPI Self and the dysfunction of codependence as described by McIntosh and Rima's (2007) DSLP inventory among church lay leaders in two specific congregations?

2. Does a relationship exist between Modeling-the-Way, as measured by Kouzes and Posner's (2012a) LPI Self and the dysfunction of compulsion as described by McIntosh and Rima's (2007) DSLP inventory among church lay leaders in two specific congregations?

3. Does a relationship exist between Modeling-the-Way, as measured by Kouzes and Posner's (2012a) LPI Self and the dysfunction of narcissism as described by McIntosh and Rima's (2007) DSLP inventory among church lay leaders in two specific congregations?

4. Does a relationship exist between Modeling-the-Way, as measured by Kouzes and Posner's (2012a) LPI Self and the dysfunction of paranoia as described by McIntosh and Rima's (2007) DSLP inventory among church lay leaders in two specific congregations? 
5. Does a relationship exist between Modeling-the-Way, as measured by Kouzes and Posner's (2012a) LPI Self and the dysfunction of passive-aggression as described by McIntosh and Rima's (2007) DSLP inventory among church lay leaders in two specific congregations?

The following null hypothesis was tested:

$\mathrm{H} 1_{\mathrm{o}}$ : There is no correlation between Modeling-the-Way, as measured by Kouzes and Posner's (2012a) LPI Self, and the five dysfunctional leadership traits (compulsion, narcissism, paranoia, codependence, and passive-aggression), as measured by McIntosh and Rima's (2007) DSLP inventory, for lay leaders in two congregations in Tennessee.

\section{Definition of Variables}

The hypothesis tested describes the relationship or level of association between the dependent variables (Dysfunctional Leadership Traits) and the independent variable (Modeling-the-Way) as shown in Table 2. The data analysis provided insight with regards to the level of association between the dysfunctional traits and other demographic variables, such as gender, tenure as a lay leader, denomination, and tenure as a church member (Boyd, 2007: Morgan \& Harmon, 2000). Findings related to these demographic variables will be discussed in Chapters 4 and 5.

The following demographic variables were used in this study:

Gender: Gender is the sex of the study participant and was a question added to the survey.

Number of years attending this specific church: Participants estimate of the number of years attending this church. 
Table 2

Dysfunctional Variables and Modeling-the-Way Variable

\begin{tabular}{|c|c|c|c|c|}
\hline $\begin{array}{l}\text { Variable } \\
\text { Name }\end{array}$ & $\begin{array}{l}\text { Conceptual } \\
\text { Definition \& } \\
\text { Characteristics }\end{array}$ & $\begin{array}{l}\text { Operational } \\
\text { Definition }\end{array}$ & Instrument Definition & $\begin{array}{l}\text { Supporting } \\
\text { Literature }\end{array}$ \\
\hline Compulsion & $\begin{array}{l}\text { To maintain order to } \\
\text { the extent of over } \\
\text { emphasizing } \\
\text { controlling } \\
\text { tendencies; order in } \\
\text { personal life demands } \\
\text { the same order in } \\
\text { organizational life }\end{array}$ & $\begin{array}{l}\text { Self-administered } \\
\text { survey consisting of } \\
\text { reaction to } 12 \\
\text { statements from a } \\
60 \text {-statement } \\
\text { survey. It uses an } \\
\text { interval scale with a } \\
\text { range from } 1 \text { to } 5 .\end{array}$ & $\begin{array}{l}\text { Statements } 1-12 \text { in the survey inquire } \\
\text { about compulsion. Each item has a } \\
\text { Likert scale } 1 \text { thru } 5 \text { with } 1=\text { strongly } \\
\text { disagree thru } 5 \text { strongly agree. See } \\
\text { Appendix A for items list. } \\
>20=\text { not compulsive } \\
<20 \text { but }>40 \text { some compulsive } \\
<40 \text { compulsive leader }\end{array}$ & $\begin{array}{l}\text { McIntosh and Rima } \\
(2007) \\
\text { Palmer (1994) } \\
\text { Conger (1990) } \\
\text { Franklin (2011) }\end{array}$ \\
\hline Narcissism & $\begin{array}{l}\text { Overly self-absorbed; } \\
\text { overinflated since of } \\
\text { importance; believes } \\
\text { in entitlement; great } \\
\text { ambition and } \\
\text { grandiose fantasies of } \\
\text { self; need to be } \\
\text { admired and } \\
\text { recognized }\end{array}$ & $\begin{array}{l}\text { Self-administered } \\
\text { survey consisting of } \\
\text { reaction to } 12 \\
\text { statements from a } \\
60 \text {-statement } \\
\text { survey. It uses an } \\
\text { interval scale with a } \\
\text { range from } 1 \text { to } 5\end{array}$ & $\begin{array}{l}\text { Statements } 13-24 \text { in the survey inquire } \\
\text { about narcissism. Each item has a } \\
\text { Likert scale } 1 \text { thru } 5 \text { with } 1=\text { strongly } \\
\text { disagree thru } 5 \text { strongly agree. See } \\
\text { Appendix A for items list. } \\
>20=\text { not narcissistic } \\
<20 \text { but }>40 \text { some narcissism } \\
<40 \text { narcissistic leader }\end{array}$ & $\begin{array}{l}\text { McIntosh and Rima } \\
(2007) \\
\text { McClesky (2012) } \\
\text { Bennis (1989) } \\
\text { Conger (1990) } \\
\text { Brown (1991) }\end{array}$ \\
\hline Paranoia & $\begin{array}{l}\text { Trust damaged or } \\
\text { destroyed in others } \\
\text { leading to } \\
\text { suspicion, hostility, } \\
\text { fearfulness, and } \\
\text { jealousy; insecure } \\
\text { lacking confidence }\end{array}$ & $\begin{array}{l}\text { Self-administered } \\
\text { survey consisting of } \\
\text { reaction to } 12 \\
\text { statements from a } \\
60 \text {-statement } \\
\text { survey. It uses an } \\
\text { interval scale with a } \\
\text { range from } 1 \text { to } 5\end{array}$ & $\begin{array}{l}\text { Statements } 25-36 \text { in the survey inquire } \\
\text { about paranoia. Each item has a Likert } \\
\text { scale } 1 \text { thru } 5 \text { with } 1=\text { strongly } \\
\text { disagree thru } 5 \text { strongly agree. See } \\
\text { Appendix A for items list. } \\
>20=\text { not paranoid } \\
<20 \text { but }>40 \text { some paranoia } \\
<40 \text { paranoid leader }\end{array}$ & $\begin{array}{l}\text { McIntosh and Rima } \\
\text { (2007) } \\
\text { Million et al. (2004) } \\
\text { Sorkin (2009) } \\
\text { Palmer (1994) }\end{array}$ \\
\hline Codependence & $\begin{array}{l}\text { Prolonged exposure } \\
\text { to oppressed rules } \\
\text { leading to covering } \\
\text { up problems rather } \\
\text { than face them and } \\
\text { putting social } \\
\text { structure ahead of } \\
\text { personal or } \\
\text { organizational } \\
\text { mission }\end{array}$ & $\begin{array}{l}\text { Self-administered } \\
\text { survey consisting of } \\
\text { reaction to } 12 \\
\text { statements from a } 60 \text { - } \\
\text { statement survey. It } \\
\text { uses an interval scale } \\
\text { with a range from } 1 \\
\text { to } 5\end{array}$ & $\begin{array}{l}\text { Statements } 37-48 \text { in the survey inquire } \\
\text { about codependence. Each item has a } \\
\text { Likert scale } 1 \text { thru } 5 \text { with } 1=\text { strongly } \\
\text { disagree thru } 5 \text { strongly agree. See } \\
\text { Appendix A for items list. } \\
>20=\text { not codependent } \\
<20 \text { but }>40 \text { some codependency } \\
<40 \text { codependent leader }\end{array}$ & $\begin{array}{l}\text { McIntosh and Rima } \\
(2007) \\
\text { Beattie (1987) } \\
\text { Conger (1990) } \\
\text { Boyd (2007) }\end{array}$ \\
\hline $\begin{array}{l}\text { Passive- } \\
\text { aggression }\end{array}$ & $\begin{array}{l}\text { Stubborn, forgetful, } \\
\text { intentionally } \\
\text { inefficient. Tend to } \\
\text { complain, } \\
\text { procrastinate, and } \\
\text { resist demands. Is } \\
\text { anger and bitter and } \\
\text { has fear of success } \\
\text { because it may lead } \\
\text { to higher } \\
\text { expectations }\end{array}$ & $\begin{array}{l}\text { Self-administered } \\
\text { survey consisting of } \\
\text { reaction to } 12 \\
\text { statements from a } 60- \\
\text { statement survey. It } \\
\text { uses an interval scale } \\
\text { with a range from } 1 \\
\text { to } 5\end{array}$ & $\begin{array}{l}\text { Statements } 49-60 \text { in the survey inquire } \\
\text { about passive-aggressive. Each item } \\
\text { has a Likert scale } 1 \text { thru } 5 \text { with } \\
1=\text { strongly disagree thru } 5 \text { strongly } \\
\text { agree. See Appendix A for items list. } \\
\text { leader }>20=\text { not passive-aggressive } \\
<20 \text { but }>40 \text { some passive-aggressive } \\
<40 \text { passive-aggressive leader }\end{array}$ & $\begin{array}{l}\text { McIntosh and Rima } \\
\text { (2007) } \\
\text { Million et al. (2004) }\end{array}$ \\
\hline $\begin{array}{l}\text { Modeling- } \\
\text { the-Way }\end{array}$ & $\begin{array}{l}\text { Discovering and } \\
\text { authentically } \\
\text { expressing values } \\
\text { and beliefs. } \\
\text { Sensitive about } \\
\text { values alignment in } \\
\text { an organization }\end{array}$ & $\begin{array}{l}\text { Self-administered } \\
\text { survey consisting of } \\
\text { reaction to } 6 \\
\text { statements } \\
\text { (measuring } \\
\text { Modeling-the-Way). } \\
\text { It uses an interval } \\
\text { scale with a range } \\
\text { from } 1 \text { to } 10\end{array}$ & $\begin{array}{l}\text { A 6-statement survey inquiring about } \\
\text { values and beliefs represented by the } \\
\text { Modeling-the-Way Self portion of the } \\
\text { LPI. Each item has a Likert scale } 1 \\
\text { thru } 10 \text { with } 1=\text { almost never thru } \\
10=\text { almost always. See Appendix B } \\
\text { for items list. } \\
\text { High is } 0 \text { to } 4.12 \\
\text { Moderate is } 4.13 \text { to } 12.35 \\
\text { Low is } 12.36 \text { and above }\end{array}$ & $\begin{array}{l}\text { Kouzes and Posner } \\
(2001,2003,2012 \mathrm{a}) \\
\text { Drucker }(1999) \\
\text { Kellerman }(2012) \\
\text { Parker }(1994) \\
\text { C. Johnson (2012) } \\
\text { George and Sims } \\
(2007) \\
\text { Martin (2007) } \\
\text { Francis (2012) } \\
\text { Northouse (2013) }\end{array}$ \\
\hline
\end{tabular}


Number of years in a current position of leadership in the church: Participants quantified the number of years they have been in their current leadership position and/or past leadership positions within the church.

If not currently in a leadership position but have been in a leadership position in the past three years, number of years in that position: Participants quantified, if not currently in a leadership position but were in a lay leadership position in the last three years, the number of years in a past leadership position.

Denomination: Participants disclosed what denomination they have their current church membership with.

\section{Instrumentation, Reliability, and Validity}

In this quantitative study, I used two instruments to collect data from participant's responses to the instrument's closed ended questions. One instrument provided numerical representations of the exemplary leadership trait, Modeling-the-Way (Kouzes \& Posner, 2012a) represented by the LPI Self, and the other measured the dark, or dysfunctional, category of leadership (McIntosh \& Rima, 2007) assessed by the DSLP survey. This study measured leadership discovery and expression of beliefs and values according to Kouzes and Posner's (2012a) Modeling-the-Way portion of the LPI Self. This portion of their inventory used a ten point Likert scale, where a higher value represents a more frequent use of the leadership behavior. For example a "1" indicates "almost never" and a "10" indicates "almost always." The LPI Self contains thirty statements with six statements for measuring each of the five characteristics of exemplary leadership. With 30 behaviors being ranked by each respondent scores range from " 6 " to " 60 ," this study was primarily concerned with the exemplary practice, Modeling-the-Way. The higher a 
participant scores on the LPI Self, examining the exemplary practice of Modeling-theWay, the more one has discovered and is able to express values and beliefs.

Of the two self-administered instruments used in this study the second, the DSLP, developed by McIntosh and Rima (2007), measures the degree of dysfunction in an individual's leadership. This inventory used a five point scale, where "1" represents strong agreement and " 5 " represents strong disagreement to statements relating to leadership dysfunctions. This inventory thus measured the dysfunction of the sample by congregation and then measured each individual participant's degree of that particular dysfunction. The DSLP is comprised of 60 closed-ended questions, or 12 questions per dysfunction measurement. A participant could have a score as low as 12 indicating a low level of the dysfunction, or a score as high as 60 indicating a high level of dysfunction. According to McIntosh and Rima, a score of 20 or below indicates a leader is probably not behaviorally affected by the dysfunction; a score falling between 21 and 40 indicates a likelihood of that specific dysfunction; and a score of 41 or above indicates that a leader is directly affected by that dysfunction. Table 2 presents definitions and literature support for the variables and their reliability and validity estimates.

This study is interested in the correlation, if any, between the LPI Self, Modelingthe-Way score, and the scores associated individually with each of the dysfunctions measured by the DSLP survey. Appendix A presents the specific statements by dysfunctional variable. Appendix B represents the statements used to measure Modelingthe-Way according to Kouzes and Posner (2012a).

This section describes reliability and validity and presents previous work pertaining to the reliability and construct validity of the LPI Self, developed by Kouzes 
and Posner (2012a), and the DSLP developed by McIntosh and Rima (2007). This section also includes analysis of reliability and validity of these instruments conducted by this research.

Research needs to select instruments that are reliable and valid. Reliability means "that scores from an instrument are stable and consistent" (Creswell, 2012, p. 159). Validity "is the development of sound evidence to demonstrate that the test interpretation (of scores about the concept or construct that the test is assumed to measure) matches its proposed use" (p. 159). Creswell posits that validity and reliability "are bound together in complex ways" (p. 159). Validity is usually considered as broader and more encompassing as the researcher assesses the choice of an instrument. Reliability measures consistency. Creswell states, "If scores are not reliable, they are not valid; scores need to be stable and consistent first before they can be meaningful” (p. 159).

Validity is important for it addresses whether or not an instrument really measures what it claims to measure. A common assessment of validity known as face validity considers whether an instrument reports what it claims based on subjective evaluation. Because the participants of the LPI Self relate to self-perceptions of their own or their perception of others personal-best leadership experiences, Kouzes and Posner (2002) argue that the LPI Self has excellent face validity.

Validity is also empirically derived, i.e., approached more objectively. Kouzes and Posner (2002) defend the validity of the LPI Self by applying a factor analysis to determine the extent to which the instrument items measure common or different content areas. Kouzes and Posner (2002) state, "The stability of the five factor solution was tested by factor-analyzing the data from different subsamples. In each case, the factor structure 
was essentially similar to the one involving the entire sample" (Kouzes \& Posner, 2002,

p. 14). Professor Herold and his colleagues from the University of Georgia (as cited by

Kouzes \& Posner, 2002) conducted their own factor analysis. Their conclusion:

Estimating [the] correlation factors model corresponding to the oblique factor rotation, modified to reflect intercorrelations among the error items for the LPI items that had correlations with other items exceeding .50, resulted in a confirmation model with acceptable fit (Chi Square $=399.9, d f=363, p<.09$ ). In addition, all of the hypothesized structural coefficients linking the observed variables to the five factors were highly significant with all $t$ values exceeding 7.0. (pp. 14-15)

Correlations with other instruments have further enhanced confidence that the LPI Self measures what it purports to and not other phenomena (construct validity). Relevant to this study the LPI Self has been used in other investigations of spiritual or religious concepts that also reported confidence in the LPI Self's validity (Boyd, 1007; Strack, 2001).

Irving's (1994) study stated that though his results were not conclusive, his evaluation of the DSLP supports its reliability and validity. Irving states: "Practically, this means that the ministry leaders may utilize DSLP in a process of self-leadership with a moderate level of confidence that the instrument is consistently measuring the intended constructs" (p. 9). In order to limit threats to internal validity the entire population of lay leaders and former lay leaders of three years or less removed was solicited to participate. The solicitation was the same for each potential participant with a survey emailed followed by a phone call from a research assistant.

Creswell (2012) challenges researchers to look for evidence of validity by examining other studies that have used the instrument; look at the purpose for which the instrument was used; look at how the researcher interpreted the results; does the author provide adequate evidence that links the interpretation to their use. I found numerous 
studies that used the LPI Self and one study that used the DSLP instrument.

Kouzes and Posner (2002), the authors of the LPI Self, refer to reliability as the “extent to which an instrument contains 'measurement errors' that cause scores to differ for reasons unrelated to the individual respondent" (p. 5). The fewer such errors, the more reliable the instrument and perhaps also more valid. The authors cite Aiken (1997) arguing that instrument reliabilities above .60 are good. The Cronbach alpha, or the degree the questions in the study reflect the underlying construct (Trochim, 2006), for the LPI Self range between 0.75 and 0.87 among the five exemplary traits. Modeling-theWay, of specific interest in this study, measured 0.77 (Kouzes \& Posner, 2002). The authors state that the test-retest reliability for the five leadership practices "have been consistently strong, generally at the 0.90 level or above" (p. 8). The LPI Self has consistently been a survey of choice to many researchers globally and thus the psychometric properties of the LPI Self have been inspected in many research projects. I found two studies that defended the validity of Modeling-the-Way LPI Self using the same authors and data referenced above (Boyd, 2007; Sarantopoulos, 2008). Both of these studies explored the nonprofit sector, with Boyd (2007) studying an aspect of religious leaders, similar to this study. Both researchers suggest with strong certainty that the LPI Self is a valid instrument.

I located one study that evaluated the validity and reliability of the DSLP (Irving, 1994). As previously cited, the DSLP contains 60 questions with 12 questions dedicated to each of the 5 dysfunctions: compulsion, narcissism, paranoia, codependence, and passive-aggression. This profile uses a 5-point Likert scale for evaluating responses. Irving (1994) in his testing used factor analysis and used a web-based format to 
administer his survey instrument. He only invited religious leaders, similar to this study, to participate. Irving invited religious leaders from the Baptist General Conference to participate using email. A total of 47 surveys were received.

Measuring convergent reliability, Irving (1994) utilized the Positive and Negative Affect Scale (PANAS) designed by Watson, Clark, and Tellegen (1988). Irving (1994) reported the alpha coefficients for the five scales making up the DSLP range from 0.62 to 0.80. Irving found reliability coefficients for the compulsive and codependence scales to be 0.6243 and 0.6262 , respectively. These were the only scales below 0.70 . Irving later discovered that by removing the influence of items that lowered the degree of internal reliability revised reliability coefficients of 0.72 for codependence and 0.68 for compulsion were obtained. The items removed were demographic in nature to include questions on gender, education level, military background, organizational questions, tenure as a religious leader, social upbringing, church attendance, ethnicity, and denomination. Irving also measured the alpha coefficients using each scale independently thus asking these demographic questions as a preamble to the 12 questions of each trait separately. Irving's findings are represented in Table 3. Following Creswell's (2012) advice to review other studies to show validity, Boyd (2007) successfully defended his research using these data defending the validity of the DSLP when studying the codependent dysfunction among religious leaders. Boyd concluded, as did Irving (1994), with a moderate degree of certainty, that the DSLP was a valid tool for research.

Until now reliability and validity have been described as reliability pertaining to instruments that are stable and consistent and validity pertaining to instruments that assess what they purport to measure. In addition I have profiled studies that supported the 
Table 3

DSLP Reliability Analysis

\begin{tabular}{lccc}
\hline \multicolumn{1}{c}{ Scale } & Alpha & Deleted Items & New Alpha \\
\hline Codependence & .6262 & $1,3, \& 4$ & .7215 \\
Compulsion & .6243 & $6,7 \& 11$ & .6800 \\
Narcissism & .7130 & $6,8, \& 12$ & .7514 \\
Paranoia & .8011 & ---- & --- \\
Passive-aggression & .7497 & --- & --- \\
\hline
\end{tabular}

validity of the tools used in this study (Boyd, 2007; Irving, 1994; Kouzes \& Posner, 2002). I now extend this examination by conducting my own investigation of reliability based on these original data.

As previously established, reliability is concerned with stability and consistency of measurement. This research used Cronbach's alpha due to its popularity and availability in SPSS. This test measures internal reliability and consistency of items in addition to testing items that have more than two answers, such as Likert scales (Vogt, 1999). As previously purported, Vogt posits that scores above 0.7 suggest that the items are statistically stable and reliable while Aiken (1997) argues that scores above 0.6 suggest that the items are statistically reliable.

The dysfunction scores had Cronbach's alphas ranging from 0.727 (paranoia) to 0.807 (narcissism). Modeling-the-Way has a Cronbach's alpha score of 0.65. All dysfunction scores support statistical reliability in that they are above .70 . Though Modeling-the-Way scored below 0.70 at 0.65 , this is still above 0.60 argued by Aiken (1997) as being statistically reliable. Furthermore, this score measures reasonably close to the 0.70 standard posited by Vogt (1999). Table 4 summarizes the Cronbach alpha reliability scores. 
Table 4

Cronbach Alpha Score for Reliability Among Participants

\begin{tabular}{lcc}
\hline & Cronbach Alpha & $N$ \\
\hline Codependence & 0.76 & 12 \\
Compulsion & 0.77 & 12 \\
Narcissism & 0.81 & 12 \\
Paranoia & 0.73 & 12 \\
Passive-aggression & 0.78 & 12 \\
Modeling-the-Way & 0.65 & 6 \\
\hline
\end{tabular}

\section{Data Collection}

Creswell (2012) identifies five steps in the process of data collection. These steps include determining the participants to be studied, obtaining permission from the individuals and organizations, considering what types of information to collect, locating and selecting instruments, and administering data collection process. Previous chapters and sections have discussed the types of information to be collected and locating and selecting the instruments and a description of the population and sample (see Table 1). This section is thus devoted to gaining permission to include ethical considerations, and data collection procedures.

\section{Permission to Conduct Study and Ethical Considerations}

Permission was granted to solicit participation by the lead pastor of Christ United Methodist Church (see Appendix C) and Collegedale Community Church (see Appendix D). The Institutional Review Board approved the study to solicit participation. The congregational representatives attempted to communicate via personal meeting, phone call, or e-mail to introduce participants to the study and to answer any questions. Each lay leader was sent an introduction to the study (see Appendix E), a link that would present a 
consent letter (see Appendix F) and a response box to either accept or decline participation. Of those that visited the site $98 \%$ accepted, thus consenting to participate. Two declined to participate and were simply removed from the site. By clicking the 'accept' button the leader agreed to participate in the study and was presented the survey. Creswell (2012) submits potential ethical issues in conducting correlation research. They include issues relating to data collection, data analysis, and data reporting and presenting. Data collection is concerned with data controls to ensure invited participants were not biased to include age, gender, race, and other descriptions. Since the entire population of lay leaders was solicited to participate, this was not an issue. Data analysis is concerned with inappropriately editing the data. Only participants that answered every question with no efforts made to change the responses of participants this also is not a concern. Finally, data reporting and presenting are concerned with ensuring that the research reports contradictory findings or does not omit findings not consistent with my argument. This research reported all findings, contradictory or not contradictory and will present the same. Ethical issues concerning the data collection process are reserved for the next section.

\section{Administrating the Data Collection Process}

Creswell (2012) acknowledges that data collection differs depending on the instruments or documents used. However, two aspects are standard across all forms of data collection: standardization and ethical issues.

This study recognizes the importance of standardized procedures to further negate bias that may contaminate the data (Creswell, 2012). For this reason delivering, executing, and collecting the surveys were accomplished via email formatted the same 
for everyone. On-line participants received surveys via email with questions arranged in a random order for each participant to minimize inter-item bias or survey fatigue.

Additionally, participants who declined to participate or failed to answer all the questions were not included in the study, remained anonymous, and received no more communication to participate. Figure 1 represents the research approach.

This study recognized that data collection must appreciate an ethical process that respects the individual and the church that they are members of (Creswell, 2012). Protecting anonymity was a priority for this process to be ethical. For this reason all surveys were forwarded to the statistics representative at Andrews University in Berrien Springs located approximately 582 miles from the community where these churches are located. This representative has no affiliation with either of the churches being studied except for the fact that she claims Seventh-day Adventism as her denomination of choice and Collegedale Community Church is a Seventh-day Adventist church. However, she claims to have no relationship, personally or professionally, with either congregation. The congregational representatives and I did not have access to any individual surveys. Each participant was coded with a number (1 thru 230) as his/her data are loaded into the SPSS system to further support participant anonymity. For those who chose not to participate those wishes were respected and no effort was made to change that decision.

Institutional Review Board approval was obtained prior to conducting this study. I assigned a representative from each congregation to manage the data collection process respectively. Emails were sent to each current lay leader and former lay leader within three years explaining the purpose and procedures of the research. The cover letter indicated that completing the survey implied that the participant gave consent to 


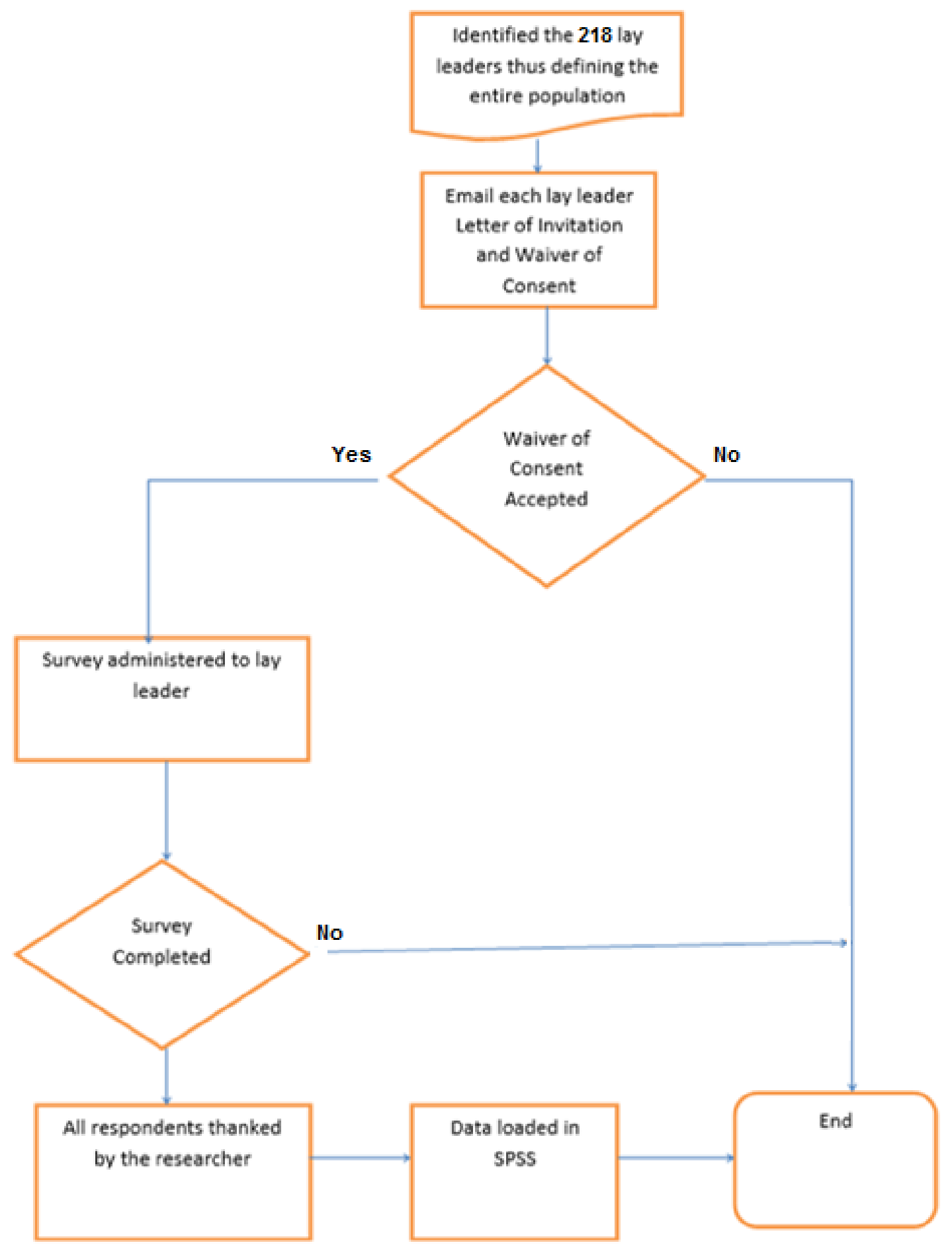

Figure 1. Research approach. 
participate. Included in the emailed letter was a link to the survey. Participants were asked to complete the survey via the link supplied utilizing SurveyMonkey.com.

The congregational representative followed up the e-mails via telephone. Two participants requested hard copy surveys but did not return the surveys as instructed and thus were not included in the study. Upon return of the survey the statistical representative recorded the data into SPSS. Coding was used to ensure all participants enjoy an anonymous contribution to the study. Demographic questions were asked regarding gender, length of membership and tenure of lay leadership in the church being studied and denomination. This demographic data will be used to describe the sample.

\section{Data Analysis}

An analysis was conducted to see if the data indicate a statistically significant relationship between the independent variable, Modeling-the-Way, as measured by the LLP Self, and each of the dependent variable dysfunctions, as measured by the DSLP, by examining their associated $p$ values. Since correlation and regression "are measures of association between variables" (Casson \& Franzco, 2014, p. 590) a correlation and regression analysis was conducted to test if a relationship exists. Correlation analysis provides evidence as to the strength and overall direction of the relationship (negative or positive) (Casson \& Franzco, 2014; Howell, 2013; Rowntree, 1981). A Pearson's $r$ correlation coefficient was calculated representing a standardized covariance (coefficient between -1 and +1$)$. The larger the number the greater the correlation while a negative or positive number represents a negative or positive correlation respectively (Bryant \& Yarnold, 1995). A linear regression analysis provides evidence as to how "one variable does, in fact, influence another, and to make predictions about outcomes given certain 
information" (Casson \& Franzco, 2014, p. 592). Howell (2013) states, "The general problem then becomes one of developing an equation to predict one variable from the knowledge of the other (regression) and of obtaining a measure of the degree of this relationship (correlation)" (p. 253). In addition the simple linear regression allowed the research to investigate separately the core components to Modeling-the-Way allowing for a more detailed evaluation of the relationship in terms of strength and direction.

Guided by the research question and to test the null hypothesis the relationship between Modeling-the-Way and each dysfunction was explored separately. Because the relationships between Modeling-the-Way and the individual dysfunctions were each of interest rather than an overall, 'umbrella' relationship (requiring a multivariate regression analysis), each dysfunction's independent relationship to Modeling-the-Way was modeled using simple linear regression, thus in effect, testing five separate statistical null hypotheses. Specifically, five linear regression analyses were conducted to test for a relationship between the predicted and predictor variables as specified by the research question and hypothesis. To corroborate that analysis a Pearson's $r$ correlation analysis was also conducted. 


\section{CHAPTER 4}

\section{RESULTS}

\section{Introduction}

The purpose of this quantitative correlation study was to explore if discovering and expressing values, as measured by Kouzes and Posner's (2012a) Modeling-the-Way LPI Self, showed a relationship with dysfunctional leadership traits, measured by McIntosh and Rima's (2007) DSLP, among lay leaders in two different congregations, Christ United Methodist Church and Collegedale Community (SDA) Church, both located in the same community. Chapter 4 presents the results of the statistical analysis relevant to the study.

This research was guided by the following question: What is the relationship between Modeling-the-Way, as measured by Kouzes and Posner's (2012a) LPI Self and the five personal dysfunctions as described by McIntosh and Rima's (2007) inventory among church lay leaders in two specific congregations?

As this study aimed at exploring if a relationship existed between variables, it follows a quantitative correlation research design (Creswell, 2012). This chapter will include demographic and descriptive statistics, statistical assumptions of the variables, hypothesis testing with inferential statistical analysis, alternative explanations, findings, and conclusion. 


\section{Demographics of the Sample}

Study participants reported their gender as $54.8 \%$ female and $45.2 \%$ male (see

Table 5) with $44 \%$ of those responding coming from Collegedale Community Church and 56\% coming from Christ United Methodist Church (see Table 6).

Table 5

Gender Frequencies

\begin{tabular}{lcc}
\hline Gender & $F$ & $\%$ \\
\hline Male & 38 & 45.2 \\
Female & 46 & 54.8 \\
\hline
\end{tabular}

$n=84$

Table 6

Denominational Frequencies

\begin{tabular}{lcc}
\hline Denomination & $F$ & $\%$ \\
\hline Collegedale Community Church & 37 & 44 \\
Christ United Methodist Church & 47 & 56 \\
\hline
\end{tabular}

$n=84$

Tenure as church members, represented in Table 7, reveals that most respondents (31\%) have been members of the church for more than five but less than ten years followed by those being members more than 10 but less than 15 years $(26.2 \%)$. The fewest number of participants is represented in the group with over 20 years $(8.3 \%)$ of church membership.

This study included, as represented in Table 8, current lay leaders (77.4\%) and 
Table 7

Tenure as Church Members

\begin{tabular}{lcc}
\hline Tenure as Church Members & $F$ & $\%$ \\
\hline Less than 5 years & 16 & 19.0 \\
More than 5 but less than 10 years & 26 & 31.0 \\
More than 10 but less than 15 years & 22 & 26.2 \\
More than 15 but less than 20 years & 13 & 15.5 \\
More than 20 years & 7 & 8.3 \\
\hline
\end{tabular}

$n=84$

Table 8

Current Lay-Leader Status

\begin{tabular}{lcc}
\hline Current Lay-Leader Status & $F$ & $\%$ \\
\hline Currently a lay leader & 65 & 77.4 \\
Been a lay leader in the past 3 years & 16 & 19.0 \\
Neither & 3 & 3.6 \\
\hline
\end{tabular}

$n=84$

past lay leaders removed for not more than three years (19\%) with $3.6 \%$ categorized as neither. Table 9 shows most of the participants have been a lay leader for more than five years $(36.9 \%)$ followed by those that had been in a lay leader position for more than one but less than three years $(28.6 \%)$.

Table 10 represents the means and standard deviations of the DSLP. These scores are considered to be moderate (scoring between 20 and 40) according to McIntosh and Rima (2007) indicating the existence of all dysfunctions to a moderate degree. Among the dysfunctions codependence in Collegedale Community Church scored the highest $(M=30.46, S D=7.96)$ followed closely by compulsive $(M=29.88, S D=7.23)$. The lowest dysfunction score was Paranoia $(M=21.74, S D=5.20)$. The dysfunction that 
Table 9

Tenure as Lay Leaders

\begin{tabular}{lcc}
\hline Tenure as Lay Leaders & $F$ & $\%$ \\
\hline Less than 1 year & 10 & 11.9 \\
More than 1 but less than 3 years & 24 & 28.6 \\
More than 3 but less than 5 years & 19 & 22.6 \\
More than 5 years & 31 & 36.9 \\
\hline$n=84$ & &
\end{tabular}

Table 10

Average Scores for Dysfunctions by Location and Gender

\begin{tabular}{|c|c|c|c|c|c|c|c|c|c|c|}
\hline & \multicolumn{2}{|c|}{$\begin{array}{c}\text { Codependence } \\
(n=84)\end{array}$} & \multicolumn{2}{|c|}{$\begin{array}{c}\text { Compulsion } \\
(n=84)\end{array}$} & \multicolumn{2}{|c|}{$\begin{array}{c}\text { Narcissism } \\
(n=84)\end{array}$} & \multicolumn{2}{|c|}{$\begin{array}{c}\text { Paranoia } \\
(n=84)\end{array}$} & \multicolumn{2}{|c|}{$\begin{array}{c}\text { Passive- } \\
\text { aggression } \\
(n=84)\end{array}$} \\
\hline & $M$ & $S D$ & $M$ & $S D$ & $M$ & $S D$ & $M$ & $S D$ & $M$ & $S D$ \\
\hline $\mathrm{CCC}$ & 30.46 & 7.96 & 29.32 & 7.67 & 24.62 & 6.39 & 21.54 & 5.27 & 23.19 & 5.87 \\
\hline CUM & 28.77 & 6.44 & 30.32 & 6.91 & 25.66 & 6.44 & 21.89 & 5.19 & 22.87 & 5.94 \\
\hline $\begin{array}{l}\text { Male } \\
(n=38)\end{array}$ & 29.18 & 6.71 & 30.13 & 7.12 & 25.58 & 6.00 & 22.00 & 4.82 & 24.68 & 5.36 \\
\hline $\begin{array}{l}\text { Female } \\
(n=46)\end{array}$ & 29.78 & 7.57 & 29.67 & 7.38 & 24.89 & 6.76 & 21.52 & 5.53 & 21.63 & 5.97 \\
\hline Total & 29.51 & 7.16 & 29.88 & 7.23 & 25.20 & 6.40 & 21.74 & 5.20 & 23.01 & 5.87 \\
\hline
\end{tabular}

scored the highest mean for Christ United Methodist Church was compulsion $(M=30.32$, $S D=6.91)$ followed by codependence $(M=28.77, S D=6.44)$. The dysfunction that scored the lowest mean for both congregations was paranoia (CCC: $M=21.54, S D=$

\subsection{7; CUM: $M$}

$=21.89, S D=5.19)$. The dysfunction that scored the lowest mean for both genders was also paranoia (males: $M=22.00, S D=4.82$; females: $M=21.52, S D=5.53$ ).

Table 11 represents the Modeling-the-Way LPI Self scores. These scores $(M=$ $46.19, S D=6.78$ ) are considered to be high (scoring between 40 and 60) according to 
Table 11

Average Scores for Modeling-the-Way

\begin{tabular}{lcc}
\hline & \multicolumn{3}{c}{$\begin{array}{c}\text { Modeling-the-Way } \\
(n=84)\end{array}$} \\
\cline { 2 - 3 } & $\mathrm{M}$ & $\mathrm{SD}$ \\
\hline CCC & 45.86 & 6.49 \\
CUM & 46.45 & 7.06 \\
Male $(n=38)$ & 46.42 & 6.43 \\
Female $(n=46)$ & 46.00 & 7.13 \\
Total & 46.19 & 6.78 \\
\hline
\end{tabular}

Kouzes and Posner (2012a) indicating the sample had generally defined and advertised their values and beliefs.

\section{Statistical Assumptions for the Variables}

Parametric statistics are inferential statistics that make specific assumptions about the characteristics (parameters) of underlying population distributions. These assumptions must be evaluated prior to testing to see if a relationship between the dysfunctions (dependent variable) data and Modeling-the-Way (independent variable) data exist. The following assumptions were considered (Howell, 2013; Weinfurt, 1995):

1. The values for each dysfunction and Modeling-the-Way for the lay leaders are normally distributed.

2. All self-observations (numerical representations provided by the selfadministered surveys) for each dysfunction and Modeling-the-Way for church lay leaders are independent of each other.

3. The variances of DSLP scores are the same across all Modeling-the-Way scores, and thus homogeneity of variance can be assumed. 
In evaluating the normality assumption a test for skewness was conducted (see Table 12) and histograms were constructed for inspection (see Appendix G). All variables appear to be normally distributed on the histograms with normality being supported by the tests for skewness in that all data falls within -1 and +1 . As indicated in Table 12 and the histograms, paranoia produced a skewness of .416 with the histogram appearing to be normally distributed, passive-aggressive produced a skewness of .319 with the histogram appearing to be normally distributed, codependence produced a skewness of .390 , compulsion produced a skewness of .339 , and narcissism produced a skewness of .353 with the respective histograms appearing normally distributed though slightly positively skewed. Modeling-the-Way produced a skewness of -.569 with the histogram appearing to be normally distributed though slightly negatively skewed.

The second assumption states that all self-observations (numerical representations provided by the self-administered surveys) for each dysfunction and Modeling-the-Way for church lay leaders are independent of each other (Weinfurt, 1995). Weinfurt's specific concern is that interaction between subjects may affect the scores, thus negatively impacting the independence of each inquiry. Further, Weinfurt posits that "the tenability of the assumption is suspect by looking at the research methods" (p. 257). The author asks specific questions to test for this independence:

1. Were the study conditions administered on an individual or group basis?

2. Could other subjects have affected a person's responses at the time the dependent variables were measured?

The answer to the first question is that the conditions were such that the surveys were administered on an individual basis. Personal emails were used to deliver the 
Table 12

Variables of the Study with Ranges and Skewness

\begin{tabular}{lcccccc}
\hline & $N$ & Mean & $S D$ & Minimum & Maximum & Skewness \\
\hline Codependence & 84 & 29.51 & 7.16 & 12.00 & 48.00 & .390 \\
Compulsion & 84 & 29.88 & 7.23 & 13.00 & 53.00 & .339 \\
Narcissism & 84 & 25.20 & 6.40 & 12.00 & 46.00 & .353 \\
Paranoia & 84 & 21.74 & 5.20 & 13.00 & 36.00 & .416 \\
Passive-Aggression & 84 & 23.01 & 5.87 & 13.00 & 37.00 & .319 \\
Modeling-the-Way & 84 & 46.19 & 6.78 & 23.00 & 58.00 & -.569 \\
\hline
\end{tabular}

survey. The congregational representatives requested that participants take the survey in such a way that their answers were an honest reflection of themselves independent of outside influences. In that context confidentiality of the individual scores and responses were of high priority. The answer to the second question is that the only way subjects could affect each other's responses is if they collaborated on the answers or took the survey together as part of a group. The congregational representatives requested that participants complete the survey in private in hope of minimizing any outside influences.

The third assumption states that the variances of DSLP scores are the same across all Modeling-the-Way scores, and thus the homoscedasticity of variance assumption can be accepted. This research used the Levene test to test if the populations appear to have the same variance between the congregations and between male and female participants. These assumptions that the relevant populations have the same variances were tested at the 0.05 alpha level.

In comparing the population variances of lay leader participants of Collegedale Community Church and Christ United Methodist Church, the assumption of equal population variances is not rejected at an alpha level of 0.05 for every survey construct 
except Codependence $(p=.043)$. The Levene tests for all other dysfunctions did not reach significance (see Table 13) implying homogeneity of variance for these data is supported.

In comparing the population variances of lay leader participants based on gender, the assumption of equal variances could not be rejected at an alpha level of 0.05 . compulsion recorded a significance of 0.93 , Modeling-the-Way 0.86 , passive-aggression 0.78 , narcissism 0.47 , paranoia 0.40 , and codependence 0.31 (see Table 14).

The observed significant levels for all variables when comparing gender or congregations (with the exception of codependence) suggest support for the assumption of homogeneity of variance. Howell (2013) states that if variances "are heterogeneous you use the separate variances without pooling them" (p. 219). In analyzing the data with respect to codependence, analyses will be conducted for each congregation separately thus not pooling the variances, as recommended by Howell (2013).

\section{Test of Hypotheses}

This study explored if a relationship exists between personal dysfunctions associated with church leaders and the degree to which they have discovered and authentically expressed their values and beliefs among lay leaders in two different congregations, Christ United Methodist Church and Collegedale Community Seventhday Adventist Church, both located in the same community. This research was thus guided by the question: Does a relationship exist between Modeling-the-Way, as measured by Kouzes and Posner's (2012a) LPI Self and the five personal dysfunctions as described by McIntosh and Rima's (2007) DSLP inventory among church lay leaders in 
two specific congregations? Guided by the previously mentioned research question this analysis tested the following null hypothesis:

Table 13

Homogeneity of Variance between Congregations

\begin{tabular}{lcc}
\hline & $D f$ & $P$ \\
\hline Codependence & 83 & 0.043 \\
Compulsion & 83 & 0.830 \\
Narcissism & 83 & 0.990 \\
Paranoia & 83 & 0.920 \\
Passive-aggression & 83 & 0.960 \\
Modeling-the-Way & 83 & 0.710 \\
\hline
\end{tabular}

Table 14

Homogeneity of Variance between Males and Females

\begin{tabular}{lll}
\hline & $D f$ & $P$ \\
\hline Codependence & 83 & 0.310 \\
Compulsion & 83 & 0.930 \\
Narcissism & 83 & 0.470 \\
Paranoia & 83 & 0.398 \\
Passive-aggression & 83 & 0.780 \\
Modeling-the-Way & 83 & 0.860 \\
\hline
\end{tabular}

$\mathrm{H} 1_{\mathrm{o}}$ : There is no relationship between Modeling-the-Way LPI Self scores, as measured by Kouzes and Posner's (2012a) LPI Self, and dysfunctional leadership traits (compulsion, narcissism, paranoia, codependence, and passive-aggression) scores, as measured by McIntosh and Rima's (2007) DSLP, for lay leaders in two congregations in Tennessee. 
To test $\mathrm{H} 1_{\mathrm{o}}$ an inferential statistical analysis was conducted between Modelingthe-Way LPI Self and the DSLP inventories.

\section{Inferential Statistics, Specific Hypothesis, and Regression Analysis}

Casson and Franzco (2014) state, "Correlation and regression are measures of association between variables" (p. 590). They further posit that correlation "describes the strength of the linear relationship" (p. 590) while linear regression may "provide evidence that one variable may, in fact, influence another, and to make certain predictions about outcomes given certain information" (p. 592). The objective of a correlation study "is to describe the degree of association between two or more variables" (Creswell, 2012, p. 356). He further posits that when one independent variable is being studied (Modelingthe-Way), it is appropriate to use Pearson's correlation coefficient to measure correlation.

An argument in this study posits that LPI Self scores for Modeling-the-Way (values and beliefs) should be inversely related to DSLP scores (i.e., higher Modelingthe-Way scores should be associated with lower dysfunction scores). These procedures used Pearson's $r$ correlation, $F$-tests, and independent $t$-tests. Alpha levels of .001, .01, and .05 were used to determine significance of relationships. Further analysis was conducted summarizing the regression analysis results between the Modeling-the-Way components and dysfunctions and possible alternative explanations that examined tenure as a lay leader or tenure as a church member.

Table 15 supports a possibility that the higher a participant scores on the Modeling-the-Way LPI Self, the lower the levels of codependence in Christ United Methodist Church and the lower a participant scores in narcissism, paranoia, and passive- 
aggression tendencies as measured by the DSLP. These results suggest that the hypothesis $\mathrm{H} 1_{\mathrm{o}}$ can be rejected, that a statistical relationship may exist between the independent and dependent variables with the exception of codependence in Collegedale Table 15

Pearson's Correlation Between Modeling-the-Way and Each Dysfunction

\begin{tabular}{lcccccc}
\hline & Compulsion & $\begin{array}{c}\text { Codependence } \\
\text { CCC }\end{array}$ & $\begin{array}{c}\text { Codependence } \\
\text { CUM }\end{array}$ & Narcissism & Paranoia & $\begin{array}{c}\text { Passive- } \\
\text { aggression }\end{array}$ \\
\hline $\begin{array}{l}\text { Modeling-the- } \\
\text { Way LPI- }\end{array}$ & & & & & & \\
$\begin{array}{l}\text { Self Score } \\
p \text {-values }\end{array}$ & $-.474^{* *}$ & -.419 & $-.588^{* *}$ & $-.495^{* *}$ & $-.499^{* *}$ & $-.604^{* *}$ \\
& .003 & .406 & .007 & .001 & .001 & .000 \\
\hline
\end{tabular}

**Correlation is significant at the 0.01 level (2-tailed) or lower

Community Church. All dysfunctions studied were negatively correlated with Modelingthe-Way implying an inverse relationship between Modeling-the-Way LPI Self scores and each dysfunction as measured by the DSLP.

This research was guided by the following question: Is there a relationship between the dysfunctional leadership traits (codependence, compulsion, narcissism, paranoia, and passive-aggression) and Modeling-the-Way for religious lay leaders in two specific congregations? Because regression involves identifying the relationship between an independent variable (Modeling-the-Way) and a dependent variable (dysfunctions) it is appropriate to conduct a regression analysis to address the question. Five general questions can be derived from the guiding question exploring each dysfunction. Thus five separate linear regressions were conducted to test the relationship between Modeling-theWay and each of the five dysfunctions relevant to this study. 
The first sub question asks if there is a relationship between the leadership dysfunction, codependence, and Modeling-the-Way for religious lay leaders in the congregations being studied. Because homogeneity of variance could not be verified between the two congregations in the study this analysis will separate the participants by congregation.

$\mathrm{H} 1_{\mathrm{o}}$ states that there is no relationship between the dysfunctional leadership trait codependence for lay leaders in two congregations in Tennessee. The Pearson's $r$ correlation analysis (see Table 15) was statistically not significant in analyzing Collegedale Community Church $(r=-.419, p>0.05)$. The regression analysis (see Tables 16 and 17) for Collegedale Community Church showed no statistical significance ( $p>$ $0.05)$ with an $F$-value of 1.06. Though the analysis indicates a negative correlation and that $17.5 \%\left(R^{2}=.175\right)$ of the variance in codependence scores could be accounted for or "explained" by Modeling-the-Way scores among participants in Collegedale Community Church, this did not demonstrate statistical significance and thus the hypotheses that a relationship does not exist cannot be rejected.

This sub question also asks if there is a relationship between the leadership dysfunction of codependence and Modeling-the-Way for religious lay leaders at Christ United Methodist Church.

$\mathrm{H} 1_{\mathrm{o}}$ states that there is no relationship between the dysfunctional leadership trait of codependence for lay leaders at Christ United Methodist Church. The Pearson's $r$ correlation analysis (see Table 16) indicates a statistically significant negative relationship $(r=-.588, p<0.01)$ implying that the higher one scores on the DSLP 
codependence survey the lower one scores on the Modeling-the-Way LPI Self. The regression analysis (see Tables 17 and 18) shows the same statistical significance $(p<$ $0.01)$ with an $F$-value of 3.52. This analysis indicates that $34.6 \%\left(R^{2}=.346\right)$ of the variances in codependence scores in Christ United Methodist Church could be accounted Table 16

Model Summary of Modeling-the-Way Relationship to Codependence Dysfunction in Collegedale Community Church

\begin{tabular}{|c|c|c|c|c|c|c|}
\hline Model & $S S$ & $D f$ & $M S$ & $F$ & $p$ & $R^{2}$ \\
\hline Regression & 400.321 & 6 & 66.720 & 1.063 & .406 & 0.1753 \\
\hline Residual & 1882.868 & 30 & 62.762 & & & \\
\hline Total & 2283.189 & 36 & & & & \\
\hline
\end{tabular}

$p>0.05$

Table 17

Summary of Regression Analysis for the Components of Modeling-the-Way and Codependence Dysfunction in Collegedale Community Church

\begin{tabular}{|c|c|c|c|c|c|}
\hline & $b$ & $S E$ & $B$ & $t$ & $p$ \\
\hline (Constant) & 43.588 & 16.258 & & & \\
\hline $\begin{array}{l}\text { 1. I set personal examples of what I expect from } \\
\text { others. }\end{array}$ & 1.263 & .902 & .285 & 1.399 & .172 \\
\hline $\begin{array}{l}\text { 2. I spend time and energy making certain that } \\
\text { the people I work with adhere to the principles }\end{array}$ & & & & & \\
\hline $\begin{array}{l}\text { and standards we have agreed on. } \\
\text { 3. I follow through on the promises and }\end{array}$ & -.722 & .716 & -.222 & -1.009 & .321 \\
\hline commitments that I make. & -1.381 & 1.879 & -.144 & -.735 & .468 \\
\hline $\begin{array}{l}\text { 4. I ask for feedback on how my actions affect } \\
\text { other people's performance. }\end{array}$ & -.669 & .583 & -.214 & -1.147 & .260 \\
\hline $\begin{array}{l}\text { 5. I build consensus around a common set of } \\
\text { values for running our organization. }\end{array}$ & .020 & 1.081 & .004 & .018 & .986 \\
\hline 6. I am clear about my philosophy of leadership. & -.267 & 1.306 & -.044 & -.204 & .839 \\
\hline
\end{tabular}

$\mathrm{F}_{(6,36)}=1.06, p>0.05, R^{2}=0.175$ 
Table 18

Model Summary of Modeling-the-Way Relationship to Codependence Dysfunction at Christ United Methodist Church

\begin{tabular}{lrrrlll}
\hline Model & \multicolumn{1}{c}{$S S$} & $D f$ & \multicolumn{1}{c}{$M S$} & \multicolumn{1}{c}{$F$} & \multicolumn{1}{c}{$p$} & $R^{2}$ \\
\hline Regression & 659.429 & 6 & 109.905 & 3.520 & 0.007 & 0.3455 \\
Residual & 1248.997 & 40 & 31.225 & & & \\
Total & 1908.426 & 46 & & & & \\
\hline
\end{tabular}

$\mathrm{p}<0.01$

for or "explained" by Modeling-the-Way scores. The hypothesis is thus rejected for codependence in Christ United Methodist Church in that the data suggest an inverse relationship exists between Modeling-the-Way and codependence.

The model summary and regression analysis, represented in Tables 19 and 20, indicates a statistically significant linear relationship between Modeling-the-Way and the DSLP measuring the degree of codependence in Christ United Methodist Church $\left(F_{(6,46)}=\right.$ $3.52, R^{2}=0.34 .6$ ) with $34.6 \%$ of the variance being explained by Modeling-the-Way. The summary of regression analysis (Table 20) discovered two components of Modeling-theWay that impacted the model more than the other component with statistical significance. The Modeling-the-Way component that most impacted codependent tendencies in Christ United Methodist Church stated, "I follow through on the promises and commitments that I make" $(B=-.400, p=.010)$. The second statistically significant component that affected the model stated, "I am clear about my philosophy of leadership" $(B=-.336, p<$ $0.05)$.

Appendix I revealed a statistically significant correlation between Modeling-theWay and the DSLP, measuring codependence among female participants (-.340) but not for males. 


\section{Compulsion}

The second sub question asks if there is a relationship between the leadership dysfunction compulsion and Modeling-the-Way for religious lay leaders in the congregations being studied.

$\mathrm{H} 1_{\mathrm{o}}$ states that there is no relationship between the dysfunctional leadership trait, compulsion, for lay leaders in two congregations in Tennessee. This study measured a

Table 19

Summary of Regression Analysis for the Components of Modeling-the-Way and Codependence Dysfunction in Christ United Methodist Church

\begin{tabular}{|c|c|c|c|c|c|}
\hline & $b$ & $S E$ & $B$ & $t$ & $p$ \\
\hline (Constant) & 65.885 & 10.283 & & & \\
\hline $\begin{array}{l}\text { 1. I set personal examples of what I expect } \\
\text { from others. }\end{array}$ & .184 & .718 & .036 & .257 & .799 \\
\hline $\begin{array}{l}\text { 2. I spend time and energy making certain that } \\
\text { the people I work with adhere to the principles }\end{array}$ & & & & & \\
\hline and standards we have agreed on. & -.009 & .465 & -.003 & -.018 & .985 \\
\hline $\begin{array}{l}\text { 3. I follow through on the promises and } \\
\text { commitments that I make. }\end{array}$ & -3.100 & 1.143 & -.400 & -2.712 & .010 \\
\hline $\begin{array}{l}\text { 4. I ask for feedback on how my actions affect } \\
\text { other people's performance. }\end{array}$ & .250 & .398 & .092 & .626 & .535 \\
\hline $\begin{array}{l}\text { 5. I build consensus around a common set of } \\
\text { values for running our organization. }\end{array}$ & -.237 & .505 & -.082 & -.469 & .641 \\
\hline $\begin{array}{l}\text { 6. I am clear about my philosophy of } \\
\text { leadership. }\end{array}$ & -1.165 & .480 & -.336 & -2.430 & .020 \\
\hline
\end{tabular}

$F_{(6,46)}=3.52, \quad p<0.01, R^{2}=0.346$ 
Table 20

Model Summary of Modeling-the-Way Relationship to Compulsion Dysfunction

\begin{tabular}{lrrrrrr}
\hline Model & \multicolumn{1}{c}{$S S$} & \multicolumn{1}{c}{ Df } & \multicolumn{1}{c}{$M S$} & \multicolumn{1}{c}{$F$} & \multicolumn{1}{c}{$p$} & \multicolumn{1}{c}{$R^{2}$} \\
\hline Regression & 975.44 & 6 & 162.57 & 3.73 & .003 & 0.225 \\
Residual & 3357.37 & 77 & 43.60 & & & \\
Total & 4332.81 & 83 & & & & \\
\hline
\end{tabular}

$p<0.01$

moderate degree of compulsive dysfunction in the sample indicating that it is likely some compulsive tendencies exist $(M=29.88)$. The Pearson's $r$ correlation analysis (see Table 20) indicates a statistically significant negative relationship $(r=-.474, p<0.01)$

implying the higher a participant scores on the DSLP compulsive survey, the lower a participant scores on the Modeling-the-Way LPI Self.

The model summary and regression analysis, represented in Tables 21 and 22, indicates a statistically significant linear relationship between Modeling-the-Way and the DSLP measuring the degree of dysfunction $\left(F_{(6,83)}=3.73, R^{2}=0.225\right)$ with $22.5 \%$ of the variance being explained by Modeling-the-Way. The summary of regression analysis (see Table 22) discovered three components of Modeling-the-Way that impacted the model more than the other component with statistical significance. The Modeling-the-Way component that most impacted, inversely, compulsive tendencies stated, "I ask for feedback on how my actions affect other people's performance" $(B=-.351, p=.002)$. The other components of statistical significance, represented in Table 21, that impact the tendencies of compulsive tendencies include a positive correlation with "I spend time and energy making certain that the people I work with adhere to the principles and standards we have agreed on" ( $B=.308, p=.015)$ and a negative correlation with "I am clear about 
my philosophy of leadership" $(B=-.246, p=.028)$. The positive correlation indicates a compulsion towards adherence to principles and standards.

The mean score for compulsion for lay leaders less than one year seemed considerably lower $(M=25.78)$ than scores for the other more tenured leaders (see Appendix J). I acknowledge that this group only accounted for $11.9 \%$ of the participants (see Table 9), the lowest of all the categories; however, this may provide some evidence that the more tenured the lay leader, the more tendencies for compulsive behavior.

\section{Narcissism}

The third sub question asks if there is a relationship between the leadership dysfunction narcissism and Modeling-the-Way for religious lay leaders in the congregations being studied.

\section{Table 21}

Summary of Regression Analysis for the Components of Modeling-the-Way and Compulsion Dysfunction

\begin{tabular}{|c|c|c|c|c|c|}
\hline & $b$ & $S E$ & $B$ & $t$ & $P$ \\
\hline (Constant) & 42.558 & 8.572 & & & \\
\hline $\begin{array}{l}\text { 1. I set personal examples of what I expect from } \\
\text { others. }\end{array}$ & -.255 & .523 & -.053 & 7 & .628 \\
\hline $\begin{array}{l}\text { 2. I spend time and energy making certain that the } \\
\text { people I work with adhere to the principles and } \\
\text { standards we have aoreed on. }\end{array}$ & & & & & \\
\hline promises and & טנס & .982 & & & .829 \\
\hline $\begin{array}{l}\text { ow my actions affect } \\
\text { ce. }\end{array}$ & -1.022 & .316 & -.351 & -3.233 & .002 \\
\hline $\begin{array}{l}\text { 5. I build cons } \\
\text { values for run }\end{array}$ & -.028 & .4 & & & .953 \\
\hline 6. I am clear about my philosophy of leadership. & -1.087 & .485 & -.246 & -2.241 & .028 \\
\hline
\end{tabular}

$F_{(6,83)}=3.73, p<0.01, R^{2}=0.225$ 
Table 22

Model Summary of Modeling-the-Way Relationship to Narcissism Dysfunction

\begin{tabular}{lrrrrrl}
\hline Model & \multicolumn{1}{c}{$S S$} & \multicolumn{1}{c}{ Sf } & \multicolumn{1}{c}{$M S$} & \multicolumn{1}{c}{$F$} & $p$ & $R^{2}$ \\
\hline Regression & 834.003 & 6 & 139.000 & 4.172 & 0.001 & 0.2453 \\
Residual & 2565.557 & 77 & 33.319 & & & \\
Total & 3399.560 & 83 & & & & \\
\hline
\end{tabular}

$p=.001$

$\mathrm{H} 1_{\mathrm{o}}$ states that there is no relationship between the dysfunctional leadership trait narcissism for lay leaders in two congregations in Tennessee. The Pearson's $r$ correlation analysis (see Table 21) indicates a statistically significant negative relationship $(r=-.495$, $p=.001)$ implying the higher one scores on the DSLP narcissism survey the lower one scores on the Modeling-the-Way LPI Self. The regression analysis (see Tables 22 and 23) shows the same statistical significance $(p=.001)$ with an $F$-value of 4.17 . This analysis indicates that $24.5 \%\left(R^{2}=.245\right)$ of the variances in narcissism should be accounted for or "explained" by Modeling-the-Way scores. This portion hypothesis is thus rejected for narcissism in that the data suggest an inverse relationship exists between Modeling-theWay and narcissism.

The model summary and regression analysis for narcissism, represented in Tables 22 and 23, indicates a statistically significant linear relationship between Modeling-theWay and the DSLP, measuring the degree of dysfunction $\left(F_{(6,83)}=4.17, R^{2}=0.245\right)$ with $24.5 \%$ of the variance being explained by Modeling-the-Way. The summary of regression analysis (see Table 23) discovered two components of Modeling-the-Way that impacted the model more than the other component with statistical significance. 
The first component that most impacted the model was a negative correlation that states, "I follow through on the promises and commitments that I make" $(B=-.351, p=$ .002). The second component of statistical significance measuring a negative correlation between Modeling-the-Way and narcissism states, "I ask for feedback on how my actions affect other people's performance" $(B=-.257, p=.019)$. This component implies that the less one asks for feedback on actions affecting other's performance, the greater the degree of narcissism in the individual.

Appendix $\mathbf{J}$ reveals higher narcissistic mean scores for those that are church members between 15 and 20 years. Conversely for those leaders that have been in their lay leader position for less than a year they scored noticeable lower. In addition Appendix I supports a statistically significant correlation between Modeling-the-Way and narcissism for females (-.397) but not for males.

Table 23

Summary of Regression Analysis for the Components of Modeling-the-Way and Narcissism Dysfunction

\begin{tabular}{|c|c|c|c|c|c|}
\hline & $b$ & $S E$ & $B$ & $t$ & $p$ \\
\hline (Constant) & 53.333 & 7.493 & & & \\
\hline $\begin{array}{l}\text { 1. I set personal examples of what I expect from } \\
\text { others. }\end{array}$ & .392 & .457 & .093 & .858 & .394 \\
\hline $\begin{array}{l}\text { 2. I spend time and energy making certain that the } \\
\text { people I work with adhere to the principles and } \\
\text { standards we have agreed on. }\end{array}$ & .475 & .333 & .174 & 1.426 & .158 \\
\hline $\begin{array}{l}\text { 3. I follow through on the promises and } \\
\text { commitments that I make. }\end{array}$ & -2.718 & .858 & -.351 & -3.166 & .002 \\
\hline $\begin{array}{l}\text { 4. I ask for feedback on how my actions affect } \\
\text { other people's performance. }\end{array}$ & -.663 & .276 & -.257 & -2.399 & .019 \\
\hline $\begin{array}{l}\text { 5. I build consensus around a common set of } \\
\text { values for running our organization. }\end{array}$ & -.280 & .411 & -.085 & -.683 & .497 \\
\hline 6. I am clear about my philosophy of leadership. & -.342 & .424 & -.087 & -.805 & .423 \\
\hline
\end{tabular}

$\mathrm{F}_{(6,83)}=4.17, \mathrm{p}=.001, \mathrm{R}^{2}=0.245$ 


\section{Paranoia}

The fourth sub question asks if there is a relationship between the leadership dysfunction paranoia and Modeling-the-Way for religious lay leaders in the congregations being studied.

$\mathrm{H} 1_{\mathrm{o}}$ states that there is no relationship between the dysfunctional leadership trait paranoia for lay leaders in two congregations in Tennessee. The Pearson's $r$ correlation analysis (see Table 24) indicates a statistically significant negative relationship $(r=-.499$, $p=.001$ ) implying the higher one scores on the DSLP paranoia survey the lower one scores on the Modeling-the-Way LPI Self. The regression analysis (see Tables 20 and 21) shows a same statistical significance $(p=.001)$ with an $F$-value of 4.26 . This analysis indicates that $24.9 \%\left(R^{2}=.249\right)$ of the variances in paranoia scores could be accounted for or "explained" by Modeling-the-Way scores. The hypothesis is thus rejected for paranoia in that the data suggest an inverse relationship between Modeling-the-Way and paranoia.

Table 24

Model Summary of Modeling-the-Way Relationship to Paranoia Dysfunction

\begin{tabular}{lrrllll}
\hline Model & \multicolumn{1}{c}{$S S$} & Df & \multicolumn{1}{c}{$M S$} & $F$ & $p$ & $R^{2}$ \\
\hline Regression & 559.176 & 6 & 93.196 & 4.264 & .001 & 0.2494 \\
Residual & 1683.062 & 77 & 21.858 & & & \\
Total & 2242.238 & 83 & & & & \\
\hline$p=.001$ & & & & & &
\end{tabular}

A model summary and regression analysis, represented in Tables 24 and 25, indicate a statistically significant linear relationship between Modeling-the-Way and the DSLP measuring the degree of paranoia $\left(F_{(6,83)}=4.26, R^{2}=0.249\right)$ with $24.9 \%$ of the 
variance being explained by Modeling-the-Way. The Modeling-the-Way component that most impacted paranoia stated, "I ask for feedback on how my actions affect other people's performance" $(B=-.326, p=.003)$. The other statistically significant component to Modeling-the-Way that was positively correlated states, "I spend time and energy making certain that the people I work with adhere to the principles and standards we have agreed on." This component has a positive correlation $(B=.298, \mathrm{p}=.017)$ indicating that articulating one's values and beliefs enhances paranoia tendencies.

Table 25

Summary of Regression Analysis for the Components of Modeling-the-Way and Paranoia Dysfunction

\begin{tabular}{|c|c|c|c|c|c|}
\hline & $b$ & $S E$ & $B$ & $t$ & $p$ \\
\hline (Constant) & 37.656 & 6.069 & & & \\
\hline $\begin{array}{l}\text { 1. I set personal examples of what I expect from } \\
\text { others. }\end{array}$ & .285 & .370 & .083 & .769 & .444 \\
\hline $\begin{array}{l}\text { 2. I spend time and energy making certain that the } \\
\text { people I work with adhere to the principles and } \\
\text { standards we have agreed on. }\end{array}$ & .660 & .270 & .298 & 2.445 & .017 \\
\hline $\begin{array}{l}\text { 3. I follow through on the promises and } \\
\text { commitments that I make. }\end{array}$ & -1.307 & .695 & -.208 & -1.879 & .064 \\
\hline $\begin{array}{l}\text { 4. I ask for feedback on how my actions affect } \\
\text { other people's performance. }\end{array}$ & -.681 & .224 & -.326 & -3.045 & .003 \\
\hline $\begin{array}{l}\text { 5. I build consensus around a common set of } \\
\text { values for running our organization. }\end{array}$ & -.378 & .333 & -.141 & -1.137 & .259 \\
\hline 6. I am clear about my philosophy of leadership. & -.423 & .343 & -.133 & -1.232 & .222 \\
\hline
\end{tabular}

$F_{(6,83)}=4.26, p=.001, R^{2}=0.249$

\section{Passive-aggression}

The fifth sub question asks if there is a relationship between the leadership dysfunction passive-aggression and Modeling-the-Way for religious lay leaders in the congregations being studied. 
$\mathrm{H} 1_{\mathrm{o}}$ states that there is no relationship between the dysfunctional leadership trait, passive-aggression, for lay leaders in two congregations in Tennessee. The Pearson's $r$ correlation analysis (see Table 26) indicates a statistically significant negative relationship $(r=-.604, p<0.001)$ implying that the higher a participant scores on the DSLP passive-aggression survey, the lower a participant scores on the Modeling-theWay LPI Self. The regression analysis (see Tables 26 and 27) shows the same statistical significance $(p<.001)$ with an $F$ value of 7.39 . This analysis indicates that $36.5 \%\left(R^{2}=\right.$ $.365)$ of the variance in passive-aggression scores could be accounted for or "explained" by Modeling-the-Way scores. The hypothesis is thus rejected for passive-aggression in that the data suggest an inverse relationship exists between Modeling-the-Way and passive-aggression.

In addition a model summary and regression analysis, represented in Table 26 and Table 27, indicates a statistically significant linear relationship between Modeling-theWay and the DSLP measuring the degree of dysfunction $\left(F_{(6,83)}=7.39, R^{2}=0.365\right)$ with

Table 26

Model Summary of Modeling-the-Way Relationship to Passive-aggression Dysfunction

\begin{tabular}{lcrrrrr}
\hline Model & $S S$ & $d f$ & \multicolumn{1}{c}{$M S$} & $F$ & $p$ & $R^{2}$ \\
\hline Regression & 1045.729 & 6 & 174.288 & 7.385 & 0.000 & 0.3653 \\
Residual & 1817.259 & 77 & 23.601 & & & \\
Total & 2862.988 & 83 & & & & \\
\hline
\end{tabular}

$p<0.001$ 
Table 27

Summary of Regression Analysis for the Components of Modeling-the-Way and Passiveaggression Dysfunction

\begin{tabular}{|c|c|c|c|c|c|}
\hline & $b$ & $S E$ & $B$ & $t$ & $p$ \\
\hline (Constant) & 50.006 & 6.306 & & & \\
\hline $\begin{array}{l}\text { 1. I set personal examples of what I expect from } \\
\text { others. }\end{array}$ & .271 & .385 & .070 & .705 & .483 \\
\hline $\begin{array}{l}\text { 2. I spend time and energy making certain that the } \\
\text { people I work with adhere to the principles and } \\
\text { standards we have agreed on. }\end{array}$ & .539 & .281 & .215 & 1.923 & .058 \\
\hline $\begin{array}{l}\text { 3. I follow through on the promises and } \\
\text { commitments that I make. }\end{array}$ & -1.902 & .722 & -.268 & -2.633 & .010 \\
\hline $\begin{array}{l}\text { 4. I ask for feedback on how my actions affect } \\
\text { other people's performance. }\end{array}$ & -.831 & .232 & -.351 & -3.573 & .001 \\
\hline $\begin{array}{l}\text { 5. I build consensus around a common set of } \\
\text { values for running our organization. }\end{array}$ & -.367 & .346 & -.121 & -1.061 & .292 \\
\hline 6. I am clear about my philosophy of leadership. & -.893 & .357 & -.249 & -2.501 & .014 \\
\hline
\end{tabular}

$F_{(6,83)}=7.39, p<.001, R^{2}=0.365$

$36.5 \%$ of the variance being explained by Modeling-the-Way. The summary of regression analysis discovered three components of Modeling-the-Way that impacted the model more than the other component with statistical significance (see Table 27). The Modeling-the-Way component that most impacted passive aggressive tendencies stated, "I ask for feedback on how my actions affect other people's performance $(B=-.351, p=$ .001). The other two components with statistical significance included first, "I follow through on the promises and commitments that I make" $(B=-.268, p=.010)$ and, "I am clear about my philosophy of leadership" $(B=-.249, p=.014)$.

Appendix $\mathrm{J}$ reveals the mean of males when measuring passive-aggressive $(M=$ 24.68) was noticeably higher (over 3 points) than females $(M=21.63)$ when compared to the means between genders of the other dysfunctions (none were more than a point different). In addition Appendix I revealed a statistically significant correlation between 
Modeling-the-Way and the DSLP measuring passive-aggression among female participants (-.500). Males did not satisfy to statistical significance such a correlation. Appendix J reports Passive-aggressive tendencies measured noticeably higher among more senior members of the church (members between 10 and 20 years of membership). Given that this accounts for 35 of the 84 participants (see Table 7) and it is this group that would have been a lay leader longer than 5 years (31 participants, see Table 9).

\section{Summary of Regression Analysis for Components}

To further analyze if a relationship exists between Modeling-the-Way and the measured dysfunctions, Table 28 presents the standard error and corresponding beta coefficients as they relate to each principle component of Modeling-the-Way and each dysfunction. Creswell (2012) describes beta weights as follows: "The coefficient of a beta weight identifies the strength of the relationship of a predictor variable of the outcomes and enables a researcher to compare the strength of one predictor variable with the strength of other predictors" (p. 351).

Howell (2013) describes the standard error as "the most common measure of the error of prediction" (p. 267). The closer the beta weight is to -1 or +1 the stronger the 
Table 28

Summary of Regression Analysis Standard Error and Beta Coefficients for Modeling-the-Way Components and Dysfunctions

\begin{tabular}{|c|c|c|c|c|c|c|c|c|c|c|c|c|}
\hline & \multicolumn{2}{|c|}{ Compulsion } & \multicolumn{2}{|c|}{ Narcissism } & \multicolumn{2}{|c|}{ Paranoia } & \multicolumn{2}{|c|}{$\begin{array}{l}\text { Codependence } \\
\text { CCC }\end{array}$} & \multicolumn{2}{|c|}{$\begin{array}{l}\text { Codependence } \\
\text { CUM }\end{array}$} & \multicolumn{2}{|c|}{ Passive-aggression } \\
\hline & $\mathrm{SE}$ & B & $\mathrm{SE}$ & $\mathrm{B}$ & SE & B & $\mathrm{SE}$ & $\mathrm{B}$ & $\mathrm{SE}$ & $\mathrm{B}$ & SE & $\mathrm{B}$ \\
\hline $\begin{array}{l}\text { 1. I set personal examples } \\
\text { of what I expect from } \\
\text { others. } \\
\text { 2. I spend time and energy } \\
\text { making certain that the } \\
\text { people I work with adhere } \\
\text { to the principles and }\end{array}$ & 0.523 & -.053 & 0.457 & 0.093 & 0.370 & 0.083 & 0.902 & 0.285 & 0.718 & 0.036 & 0.39 & 0.070 \\
\hline $\begin{array}{l}\text { on. } \\
\text { 3. I follow through on the } \\
\text { promises and }\end{array}$ & 0.381 & $.308 * *$ & 0.333 & 0.174 & 0.270 & $0.298 * *$ & 0.716 & -.222 & 0.465 & -.003 & 0.28 & 0.215 \\
\hline $\begin{array}{l}\text { commitments that I make. } \\
4 . \text { I ask for feedback on } \\
\text { how my actions affect } \\
\text { other people's } \\
\text { performance. }\end{array}$ & 0.982 & -.024 & 0.858 & $-.351 * * *$ & 0.695 & -.208 & 1.879 & -.144 & 1.143 & $-.400 * * *$ & 0.72 & $-.268 * * *$ \\
\hline $\begin{array}{l}\text { performance. } \\
5 \text {. I build consensus } \\
\text { around a common set of } \\
\text { values for running our }\end{array}$ & 0.316 & $-.351 * * *$ & 0.276 & $-.257 * *$ & 0.224 & $-.320+\cdots$ & 0.583 & -.214 & 0.398 & 0.092 & 0.23 & $-.351+64$ \\
\hline $\begin{array}{l}\text { organization. } \\
6 \text {. I am clear about my }\end{array}$ & 0.470 & -.007 & 0.411 & -.085 & 0.333 & -.141 & 1.081 & -.004 & 0.505 & -.082 & 0.42 & -.121 \\
\hline philosophy of leadership. & 0.485 & $-.246^{*}$ & 0.424 & -0.087 & 0.343 & -.133 & 1.306 & -.044 & 0.48 & $-.336^{* *}$ & 0.36 & $-.249 * *$ \\
\hline
\end{tabular}

$*_{p}<.05 ; * * p<.02 ; * * * p<.01$ 
relationship. The lower the standard error the more precise is the beta weight. Table 28 shows the relative higher statistically significant beta coefficient ranging between -.300 and -.400 with the relative lower statistically significant beta coefficients ranging between -.200 and -.299 . Standard error ranged from 1.143 at the relative high to .224 at the relative low among the statistically significant data. It is noted that Component 4 , which states, "I ask for feedback on how my actions affect other people's performance," with the exception of Codependence, had negative beta coefficients that were statistically significant in all dysfunctions. In addition, the first component "I set personal examples of what I expect from others" and the fifth component "I build consensus around a common set of values for running an organization" did not reach statistical significance in any dysfunction. It is further noted that all beta coefficients that are statistically significant were negatively correlated except those pertaining to the second component "I spend time and energy making certain that the people I work with adhere to the principles and standards we have agreed on" of which showed a positive correlation.

\section{Alternative Explanations}

The study considered that alternative explanations could account for the results. For example, experience as a lay leader could improve Modeling-the-Way quite apart from any discovery or articulation of personal values. Thus, Time-as-a-Lay-Leader might be confounded with awareness of and ability to articulate personal values. To test this possibility, measures on the core Modeling-the-Way variables were evaluated as a function of tenure as a lay leader, using MANOVA. No significant differences on any of the variables were obtained.

It was also thought that perhaps if Time-as-a-Church-Member were statistically 
controlled, the effect of Lay Leader Tenure on measures of Modeling-the-Way would achieve significance. Using ANCOVA, this possibility was also tested with essentially identical outcomes (see Figures 2 and 3 for illustrative results). These figures reflect Modeling-the-Way scores between 7 and 9 for all participants independent of tenure as a leader or member.

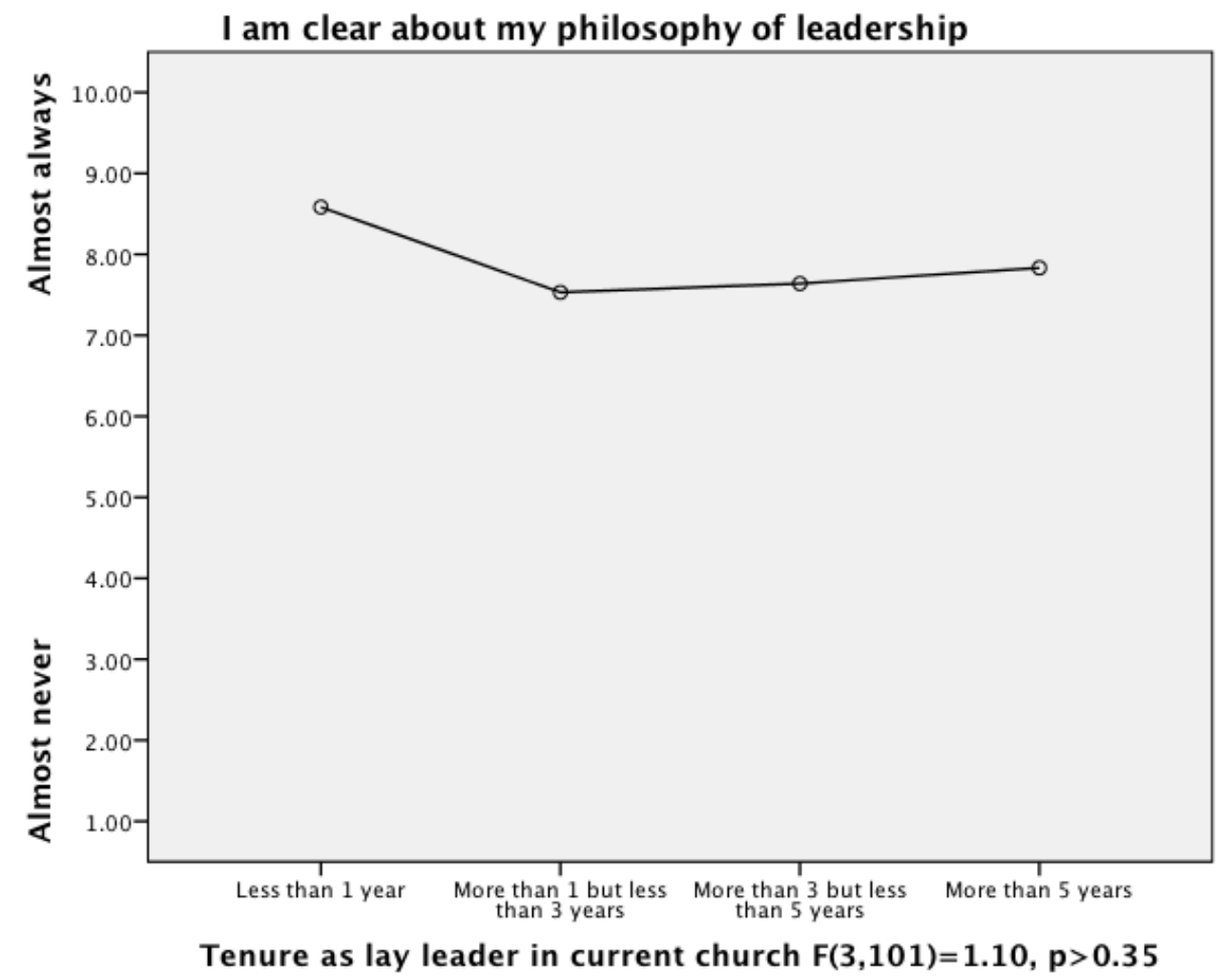

Figure 2. Modeling-the-Way versus Tenure as a Lay Leader. 


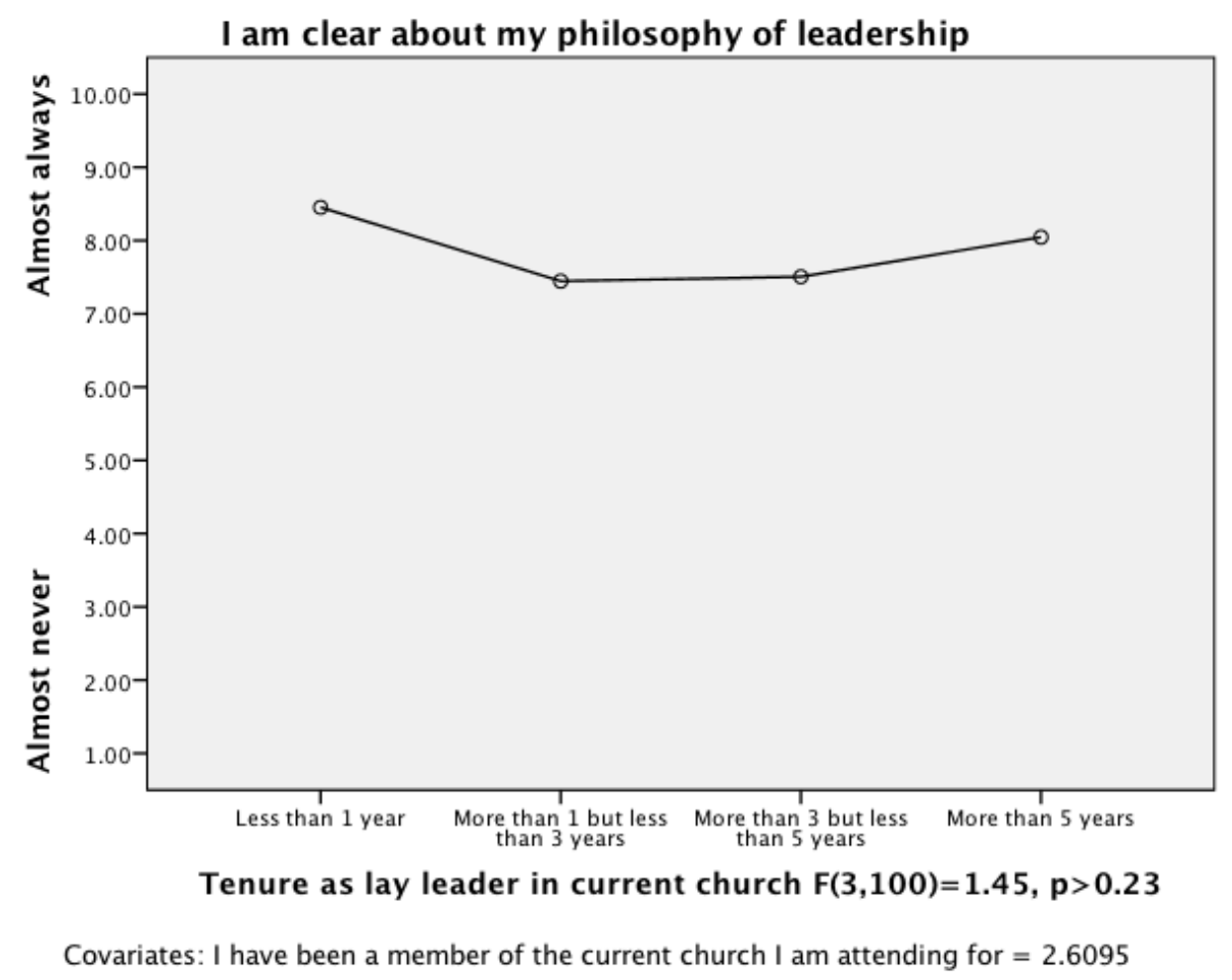

Figure 3. Modeling-the-Way versus Tenure as a Church Member

\section{Conclusion and Findings}

Descriptive statistics describe the sample as $45 \%$ male and $55 \%$ female with $44 \%$ from Collegedale Community Church and 56\% from Christ United Methodist Church. Thirty-seven percent of the sample had been lay leaders more than five years followed by $29 \%$ being lay leaaders more than one but less than three years. Thirty-one percent of the sample had been members of the church for more than five but less than 10 years followed by $26 \%$ of the sample being members for more than 10 but less than 15 years.

The statistical assumptions among variables indicated the values of each measured dysfunction and Modeling-the-Way LPI Self appear normally distributed and evidence suggests that each participant contributions were made independently. 
Homongeniety of variance was supported between congregations and between gender among the variables with the exception of codependence and Modeling-the-Way and the two congregations studied. Hence further correlated work separated the two congregations when analyzing the relationship between codependence and Modeling-theWay.

Correlation and regression analysis were used to test if their existed a relationship between Modeling-the-Way and the DSLP. The study concluded that the higher one scores on the Modeling-the-Way LPI Self, the lower the levels of codependence in Christ United Methodist Church and the lower one scores in narcissism, paranoia, and passive-aggression as measured by the DSLP. The results of the six regression analyses concluded, with one exception, to a very statistically significant degree $(p<0.01)$, that a relationship does exist between Kouzes and Posner's (2012a) LPI Self measuring values and beliefs and McIntosh and Rima's (2007) DSLP measuring dysfunctions. The one exception being codependence among lay leaders in Collegedale Community Church. With that exception the null hypothesis, $\mathrm{H}_{1}$, that there is no relationship between the Modeling-the-Way LPI Self scores, as measured by Kouzes and Posner's (2012a) LPI Self, and the dysfunctional leadership traits (compulsion, narcissism, paranoia, codependence, and passive-aggression) scores, as measured by McIntosh and Rima's (2007) DSLP, for lay leaders in two congregations in Tennessee is rejected. 


\section{CHAPTER 5}

\section{INTREPRETING RESULTS}

\section{Introduction}

This chapter summarizes the study and its findings and interprets and discusses those in relationship to the literature and practice. First, the research background and literature, problem statement, purpose, research question, design and procedures are reviewed. This is followed by a summary of the findings to include a description of the statistics discovered, general results, and a discussion of those results and their relationship with current literature. Finally, the chapter ends with some concluding thoughts, and recommendations for practice and for policy makers and future research.

\section{Background of the Study}

Kouzes and Posner (2012a) suggest that people want leaders that behave and make decisions based on guiding principles and beliefs. They further posit that these deeply held beliefs frame the values, standards, ethics, and ideals that drive decisions and behavior. This study has presented literature supporting the notion that leaders are more effective when they have discovered their values and authentically expressed those values to their constituents (Drucker, 1999; Francis, 2012; George \& Sims, 2007; Johnson, 2012; Kouzes \& Posner, 2012a; Rokeach, 1979; Schwartz, 2012). This study also cites literature suggesting that certain dysfunctions negatively affect a leader's decisions and behaviors making them less effective (Beattie, 1987; Bennis, 1989; Conger, 1990; 
George \& Sims, 2007; Kellerman, 2012; McIntosh \& Rima, 2007; McKlesky, 2012). This raises the question as to whether the discovery and authentic expression of values and beliefs may have an inverse relationship with the dysfunctions that may make leaders less effective. A review of the pertinent literature suggests an inverse relationship among nonprofit leaders may exist, including the church; however, no research was done among lay leadership in specific churches, which is the subject of this study (Boyd, 2007; Sarantopoulos, 2008).

Values can be a moral compass that guides effective leadership (George \& Sims, 2007; Johnson, 2012) and can be principal components to behavior, decisions, and actions (Kouzes \& Posner, 2012a; Rokeach, 1979; Schwartz, 2012). The intentional selfdiscovery of values is a principal component to defining a leader's thoughts, behaviors, and decisions, that are credible and evolve into effective leadership (George \& Sims, 2007; Johnson, 2012; Kouzes \& Posner, 2012a; Palmer, 1994).

Studies have empirically examined the discovery and articulation of values as a component to leadership effectiveness with some using Kouzes and Posner's (2012a) LPI Self Modeling-the-Way as an instrument of measurement (Bruno \& Lay, 2008; Groves \& LaRocca, 2012; Mancheno-Smoak et al., 2009; Shoemaker, 2003). Some have even extended their study into the nonprofit and even church leadership community (Anderson, 2009; Baloglu, 2012; Boeckmann \& Dickinson, 2001; Boyd, 2007; Sarantopoulos, 2008). All of these studies, to at least a moderate level of certainty, confirmed the discovery and expression of values as a component to leadership effectiveness. Boyd (2007) explored empirically if a relationship existed between the discovery and articulation of values and certain dysfunctions that may inhibit leadership 
effectiveness in the church. Boyd's study argued to a statistically significant degree that a relationship does exist between the discovery and articulation of values, represented by Modeling-the-Way, and codependence but only among clergy and only exploring the relationship of one dysfunction.

Some have suggested that recent decades have produced leadership void of values and beliefs causing a loss of credibility and degraded leadership effectiveness (George \& Sims, 2007; Gilkeson, 2007; Hughes et al., 2012; Rosenzweig, 2007; Sorkin, 2009). Some have gone so far as to describe this as a values crisis (Kellerman, 2012; Morin, 1995). Some have connected this to certain dysfunctions in leadership that can work against moral values and beliefs important to effective leadership to include leadership in the church (Clements \& Washburn, 1999; Collins, 2005; George \& Sims, 2007; C. Johnson, 2012; Judge et al., 2009; Kellerman, 2012; McIntosh \& Rima, 2007; Mead, 2008; Savage et al., 2004; Torrenzano, 2008; Wiehl, 2004). Literature has supported the premise that dysfunctional traits have contributed to the loss of leadership credibility (Judge et al., 2009; McIntosh \& Rima, 2007; Million et al., 2004) and has spanned across all sectors of society to include the church, which is the focus of this study (Baumgartner, 1990; Boyd, 2007; Collins, 2005; McIntosh \& Rima, 2007; McKlesky, 2012; Mead, 2008; Torrenzano, 2008).

McIntosh and Rima (2007) specifically studied five dysfunctions (compulsion, narcissism, paranoia, codependence, and passive-aggression), what they referred to as the "dark side" of leadership that exists among church leaders. McIntosh and Rima (2007) encouraged scholars to explore opportunities that will limit these dysfunctions among church leaders. This study thus explored the relationship between the discovery and 
articulation of values, represented by Modeling-the-Way, and five dysfunctions, represented by McIntosh and Rima's (2007) DSLP.

The two specific congregations studied were Christ United Methodist Church (CUM) and Collegedale Community Church (CCC) of a Seventh-day Adventist denomination. Descriptions of these churches can be found in Chapter 1, however these churches were selected because of similarity in size, similarities of the lead pastors, and though they exist reasonably close to each other there is no known formal, informal, or denominational association between the congregations or their leaders. Literature suggests similar values represented in effective leadership between theses denomination in that the Seventh-day Adventist pioneers in the United States came from a Methodist background (Bruinsma, 2009). Values of an effective Seventh-day Adventist and Methodist leader have included patience, humility, having a vision, respects others, and is well studied in scripture (Hucks, 2003; Pierson, 1996).

\section{Statement of the Problem}

Leaders face challenges from within themselves and from others. Dysfunctions within the leader and with their group can lessen leadership effectiveness. It appears some leaders manage these dysfunctions better than others. More needs to be understood about how these dysfunctions are best mediated and some have suggested clarification of values and beliefs can do that.

\section{Purpose}

This study explored if a relationship exists between personal dysfunctions and the degree to which they have discovered and authentically expressed their values and beliefs among lay leaders in two different congregations, Christ United Methodist Church and 
Collegedale Community Seventh-day Adventist Church, both located in the same community.

\section{Research Questions}

This research was guided by the question: Is there a relationship between leadership dysfunctions in the specific congregation and Modeling-the-Way for religious lay leaders in two specific congregations?

There were also five sub questions as follows:

1. Does a relationship exist between Modeling-the-Way, as measured by Kouzes and Posner's (2012a) LPI Self and the dysfunction of codependence as described by McIntosh and Rima's (2007) DSLP inventory among church lay leaders in two specific congregations?

2. Does a relationship exist between Modeling-the-Way, as measured by Kouzes and Posner's (2012a) LPI Self and the dysfunction of compulsion as described by McIntosh and Rima's (2007) DSLP inventory among church lay leaders in two specific congregations?

3. Does a relationship exist between Modeling-the-Way, as measured by Kouzes and Posner's (2012a) LPI Self and the dysfunction of narcissism as described by McIntosh and Rima's (2007) DSLP inventory among church lay leaders in two specific congregations?

4. Does a relationship exist between Modeling-the-Way, as measured by Kouzes and Posner's (2012a) LPI Self and the dysfunction of paranoia as described by McIntosh and Rima's (2007) DSLP inventory among church lay leaders in two specific congregations? 
5. Does a relationship exist between Modeling-the-Way, as measured by Kouzes and Posner's (2012a) LPI Self and the dysfunction of passive-aggression as described by McIntosh and Rima's (2007) DSLP inventory among church lay leaders in two specific congregations?

\section{Research Design and Procedures}

This research explored whether the discovery and authentic articulation of beliefs and values, as measured in Kouzes and Posner's (2012a) Modeling-the-Way LPI—Self (independent variable) correlated with any or all of McIntosh and Rima's (2007) five leadership dysfunctions (compulsion, narcissism, paranoia, codependence, and passiveaggression) associated with ineffective leadership (the dependent variable) as measured by the DSLP inventory among lay leaders within two specific church congregations.

This study used a quantitative research design. Data were obtained using surveys that participants completed on line. Participants were selected from Christ United Methodist Church of Chattanooga, Tennessee and Collegedale Community Seventh-day Adventist Church of Collegedale, Tennessee. All current lay leaders, and former lay leaders, three or less years removed, were solicited to participate in the survey. Demographic variables are not a construct used in this study; however, data were collected to describe the sample, including gender, tenure as a member and lay leader in the church, and denomination recognizing its possible value for further studies. Since the study sought to discover a relationship a correlation design was used that included a Pearson's $r$ correlation test and a simple linear regression analysis.

The instruments used were the LPI Self (Kouzes \& Posner, 2001) and McIntosh and Rima's (2007) DSLP. Survey Monkey was used to administer the surveys and data 
were collected over approximately a four-week period. The survey was done on-line and the questions/responses were randomly shuffled to minimize the effects of survey fatigue.

\section{Population and Sample}

This study focused on current lay leaders and previous lay leaders, in the past three years, from Christ United Methodist Church of Chattanooga, Tennessee and Collegedale Community Seventh-day Adventist Church of Collegedale, Tennessee. Lay leader, for the purposes of this study, is defined as anyone in a position to influence an organized group toward a defined goal (Hughes et al., 2012) that is not being compensated for their leadership responsibilities.

The total population of 218 current and former lay leaders in Christ United Methodist Church and Collegedale Community Seventh-day Adventist Church were invited to participate in the study. Of those invited to participate 84 accepted the invitation and answered all of the questions and thus were included in the study. Since Field (2009) recommends 10 to 15 cases of data per predictor variable and since this study has five predictor variables - suggesting a minimum of 50 to 75 participants, 84 participants is above the minimum acceptable number to represent the population. The proportional stratification sampling approach (Creswell, 2012) suggests that $61 \%$ of the sample should come from Christ United Methodist Church and 39\% of the sample should come from Collegedale Community Seventh-day Adventist Church. Of the 84 total participants the proportional participants were reasonably close to that advised by Creswell's (2012) stratification approach with 44\% coming from Collegedale Community Seventh-day Adventist Church and 56\% coming from Christ United Methodist Church. 
Once the tools were selected that were used to measure the independent variable (Modeling-the-Way) and dependent variables (DSLP), permission to use the tools were requested and granted by the publishers, Wiley Publishing and the Baker Publishing Group. Demographic questions were scripted to capture the participant's tenure as a church member and lay leader, gender, and denomination. Permission to collect data was requested and granted by the International Review Board. Congregational representatives were then hired for each congregation to work with church secretaries to identify current lay leaders and lay leaders of the past three years, forward the contact information to the statistical representative located at Andrews University, and to answer any question that potential participants may have concerning the study. The total population of 218 lay leaders was solicited to participate. The statistical representative was responsible for the following tasks:

(a) Ensuring confidentiality of the participants' responses

(b) Employing Survey Monkey to electronically distribute the Letter of Invitation, Waiver of Informed Consent, and Leadership Reflection Survey

(c) Collecting and loading the data into SPSS

(d) Generating data from SPSS as directed.

As surveys were received, they were screened to ensure only those who agreed to participate and those who completed the entire survey were included in the study and loaded into SPSS to be included in the correlations and regressions to follow. Figure 1 represents the research approach.

Prior to conducting data analysis, literature was reviewed pertaining to the reliability and construct validity of the LPI Self, developed by Kouzes and Posner 
(2012a), and the DSLP developed by McIntosh and Rima (1997). Literature was presented with a very significant degree of certainty that the LPI Self was a reliable and valid instrument (Kouzes \& Posner, 2002). Literature was also presented supporting, with a moderate degree of certainty, that the DSLP is a valid and reliable instrument when studying leaders in the church community (Boyd, 2007; Irving, 1994; Strack, 2001). In addition this research conducted its own Cronbach alpha test. Each of the dysfunctions measured in the DSLP reported a score above 0.70 while the Modeling-the-Way LPISelf scored 0.65. These scores support to an acceptable level that these instruments are reliable (Aiken, 1997; Boyd, 2007; Vogt, 1999).

Before a statistical relational evaluation was conducted, the data were analyzed for normalcy and variance homogeneity. A test for skewness determined that the data collected were normally distributed across all the variables and histograms were constructed that appeared to be normally distributed. A Leverne test supported the notion that the variances were homogeneous across gender and, with the exception of codependence, denominational populations. In testing codependence the church populations were thus separated, as recommended by Howell (2013). Evidence was also presented that all self-observations (numerical representations provided by the selfadministered surveys) for each dysfunction and Modeling-the-Way for church lay leaders are independent of each other (Weinfurt, 1995). Since the surveys were administered on an individual basis, not as a group, I am satisfied that the results of the individuals were in fact their individual reflections and not reflections of a group or other participants. 


\section{Summary of Findings}

This section starts with a general summarization of findings associated with the descriptive statistics describing the demographics studied, followed by general findings associated with the variable relationships. It concludes with a list of primary findings.

\section{Descriptive Statistics}

Of the participants $54.8 \%$ were female and $45.2 \%$ were male and $44 \%$ were from Collegedale Community Church (Adventist) and 56\% were from Christ United Methodist Church (Methodist) (See Tables 5 and 6). Tenure as church members revealed most respondents $(33 \%)$ had been members of the church for more than five but less than 10 years followed by those being members more than 10 but less than 15 years $(26.2 \%)$. The fewest number of participants is represented in the group with over 20 years $(8.3 \%)$ of church membership. The participants included current lay leaders (77.4\%) and past lay leaders of not more than three years $(19 \%)$ with $3.6 \%$ categorized as neither. Most of the

participants had been a lay leader for more than five years $(37.4 \%)$ followed by those that had been in a lay leader position for more than one but less than three years $(28.7 \%)$ (see Tables 7, 8, and 9).

\section{Variables}

The predictor variables were the five dysfunctions (codependence, compulsion, narcissism, paranoia, and passive-aggression) as measured by the McIntosh and Rima's (2007) DSLP within two specific church congregations. Scores can range between 12 and 60 with a higher score indicating a higher tendency towards the particular dysfunction. The results indicated that the participants measured moderate degree in all five dysfunctions (see Table 10) meaning that each of the five dysfunctions scored between 
20 and 40. This indicates that the participants have a likelihood of having tendencies relating to each dysfunction.

The highest score indicating the highest tendency to a particular dysfunction was measured to be codependence at Collegedale Community Church (CCC) $(M=30.46)$. Characteristics of this type of leader include covering up problems rather than facing them, taking on more work than they can do, and place group cohesion as a higher priority than the organizational mission (Beattie, 1987; Conger, 1990; McIntosh \& Rima, 2007). Codependence in CCC was followed closely by compulsion $(M=29.88)$. The compulsive leader is primarily concerned with personal status, controlling to keep order, and has a tendency to be moralistic and judgmental (Conger, 1990; Hepworth et al., 2010; McIntosh \& Rima, 2007; Toates \& Coschug-Toates, 2005). Narcissism also scored in the moderate range $(M=25.20)$. The narcissistic leader is driven to success by admiration and acclaim, is overly ambitious, and possesses an overinflated since of importance (Bennis, 1989; Brown, 1997; Franklin \& Fong, 2011; McIntosh \& Rima, 2007; McKlesky, 2012). Though not as high but still moderately measured is passiveaggressive $(M=23.01)$. The passive-aggressive leader is characterized by being stubborn, forgetful, intentionally inefficient and an inclination to procrastinate (McIntosh \& Rima, 2007; Million et al., 2004). Lastly Paranoia measured in the lower ranges of moderate ( $M$ $=21.74)$. Paranoid leaders can be suspicious, hostile, and jealous with overriding insecurities that affect their behaviors (APA, 1994; McIntosh \& Rima, 2007; Million et al., 2004; Schweitzer, 2011).

The independent variable is calculated using Kouzes and Posner's (2012a) LPI 
Self, which measures to what level one has defined and expressed values and beliefs. Scores can range between 6 and 60 with a high level defined as any score between 40 and 60 (Kouzes \& Posner, 2012b). Since all mean scores scored between 45 and 47 (see Table 11) we surmise that the Modeling-the-Way LPI Self scores to be high. This indicates that participants had a tendency towards having discovered and authentically expressed deeply held beliefs and values (Kouzes \& Posner, 2012a).

\section{Primary Findings}

This study's guiding question asked, "What is the relationship between Modelingthe-Way and the five personal dysfunctions as described by McIntosh and Rima (2007) among church lay leaders in two specific congregations?" To determine the relationship, if it existed, a Pearson correlation and regression analysis study was conducted. The primary findings are as follows:

1. The Pearson's r correlation study revealed a statistically significant inverse correlation between Modeling-the-Way LPI Self and all dysfunctions as measured by the DSLP with one exception (codependence in Collegedale Community Church): compulsion $(r=-.474)$, narcissism $(r=-.495)$, paranoia $(r=-.499)$, codependence in Christ United Methodist Church $(r=-.588)$, and passive-aggression $(r=-.604)$.

2. All correlations were negative implying the higher one scores in Modelingthe-Way the lower one will score on the DSLP (see Table 16). Stated differently, this implies that the more lay leaders can define and authentically express their values the less will be their tendencies towards these dysfunctions.

3. The five simple, linear regression analyses had predictably similar results with the same statistical significance as the Pearson's $r$ correlations. This analysis indicated 
the percent of the variances to the mean for Modeling-the-Way that can be explained by the dysfunction (denoted as $R^{2)}$ that were statistically significant, in order of influence, were: passive-aggression (36.5\%), codependence in Christ United Methodist Church (34.5\%), paranoia (24.9\%), narcissism (24.5\%), and compulsion (22.5\%). Codependence in Collegedale Community Church was not statistically significant.

4. The null hypothesis that stated that there is no relationship between the Modeling-the-Way LPI Self scores, measuring values and beliefs, and the Darkside Leadership Profile (DSLP) measuring tendencies in the five dysfunctions, with one exception, is rejected. The one exception is codependence in Collegedale Community Church.

\section{Discussion}

Dysfunctions, or, as McIntosh and Rima (2007) term as “dark” leadership, are a natural part of being human and exist in all of us. It has been argued that an important aspect to effectively leading others is to be intentional about recognizing the dysfunctions that exist in all of us and be intentional about negating their effects on our behavior (McIntosh \& Rima, 2007; Phillips, 1992).

The review of the literature that was presented supports the notion that a leader's behavior is predicated on his or her particular values (Rokeach, 1979; Schwartz, 2012). This argument is extended to a leader's credibility when Kouzes and Posner (2012a) state, "To become a credible leader, you must first comprehend fully the deeply held beliefs - the standards, values, ethics, and ideals - that drive you" (Kouzes \& Posner, 2012a, p. 45). This challenges effective leaders to discover, through introspection, selfreflection, and an inward study, their personal values (George \& Sims, 2007; Kouzes \& 
Posner, 2012a; Palmer, 1994). This personal discovery of values and beliefs coupled with authentically expressing them to our constituents have been argued to be essential to effective leadership to include the church (Anderson, 2009; Baloglu, 2012; Boechmann \& Dickinson, 2001; Boyd, 2007; Bruno \& Lay, 2008; Francis, 2012; George \& Sims, 2007; Groves \& LaRocca, 2012; Kouzes \& Posner, 2012a, Mancheno-Smoak et al., 2009; Northouse, 2004; Palmer, 1994; Sarantopoulos, 2008; Shoemaker, 2003).

The present study has attempted to examine the relationship between discovering and authentically expressing values and beliefs, represented in Kouzes and Posner's (2012a) exemplary leadership trait of Modeling-the-Way, with the five leadership dysfunctions posited by McIntosh and Rima in a church setting, among lay leaders of two different congregations. The first congregation, Collegedale Church Community Church, located in Collegedale, Tennessee, is a Seventh-day Adventist institution. The second congregation is Christ United Methodist Church located in Chattanooga, Tennessee. This section discusses the findings of these relationships.

There were five sub questions that guided this study:

1. Does a relationship exist between Modeling-the-Way, as measured by Kouzes and Posner's (2012a) LPI Self and the dysfunction of codependence as described by McIntosh and Rima's (2007) DSLP inventory among church lay leaders in two specific congregations?

2. Does a relationship exist between Modeling-the-Way, as measured by Kouzes and Posner's (2012a) LPI Self and the dysfunction of compulsion as described by McIntosh and Rima's (2007) DSLP inventory among church lay leaders in two specific congregations? 
3. Does a relationship exist between Modeling-the-Way, as measured by Kouzes and Posner's (2012a) LPI Self and the dysfunction of narcissism as described by McIntosh and Rima's (2007) DSLP inventory among church lay leaders in two specific congregations?

4. Does a relationship exist between Modeling-the-Way, as measured by Kouzes and Posner's (2012a) LPI Self and the dysfunction of paranoia as described by McIntosh and Rima's (2007) DSLP inventory among church lay leaders in two specific congregations?

5. Does a relationship exist between Modeling-the-Way, as measured by Kouzes and Posner's (2012a) LPI Self and the dysfunction of passive-aggression as described by McIntosh and Rima's (2007) DSLP inventory among church lay leaders in two specific congregations?

The remainder of this section will discuss these questions.

\section{Codependence}

The first sub question asks if a relationship exist between Modeling-the-Way, as measured by Kouzes and Posner's (2012a) LPI Self and the dysfunction of codependence as described by McIntosh and Rima's (2007) DSLP among church lay leaders in two specific congregations?

This study indicated a moderate degree of codependent dysfunction in the sample indicating that it is likely some codependent tendencies exist among the participants. The results of this study indicate that the more one has discovered and expressed values and beliefs, represented by Modeling-the-Way, the lower are the codependent tendencies, as measured by the DSLP. Literature has been presented that supports leaders that Model 
the Way as leaders whose frame of reference is on a set of values and beliefs (Johnson, 2012; Kouzes \& Posner, 2012a). However, if someone has never been intentional about discovering their values and beliefs, it stands to reason that their frame of reference is something besides a discovered set of values and beliefs. The codependent leader resists open expression, direct discussion of personal issues, or processes where a reflection on self is involved (Beattie, 1987; George \& Sims, 2007). To the codependent leader their frame of reference is their relationship with others rather than a discovered set of personal values and beliefs (Boyd, 2007; Schweitzer, 2011). Simply put, a codependent leader may struggle with authentically expressing values and beliefs because the codependent leader has resisted the self-reflection needed to discover what they believe in.

Discovering personal values and beliefs is the first step to Modeling-theWay; however, it may be that the self-discovery and reflection, which are so important to discovering personal values (George \& Sims, 2007; Johnson, 2012; Kouzes \& Posner, 2012a, Palmer, 1994), may prevent the codependent leader from Modeling-the-Way. This study has presented literature that challenges leaders to reflect on a number of questions that may inspire the self-reflection that may lead to self-discovery supported by Modeling-the-Way tendencies and through this self-discovery maybe begin to breakdown the codependent behavior that makes a leader less effective:

1. What core values (values that you would hold regardless of whether they were rewarded) do you personally bring to your work?

2. What core values would you tell your children that you hold at work and that you hope they will hold as working adults?

3. If you were to start a new organization in a different line of work, what core 
values would you build into the new organization regardless of the industry? (Johnson, 2012, pp. 334-335).

The second component identified in the regression analysis (see Table 25) recognized as statistically significant in lessening codependent behavior states, "I am clear about my philosophy of leadership" implies a self-discovery of a leadership philosophy. Without the self-discovery it is hard to have a philosophy that supports a frame of reference of values and beliefs that helps frame a leader's decisions and behaviors. Not having a clear philosophy of leadership or not having the courage often needed to follow through on promises or commitments (the first component of Modelingthe-Way with an inverse statistically significant component linking Modeling-the-Way with codependence) is consistent with being insecure toward other group members (McIntosh \& Rima, 2007). Haaken (1993) and Knudsen and Terrell (2012) describe this as the pain associated with Codependence - an overwhelming sense of responsibility to others and their needs even at the expense of following through on one's promises and commitments.

Kouzes and Posner (2012a) describe an important aspect of Modeling-the-Way involves aligning, or making compatible, values among group members. This is also contrary to codependent behavior, which seems to support other's beliefs and values without considering one's own values and beliefs (Conger, 1990; Kouzes \& Posner, 2012a).

It appears that the results of this study coupled with literature suggests that a codependent leader, if he or she is to lessen this dysfunction, should enter into a process of deep self-reflection maybe starting with an honest reflection of the three questions 
posed by Johnson (2012). This may begin to move the leader towards a set of values and beliefs that are personal, true, and maybe can be authentically expressed. This may also move the leader further away from codependent tendencies that make his/her leadership less effective.

Appendix I shows a statistically significant correlation between Modeling-theWay and the DSLP measuring codependence among female participants but not male participants. I found no literature to support there being a difference among gender for codependent tendencies. This finding may encourage others to explore if gender may affect this relationship.

I recognize that other dynamics can moderate codependent behavior given that the regression accounts for $34.6 \%$ attributed to Modeling-the-Way (see Table 24). Given that Kouzes and Posner (2012a) recognized five dynamics to effective leadership, it stands to reason that other dynamics could also limit codependence. Kouzes and Posner (2012a) suggest that to 'Inspire a Shared Vision' one must have his own intimate beliefs and be willing to act on those beliefs even at the expense of group cohesion (Buford, 2008; Kouzes \& Posner, 2012a), contrary to codependent leader who will have a tendency to sacrifice personal beliefs in favor of group consensus. "Challenging the Process" similarly has inverse characteristics to the codependent leader. Here the effective leader is open to change that is associated with intelligence and focus to solve complex problems with group cohesion as a lesser important objective (Dinh \& Lord, 2012; Judge et al., 2009).

\section{Compulsion}

The second sub question asks if a relationship exist between Modeling-the-Way, 
as measured by Kouzes and Posner's (2012a) LPI Self and the dysfunction of compulsion as described by McIntosh and Rima's (2007) DSLP among church lay leaders in two specific congregations?

A moderate degree of compulsion in the sample participants showed up in the analysis of the data indicating that it is likely some compulsive tendencies exist among the participants. These results indicate that the higher one scores in Modeling-the-Way, indicating the more one has discovered and expressed values and beliefs, the lower are the compulsive tendencies, as measured by the DSLP. Behavior that characterizes a higher Modeling-the-Way score as affirming and authentically expressing values and beliefs recognizes that followers want leaders who believe in something and can express that belief; however, this also includes allowing others to do the same, creating a connectedness important for healthy relationships (Francis, 2012; George \& Sims, 2007; Kouzes \& Posner, 2012a). In that the compulsive leader has been described as one who has a strong need to make decisions, is challenged with deep insecurities, and has controlling tendencies that can alienate team members, it makes sense to argue that the expression of values and beliefs, without considering the values and beliefs of constituents, can encourage compulsive tendencies (Conger, 1990; McIntosh \& Rima, 2007; Palmer, 1994; Toates \& Coschug-Toates, 2005). The results of the study agree with the referenced literature.

The other components of statistical significance revealed in the regression analysis (see Table 18) that impact the tendencies of compulsive tendencies include a positive correlation with "I spend time and energy making certain that the people I work with adhere to the principles and standards we have agreed on" and a negative correlation 
with "I am clear about my philosophy of leadership." The positive correlation indicates a compulsion towards adherence to principles and standards previously agreed to. Important to being compulsive about principles and standards is how they were arrived at. In this component it is clear that they were previously agreed to, implying an effort to gain feedback and agreement from constituents, an important dynamic argued in Modeling-the-Way literature (Kouzes \& Posner, 2012a). The leader is simply being compulsive about principles and standards that leader and constituent deemed good for the team, hence the positive correlation. This also implies an effort to align, or get some agreement, about principles and standards with constituents. It is reasonable to suggest that the leader made those same efforts with values and beliefs, or maybe they were included in this agreement or part of the feedback. All of which are positive tendencies supporting Modeling-the-Way (Kouzes \& Posner, 2012a). The negative correlation with being clear about philosophy of leadership may indicate compulsion about these philosophies. However this clarity may be helpful, as compulsive as it may be, if it provides framing for the constituents to operate allowing for a more secure workplace (Conger, 1990; Kouzes \& Posner, 2012a; Toates \& Coschug-Toates, 2005).

Other dynamics can moderate compulsive behavior, factoring in that $22.5 \%$ of the variance in compulsiveness is due to Modeling-the-Way behavior (see Table 17). Given that Kouzes and Posner (2012a) recognized five dynamics to effective leadership, it is possible that other dynamics to effective leadership may possibly help minimize compulsive tendencies. When leaders 'Enable Others to Act,' the leader is less concerned about control and status and more concerned about lifting up the control and status of others. In addition when a leader 'Inspires a Shared Vision,' the leader is seeking an 
overarching purpose that everyone can rally around, allowing the leader to relinquish control in favor of other people's autonomous efforts centered around this common purpose (Collins, 2005; Kouzes \& Posner, 2012a; Northouse, 2004; Turak, 2013).

In concluding this discussion on compulsion, one observation surfaced that literature in this report could not explain. The mean score for Compulsion for lay leaders less than one year seemed considerably lower $(M=25.78)$ than scores for the other more tenured leaders (see Appendix J). I acknowledge that this group only accounted for $11.9 \%$ of the participants (see Table 9), the lowest of all the categories; however, this may provide some evidence that the more years a lay leader functions in their church capacities, the more tendencies towards a compulsive behavior.

\section{Narcissism}

The third sub question asks if a relationship exist between Modeling-the-Way, as measured by Kouzes and Posner's (2012a) LPI Self and the dysfunction of narcissism as described by McIntosh and Rima's (2007) DSLP among church lay leaders in two specific congregations?

This study indicated that the participants that filled out the surveys exhibited moderate degree of narcissistic dysfunction. The results of this study indicate that the more one has discovered and expressed values and beliefs, represented by Modeling-theWay, the lower are the narcissistic tendencies, as measured by the DSLP.

Behavior that characterizes a higher Modeling-the-Way score as affirming and authentically expressing values and beliefs recognizes that followers want leaders who are secure about what their values represent and how they are expressed, are sensitive and empathetic to the constituents' values and beliefs, and focus on helping others rather than 
taking credit for self (Kouzes \& Posner, 2012a). These characterizations are contrary to the narcissistic leader which literature has characterized as someone with a poor selfimage (McIntosh \& Rima, 2007; McKlesky, 2012) countered by infusing the self with intense ambition, fantasies of accomplishment, overdependence on external admiration and acclaim, a sense of entitlement, a lack of empathy, arrogance, and/or the belief that he or she is special (APA, 2000; Bennis, 1989). Behaviors consistent with the narcissistic leader being contrary to the behaviors in Modeling-the-Way may include exaggerating ones accomplishments, taking credit for work or achievements accomplished by others, or rationalizing unacceptable behavior as acceptable (Brown, 1997; Conger, 1990).

The model summary and regression analysis (see Tables 19 and 20) indicates a statistically significant linear relationship between Modeling-the-Way and the DSLP. The summary of regression analysis (see Table 20) discovered two components of Modelingthe-Way that impacted the model more than the other component with statistical significance.

The first component that most impacted the model was a negative correlation that states, "I follow through on the promises and commitments that I make." This is consistent with the literature that describes narcissistic tendencies as a belief that one is entitled to things that others are not (does not have to follow through on promises and commitments like others), belief that the narcissist is more special than others (again, their feelings of being special and perceiving themselves as being above others), or an arrogance that implies the rules just do not apply to them (Franklin \& Fong, 2011; McIntosh \& Rima, 2007).

The second component of statistical significance measuring a negative correlation 
between Modeling-the-Way and narcissism states, "I ask for feedback on how my actions affect other people's performance." This component implies that the less one asks for feedback on actions affecting other's performance, the greater the degree of Narcissism in the individual. Given that narcissistic tendencies include exploiting others rather than helping others and a preoccupation with self rather than others, it is consistent that a narcissist would not be as interested in getting feedback to help others (APA, 2000; Brown, 1997).

The regression model account for $24.5 \%$ of the variances due to Modeling-theWay (see Table 19). Since Kouzes and Posner (2012a) recognized five dynamics to effective leadership other dynamics to effective leadership could possibly help minimize narcissistic tendencies. One dynamic includes 'Inspire a Shared Vision' of which has been described as paying attention to the goals of all constituents (Northouse, 2013) and connecting peers with purpose and vision (Fullan, 2008). Another dynamic described by Kouzes and Posner (2012a) that may inhibit narcissistic behavior is 'Enabling Others to Act.' This dynamic encourages leaders to be inclusive and have genuine concern for the wellbeing of others (Dhar \& Mishra, 2001; Judge et al., 2009), all characteristics that appear counter to narcissistic tendencies.

An important characteristic to the Modeling-the-Way leader includes genuine efforts to be inclusive and recognizing the values and beliefs in others (Kouzes \& Posner, 2012a). It seems that these genuine efforts to 'include and recognize' others is counter to the narcissistic leader. This study has presented literature that indicates narcissism makes a leader less effective and Modeling-the-Way tendencies as making a leader more effective. Given these findings it would seem that the leader who wants to lessen the 
degree of narcissism in his/her leadership, and become more effective, could make intentional efforts to include and recognize others in the workplace.

Appendix $\mathrm{J}$ reveals the noticeable higher narcissistic mean scores for those that are church members between 15 and 20 years. Conversely, those leaders that have been in their lay leader position for less than a year, their scores were noticeable lower. No literature was found supporting the premise that the longer one is in a leadership position the more one tends to narcissistic tendencies. In addition Appendix I supports a statistically significant negative correlation between Modeling-the-Way and Narcissism for females (-.397) but not for males. Again, no literature was found to support the premise that Modeling-the-Way has more impact on females than males to counter narcissistic tendencies.

\section{Paranoia}

The fourth sub question asks if a relationship exist between Modeling-the-Way, as measured by Kouzes and Posner's (2012a) LPI Self and the dysfunction of paranoia as described by McIntosh and Rima's (2007) DSLP among church lay leaders in two specific congregations?

This study indicated a moderate degree of paranoid dysfunction in the sample indicating that it is likely some paranoid tendencies exist among the participants. The results of this study indicate that the more one has discovered and expressed values and beliefs, represented by Modeling-the-Way, the lower are the paranoid tendencies, as measured by the DSLP. Literature has been presented that supports leaders that Model the Way as leaders whose frame of reference is on a set of values and beliefs that are authentically expressed (Johnson, 2012; Kouzes \& Posner, 2012a). The paranoid leader 
has been characterized as someone who is deeply concerned with being undermined and is thus suspicious of other team members, is guarded with relationships, and is reluctant to confide in others (McIntosh \& Rima, 2007; Million et al., 2004; Schweitzer, 2011) and is determined to protecting a self-concept that may be characterized as false (Veenker, 2000). This presents challenges to the paranoid leader as he or she relates to Modelingthe-Way tendencies on two levels: first, avoiding authentic expression of values and beliefs due to a reluctance to confide in others, and an overzealous effort to guard relationships; and, second, a false self-concept may indicate a false set of values and beliefs that are not authentic and are framed to align with paranoid behavior.

Both of these levels can be discussed within the context of the two statistically significant components revealed in the regression analysis (see Tables 20 and 21). The Modeling-the-Way component that most impacted paranoia inversely stated, "I ask for feedback on how my actions affect other people's performance.” Asking for feedback from constituents is supported by literature as being an important dynamic to more effective leadership, values clarification, and discovery (Kouzes \& Posner, 2012a; Palmer, 1994). Put differently, an atmosphere that solicits constituents to help in values discovery and alignment enhances leadership effectiveness by increasing honest and less guarded communication thus decreasing paranoid tendencies (APA, 1994; Buford, 2008; Drucker, 1999; Million et al., 2004; Schweitzer, 2011).

The other statistically significant component to Modeling-the-Way that was positively correlated states, "I spend time and energy making certain that the people I work with adhere to the principles and standards we have agreed on." One could imply from this component that spending time ensuring compliance to principles and standards 
was motivated out of suspicion and guarded relationships, both characteristics of paranoid tendencies (Million et al., 2004; Schweitzer, 2011). In addition, if the principles and standards were arrived at out of the leader's false self-concept that framed a false set of values and beliefs a paranoid focus on their compliance may prove to decrease leadership effectiveness. However, given that this one component of paranoia (unlike the other statistically significant components of paranoia) that is positively correlated with Modeling-the-Way (this component of Modeling-the-Way increases paranoia), one could suggest that spending time ensuring adherence to principles and standards that include honestly discovered values and beliefs, though this may contribute to paranoid tendencies, would increase the Modeling-the-Way score and possibly contribute to leadership effectiveness. Despite this positive correlation to this single component, collectively, the components suggest that the more one discovers and authentically express values and beliefs the less one displays paranoid tendencies.

I recognize that other dynamics can moderate paranoid behavior in that $29.8 \%$ of the variances are due to Modeling-the-Way (see Table 21). Given that Kouzes and Posner (2012a) recognized five dynamics to effective leadership, it stands to reason that other dynamics can limit paranoia. One exemplary leadership practice that could directly counter the negative implications of paranoia could be "Enabling Others to Act" (Kouzes \& Posner, 2012a). This practice encourages support and trust of team members, characterizes a leader as genuinely caring for the well-being of others, and the job satisfaction and development of others is a primary concern all of which literature suggests enhances leadership effectiveness while limiting paranoia tendencies (Bass, 1985; Dhar \& Mishra, 2001; Judge et al., 2009; McIntosh \& Rima, 2007). This seems 
consistent with the statistically significant component to Modeling-the-Way that was inversely correlated that states, "I ask for feedback on how my actions affect other people's performance" implying support and trust of team members enables others to act.

\section{Passive-Aggression}

The last sub question asks if a relationship exist between Modeling-the-Way, as measured by Kouzes and Posner's (2012a) LPI Self and the dysfunction of passiveaggression as described by McIntosh and Rima's (2007) DSLP among church lay leaders in two specific congregations?

This study indicated a moderate degree of passive-aggression dysfunction in the sample indicating that it is likely some passive-aggressive tendencies exist among the participants. The results of this study indicate that the more one has discovered and expressed values and beliefs, represented by Modeling-the-Way, the lower are the passive-aggressive tendencies, as measured by the DSLP. Literature has been presented that supports leaders that Model the Way as leaders whose frame of reference is on a set of values and beliefs that are authentically expressed (Johnson, 2012; Kouzes \& Posner, 2012a). The passive-aggressive leader has been characterized as someone who resists demands, has an intense fear of failure, is indecisive, prone to procrastinate, is stubborn, and forgetful (Hopwood et al., 2009; McIntosh \& Rima, 2007). Behavior that characterizes a higher Modeling-the-Way score as being decisive and more efficient and predictable in decisions and behavior (Kouzes \& Posner, 2012a) seems contrary to literature presented that characterizes passive-aggressive behavior as indecisive with tendencies to procrastinate and be unpredictable with decisions (McIntosh \& Rima, 2007) 
and thus supports the statistically significant inverse correlation reported (see Table 26 and 27).

The summary of regression analysis (see Table 27) discovered three components of Modeling-the-Way that were statistically significant in impacting the passiveaggressive DSLP score. The Modeling-the-Way component that most impacted passive aggressive tendencies inversely stated, "I ask for feedback on how my actions affect other people's performance.” Asking for feedback from constituents is supported by literature as being an important dynamic to more effective leadership, values clarification, and discovery (Kouzes \& Posner, 2012a; Palmer, 1994). Given that stubbornness and irritability when one does not get their way being associated with passive aggressive behavior may inhibit the passive aggressive leader from wanting to receive feedback (Hopwood et al., 2009; McIntosh \& Rima, 2007; Million et al., 2004). However, soliciting feedback as to how one can positively impact another's performance is supported in the literature as important to effective leadership (Buford, 2008; Drucker, 1999) and is supported in this study in lessening the degree of passive aggressive tendencies.

The other two components with statistical significance and inversely correlated included, "I follow through on the promises and commitments that I make" and, "I am clear about my philosophy of leadership." This again is consistent with the literature that describes a passive-aggressive leader as one who is forgetful and who is not clear about philosophies of leadership due to intentional inefficiencies in their leadership approach (McIntosh \& Rima, 2007; Million et al., 2004).

Appendix $\mathbf{J}$ reveals that the mean score of males when measuring passive- 
aggression $(M=24.68)$ was noticeably higher (over 3 points) than females $(M=21.63)$

when compared to the mean scores between genders of the other dysfunctions (none were more than a point difference). In addition Appendix I show a statistically significant correlation between Modeling-the-Way and the DSLP measuring passive-aggression among female participants, but not male participants. I found no literature to support there being a difference among gender for passive-aggressive tendencies. It may also be interesting to note that Appendix $\mathbf{J}$ reports passive-aggressive tendencies measured noticeably higher among more senior members of the church (members between 10 and 20 years of membership). Since this accounts for 35 of the 84 participants (see Table 7) and it is this group that would have been a lay leader longer than five years ( 31 participants, (see Table 9), it causes me to consider that the longer one is a member of a church or the longer one serves in a lay-leader position, the more they may be impacted by passive-aggressive tendencies, though no literature was found to support this claim.

As with the other dysfunctions, other dynamics can moderate passive-aggressive behavior given $36.5 \%$ of the variances is due to Modeling-the-Way (see Table 27). In that Kouzes and Posner (2012a) recognized five dynamics to effective leadership, it stands to reason that there is a possibility that flexibility to change represented in Challenge the Process and cited by Kellerman (2012), Grupa (2011), or Fallan (2008) should be intentionally considered when trying to limit passive-aggressive tendencies. Enabling Others to Act is also argued as a strategy to address change and a need for flexibility (Judge et al., 2009). Yet these attributes are not consistent with passive-aggressive tendencies and thus could be argued, along with Modeling-the-Way, as intentional strategies for limiting the effects of passive aggressive behaviors. 


\section{Concluding Discussion}

Since the simple regression analysis measures the percent of the variance of the DSLP score that can be explained by the Modeling-the-Way LPI Self score of a particular dysfunction that was statistically significant for every dysfunction except one (Codependence in Collegedale Community Church), I suggest a relationship does exist; thus, with that exception, the null hypothesis is rejected. The percent of the variances of the respective DSLP sores measuring the dysfunctions that can be explained by the variances of the Modeling-the-Way score ranged from the lowest of $22.5 \%$ for compulsion to the highest of $36.5 \%$ for passive-aggression. Since these scores were statistically significant, conclusions can be drawn about how one predictor (Modelingthe-Way) can influence another (dysfunctions). When predicting human behavior, any statistically significant finding is significant to the field of knowledge, so we are challenged to ponder what is really significant about this research (Frost, 2013). I find four points of significance:

1. Literature has suggested that the dysfunctions measured can negatively affect a leader's effectiveness. I have posited, to varying degrees, that the discovery and articulation of values and beliefs lessen the degree of dysfunction, as suggested from the results presented. I thus can argue that leaders that are intentional about discovering and articulating values and beliefs may be more effective leaders.

2. Table 28 reflects the weights ( $B$ weights) that the different components of Modeling-the-Way had on the regression models. I think it significant that the component that states, "I ask for feedback on how my actions affect other people's performance" carried a higher beta and was statistically significant with lowering every dysfunction 
except codependence. This could serve to inspire leaders to ask their constituents for ways they can better help in the development of those they lead. This request for feedback from the leader implies the importance of leaders being inclusive and collaborative with constituents

3. Though I can imply that the discovery and articulation of values and beliefs may lower levels of dysfunctions that make a leader less effective, I acknowledge, as does the literature, that other dynamics may affect this relationship. Insecurity about one's self, the kind of upbringing the leader experienced, and vocational experience are but a few dynamics that may deserve some attention. However, because of this study, I can argue that the discovery and articulation of values is a part of what makes a leader effective since it lowers dysfunctions that may lower a leader's effectiveness.

4. Lastly, though this research focused on lay leadership in two specific congregations, I have presented literature that supports the argument that church leadership spills over into the community at large thus impacting a much larger population than church members. In developing good church leadership, we could possibly be developing good leadership in our outside vocations, families, and other community dynamics.

\section{Conclusions}

Based on the study findings, data analysis, and review of the literature, four conclusions can be made:

1. A moderate degree of each dysfunction exists among the participants.

2. There exists a statistically significant relationship between each dysfunction and the discovery and articulation of values as measured by the LPI Self that is supported 
in literature and both the correlation and regression data. This study posits that affirming and articulating values lessen the degree of tendencies toward dysfunctions among lay leaders in the two congregations studied with the exception of codependence at Collegedale Community Church.

3. Leaders who ask their followers to provide feedback as to how the leader can best help in their performance will strengthen the negative correlation between discovery and articulation of values and the dysfunctions studied.

4. In analyzing gender it appears that the female participants were more influenced by Modeling-the-Way than their male counterparts.

\section{Limitations}

Limitations that need to be considered prior to recommendations are:

1. This study depended on volunteers to participate. I have no way of knowing why some members of the population chose to respond while others did not.

2. The entire population of lay leaders, as defined by the church was invited to participate. I have no evidence to question the accuracy of this population; however, I depended on the churches to provide the contact data and assumed their accuracy as well as the accuracy of all the lay leaders being identified.

3. It is important to keep this study in the context of the two congregations. The universe of lay leadership and leadership in general travels far beyond the borders of these churches and though one may use this information as evidence for further study, the conclusions are directly relevant to these two churches alone.

4. These churches were located in two communities located geographically next to each other. Though, as previously stated, there is no formal or informal relationship 
between these congregations in that they exist reasonably close to each other, one may suggest that a limitation to the study must include the limited geography that captures the constituents of these churches.

5. The size of these churches may be considered to be large in context to the communities in which they exist, however, a 'large' church is relative. If someone's relative description of these churches is something lesser maybe that limitation should be considered when assessing these results.

In summary, the process used in conducting this research was done in such a way to preserve the integrity of the research process with hopes of lessening the impact that limitations can bring to the project.

\section{Recommendations for Practice}

This study started with the premise that the most admired and effective leaders are leaders that possess deeply held beliefs and guiding principles. These beliefs and standards can be represented in a set of values that guide our thoughts, decisions, and behavior. This enhances credibility with our constituents and makes more effective leaders. On the other hand, in absence of values and beliefs, dysfunctional may increase subordinating the effects that having values would have had causing thoughts, decisions, and behaviors to be self-serving and possibly destructive making for less effective leaders. These recommendations for practice and policy makers are meant to inspire intentional efforts to recognize the dysfunctions that exist in all of us and be intentional about the discovery and authentic advertisement of personal values to lessen their impact. It is recommended that:

1. Christ United Methodist Church and Collegedale Community Church 
conduct lay leader workshops oriented toward better understanding the dysfunctions that exist and develop strategies for minimizing their potentially negative effects. Included in these strategies would be values based leadership training that inspires self-reflection and advertisement of personal values among the lay leaders.

2. Organizations should consider being intentional about the development and implementation of leadership training that inspires leaders to self-reflect on their individual values and share those values with peers and constituents.

3. Organizations should consider being intentional about the discovery or rediscovery of their organizational values and have training focused on a clearer understanding of those values and how they can affect thought, decisions, and behavior.

4. Institutions of higher learning (MBA, Medical Schools, Leadership, Law, etc.), where leadership could be an important dynamic to success, develop and implement curriculums focused on self-reflection toward discovering personal values and defining those values so as to be authentic in their explanation to others.

5. Theological institutions that train future pastors could help them self-reflect their personal values and then define them so that those values can be authentically advertised to peers and constituents.

\section{Recommendations for Further Research}

The following topics are offered as suggestions for further research:

1. Research is needed that includes other church lay leader populations to possibly discover if the dysfunctions studied have similarities in other churches in different communities or among different denominations. This may offer insights as to whether these studies need to be kept to separate church communities or separate 
denominations, or separate churches, or, can these conclusions be confirmed across a larger, more general church population.

2. It may be important to research if relationships exist between the discovery and authentic expression of values and beliefs and these dysfunctions in organizations outside of the church to include organizations in the nonprofit, for profit, and public sectors.

3. It may be important to extend study that measures if a relationship exists between effective leadership with the discovery and authentic advertisement of values and beliefs.

4. This study explored five dysfunctions and their relationship with the discovery and authentic expression of values and beliefs. Other dysfunctions may deserve attention as they relate to values and beliefs.

5. Further research is needed exploring values and beliefs. Not only as to their discovery and authentic advertisement but to define specifically what values are important to effective leadership.

6. Further research is needed in exploring dysfunctions that may inhibit effective leadership. This includes the development of other tools that may be more accurate in not only measuring the dysfunctions studied in this work but other dysfunctions that may inhibit leadership effectiveness.

7. This study suggests that Modeling-the-Way may lessen some of the dysfunctional tendencies studied. Further research may suggest other intentional practices that may lessen dysfunctional tendencies thus possibly contributing to more effective leadership. 
8. Further research could be conducted regarding the role of gender in Modelingthe-Way behaviors that lessen the effects of the five dysfunctions. Correlations presented in Appendix I reflected no statistical significance among males while their female counterparts recorded statistical significance between Modeling-the-Way and codependence DSLP score, narcissism DSLP score, and passive-aggression DSLP score. 
APPENDIX A

DARK SIDE LEADERSHIP PROFILE 


\section{APPENDIX A}

The answers to these questions, organized by dysfunctional category, will constitute the primary data in the study. This is not the order of the questions. The order will be randomly determined using survey monkey. Though I anticipate the hardcopy use of the survey to be employed minimally, those requesting this format will have the questions presented in a scrambled format with half the participants in each congregation using one order and the other half of the congregation using this format using an exact opposite order.

$1=$ strongly disagree $\quad 2$ =disagree $\quad 3=$ uncertain $\quad 4=$ agree $\quad 5=$ strongly agree

The Compulsive Leader

1. I often worry that my superiors do not approve of the quality of my work. 12345

2. I am highly regimented in my daily personal routines such as exercise schedule or spiritual discipline. 12345

3. When circumstances dictate that I must interrupt my daily personal routine, I find myself feeling out of sorts and even guilty of having 'skipped a day. 12345

4. I frequently find myself conscious of my status in relationship to others. 12345

5. It is difficult for me to take an unplanned day odd from work responsibilities just to goof around or spend time with friends or family, feeling like a slacker if I do. 123 45

6. While away from work, I still find myself thinking about work-related topics, often sitting down to write out my ideas at length, even if it disrupts family activities. 123 45

7. I like to plan the detail of my vacations so I don't waste time or miss anything important. 12345

8. I often explode in anger after being cut off while driving or after being irritated by other petty issues. 12345

9. I am meticulous about my personal appearance, keeping shoes shined, clothes perfectly pressed, hair perfectly cut and groomed, and fingernails clipped. 12345

10. I frequently comment about the long hours I keep and my heavy workload but am secretly proud of my work "ethic." 12345

11. When another person makes sloppy errors or pays little attention to detail, I become annoyed and judge him or her. 12345

12. I am obsessive about the smallest error, worrying that they will reflect poorly on me. 12345

The Narcissistic Leader

1. Fellow leaders in y church or organization frequently question whether my proposed goals and projects are feasible and realistic. 12345 
2. I am obsessed with how others feel about my performance. 12345

3. I find it difficult to receive criticism of any kind, reacting with anger, anxiety, or even depression when it comes. 12345

4. At times I find myself thinking, I'll show them; they could never make it around here without me, when I experience conflict situations or opposition to my proposals and plans. 12345

5. In spite of achieving what others would consider significant success, I still find myself dissatisfied and driven to achieve greater things in an effort to feel good about myself. 12345

6. I am willing to bend rules and press the envelope of acceptable behavior to accomplish my goals. 12345

7. Deep down I find myself feeling jealous of the success and achievements of associates or organizations in my area or field of expertise. 12345

8. I am often unaware of or unconcerned with the financial pressures my goals and projects place on those I lead, my family, or the organization I serve. 12345

9. Success or failure in a project has a direct bearing on my self-image and sense of personal worth. 12345

10. I am highly conscious of how colleagues and those to whom I am accountable regard my accomplishments. 12345

11. I need to be recognized or "on top" when meeting with a group of fellow leaders or associates. 12345

12. I see myself as a nationally known figure at some time in the future or have plans to attain such a position. 12345

The Paranoid Leader

1. When I see two key leaders of my organization discreetly talking, I worry that they may be talking about me. 12345

2. It really bothers me to think about my board or leadership team meeting without me being present. 12345

3. When an associate receives rave reviews for a project or some special assignment, I experience intense jealousy rather than joy in the success and recognition he or she is receiving. 12345

4. I require subordinates and associates within my organization to provide me with detailed reports of their activities. 12345

5. I struggle when an associate, rather than me, is asked to take on a high-profile special assignment or project. 12345

6. I have few intimate or meaningful relationships within my church or organization and find myself avoiding such relationships. 12345

7. I insist on absolute loyalty from those who work for me and prohibit staff from criticizing me in anyway. 12345

8. I often worry that there is a significant faction within my organization that would like to see me leave. 12345

9. I have probed people for what they know or for special information they may have relating to certain leaders in my organization. 12345

10. Those I work with often complain about my lack of a healthy sense of humor. 1234 5 
11. I routinely refer to those I lead as "my people" or "my organization," yet bristle when the same designation is spoken by an associate. 12345

12. I tend to take seriously even lighthearted comments and jokes directed at me, feeling there is probably a seed of truth in them. 12345

The Codependent Leader

1. I grew up in a family with one or more substance-dependent people (alcoholics, drug addicts, food addicts, etc.) 12345

2. I grew up in a strict legalistic religious environment that held its members to an unrealistic standard of behavior and discouraged open, honest communication about personal problems and struggles. 12345

3. I am usually willing to put up with or ignore bizarre, embarrassing, or inappropriate behavior in others. 12345

4. I often refrain from sharing $\mathrm{m}$ y opinion in a group setting until $\mathrm{I}$ have heard the opinions of others in the group. 12345

5. I frequently worry about hurting people's feelings by sharing my true feelings and thoughts. 12345

6. I often feel responsible for problems I did not create. 12345

7. I find it difficult to sleep because I worry about someone else's problems or behaviors. 12345

8. I find myself frequently overcommitted and feel my life is out of control. 12345

9. I find it extremely difficult to say no to people even when I know that saying yes will result in difficulty for me or my family. 12345

10. I constantly feel a sense of guilt but have difficulty identifying its source. 12345

11. I feel like I never measure up to those around me and have self-deprecating thoughts. 12345

12. When I receive compliments form others, I find it difficult to simply accept them without making a qualifying statement. 12345

The Passive-Aggressive Leader

1. I find myself resisting standards and procedures for formal review of my performance. 12345

2. It is common for me to procrastinate on major projects that I must do. 12345

3. I regularly resist others' ideas that could translate into increased performance or responsibility for me. 12345

4. I find myself constantly performing beneath my capabilities. 12345

5. I experience periodic but regular outbursts of anger and frustration that are just within bounds of what is considered acceptable behavior. 12345

6. Occasionally I intentionally forget suggested projects. 12345

7. Sometimes I give others the silent treatment as an expression of my behavior. 1234 5

8. I find myself telling others nothing is bothering me when in reality I am seething inside. 12345

9. I tend to be generally pessimistic and feel negative about my future. 12345

10. Others have expressed to me that I make them feel uncomfortable. 12345 
11. Strategic planning and goal setting are difficult for me, and I resist such exercises. 1 2345

12. Sometimes I catch myself trying to manipulate others in group settings by venting my anger and emotions when facing initiatives I do not support. 12345 
APPENDIX B

MODELING-THE-WAY LPI—SELF INVENTORY 


\begin{abstract}
APPENDIX B
Below you will find six statements. Each statement has a possible range of responses. Read each statement and circle the correct number that most clearly corresponds to your impressions of yourself: $10=$ almost always; $9=$ very frequently; $8=$ usually; $7=$ fairly often; $6=$ sometimes; $5=$ occasionally; $4=$ once in a while; $2=$ rarely; $1=$ almost never. The success of this study rests with your absolute integrity in answering these questions.

I set personal examples of what I expect from others.

I spend time and energy making certain that the people I work with adhere to the principles and standards we have agreed on.

I I follow through on the promises and commitments that I make.

_ I I ask for feedback on how my actions affect other people's performance.

_ I build consensus around a common set of values for running our organization.

_ I am clear about my philosophy of leadership.
\end{abstract}


APPENDIX C

LETTER OF AUTHORIZATION FROM METHODIST CHURCH 


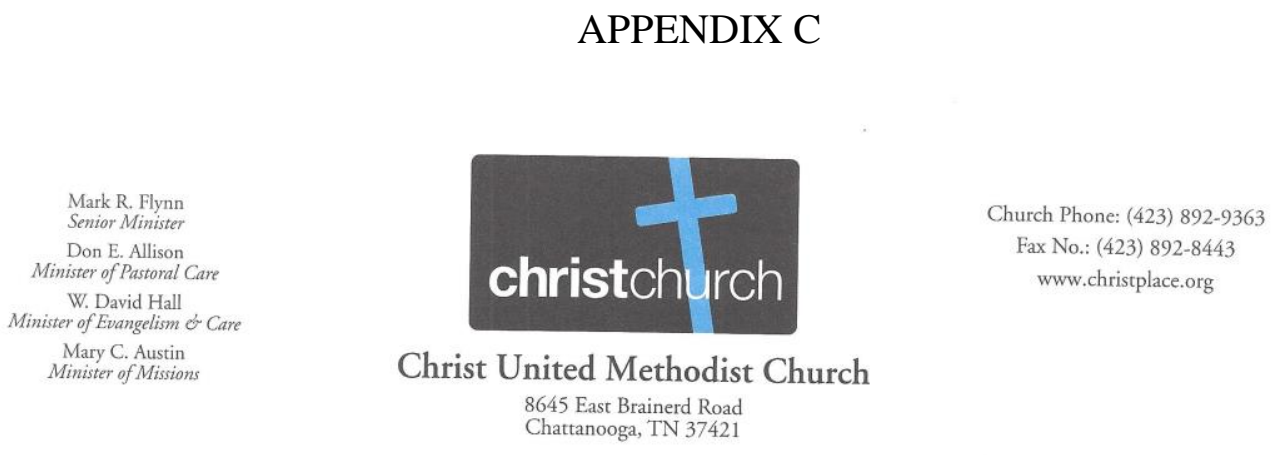

Institutional Review Board

Andrews University

Administration Building $-3^{\text {rd }}$ Floor

4150 Administration Drive

Berrien Springs, MI 49104-4910

Dear Members of the Board:

The purpose of this letter is to inform you that John Cosgrove, a PhD candidate at Andrews University, has been granted permission to collect data for his research project titled "The Impact of Values Clarification and Expression of Beliefs as measured by the LPI-Self Inventory on the Characteristic of Dysfunctional Leadership Among Lay Leaders in Two Tennessee Protestant Congregations" at Collegedale Community Church in Collegedale, Tennessee.

John will administer a survey to current and past lay leaders of our church and has agreed to meet ethical obligations when collecting data from people.

Please feel free to contact me with any questions pertaining to this permission.

Sincerely,

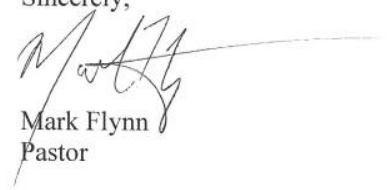


APPENDIX D

LETTER OF AUTHORIZATION FROM COLLEGEDALE COMMUNITY CHURCH 


\title{
APPENDIX D
}

\section{(C) Collegedale \\ Community Church \\ Growing with God}

\author{
Institutional Review Board \\ Andrews University \\ Administration Building $-3^{\text {rt }}$ Floor \\ 4150 Administration Drive \\ Berrien Springs, MI 49104-4910
}

February 25, 2015

Dear Members of the Board:

The purpose of this letter is to inform you that John Cosgrove, a $\mathrm{PhD}$ candidate at Andrews University, has been granted permission to collect data for his research project titled "The Impact of Vahues Clarification and Expression of Beliefs as measured by the L.PI-Self Inventory on the Characteristic of Dysfunctional Leadership Among Lay Leaders in Two Tennessee Protestant Congregations" at Collegedale Community Church in Collegedale, Tennessee.

John will administer a survey to current and past lay leaders of our church and bas agreed to meet ethical obligations when collecting data from people.

Please feel free to contact me with any questions pertaining to this permission.

Sincerely.

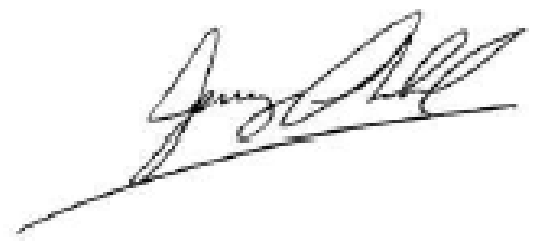

Jerry Amold, D. Min.

Senior Pastor

Collegedale Community Church 
APPENDIX E

\section{EMAIL INVITATION TO PARTICIPATE}




\title{
APPENDIX E
}

\section{EMAIL INVITATION TO PARTICIPATE}

\author{
Subject: Church Lay Leader Survey \\ Dear Survey Participant,
}

You have probably been recently contacted to participate in a study focused on the development of church lay leaders. Your participation is important and appreciated. My name is John Cosgrove and I am conducting this study with the intent of not only completing a $\mathrm{PhD}$ in leadership but to collect data from which we can forward a more intentional effort to develop lay leaders in our church.

Please 'click' the link below to access the 'Consent Letter.' At the end of the letter you will see a box that says 'accept' or 'decline.' Please 'click' that box and begin the survey, which will take about 20 minutes. If you click 'decline,' you will automatically leave the site. Please understand that your answers will be held in the highest of confidence and no one from within the church, to include myself, will connect your responses to you personally. Please respond to each question as honestly as possible.

Again thank you. Thank you not only for your participation, but for your leadership in this wonderful church. Your work is important.

Respectfully,

John Cosgrove 
APPENDIX F

INFORMED CONSENT 


\section{APPENDIX F}

\section{Andrews University}

\section{INFORMED CONSENT LETTER}

My name is John Cosgrove, and I am conducting research in the form of a dissertation, in partial fulfillment for my PhD at Andrews University, Berrien Springs, Michigan. I am conducting a research titled "The Impact of Values Clarification and Expression of Beliefs as Measured by the Leadership Practices Inventory-Self on the Characteristic of Dysfunctional Leadership Among Lay Leaders in Two Tennessee Protestant Congregations." I am requesting your participation in the study by completing a survey that will take approximately 20 minutes of your time.

Purpose of the Study: The purpose of this study will be to explore if Modeling-the-Way according to Kouzes and Posner (2012a) has a relationship with dysfunctional leadership traits as defined by McIntosh and Rima (2007) among lay leaders in two different congregations, Christ United Methodist Church and Collegedale Community Church (Adventist), both located in the same community. The results of this work will be used to provide a more informed direction for the training and development of church lay leaders. Permission has been granted to conduct this research by the pastors of each congregation.

Duration of Participation in the Study: Participation in this online survey will take approximately 20 minutes of your time.

Benefits: You are being informed that there are no direct benefits to you, however you may be able to benefit from the outcome of the study as may other participants.

Risks: There are no risks beyond normal risks related to your participation in a study.

Voluntary Participation: Your participation in this study is completely voluntary. Refusal to participate will involve no penalty or loss of benefits. You may discontinue participation at any time without penalty or loss of benefits to which you may otherwise be entitled.

Confidentiality: Your confidentiality is of high priority. You will not be identified directly in any research reports, publications, or presentations related to the study. All personal identifiers will be coded to provide privacy to you. The collected data will be kept in a safe and secure protected location. Research assistants have been instructed to ensure that ethical procedures related to human subjects are observed. The data will be kept for at least three years. After which it shall be destroyed. 
Contact: You may contact my academic advisor, Dr. Sylvia Gonzalez, at 269-757-1901, or myself, John Cosgrove, at 423-596-8300 for answers to any questions related to this study.

My acceptance to participate acknowledges that I have read this Consent Form and voluntarily consent to participate in this study. I am fully aware that if I have any additional questions that I can contact the John Cosgrove at 423-596-8300 or the advisor Dr. Sylvia Gonzalez at 269-757-1901.

To advance to the research and give your informed consent, click on the "Accept" button" and to reject participation click on the "Decline" button to be kicked out, and you will NOT advance to the survey.

Accept __ Decline 
APPENDIX G

HISTOGRAMS TESTING FOR NORMALCY 
APPENDIX G

HISTOGRAMS TESTING FOR NORMALCY

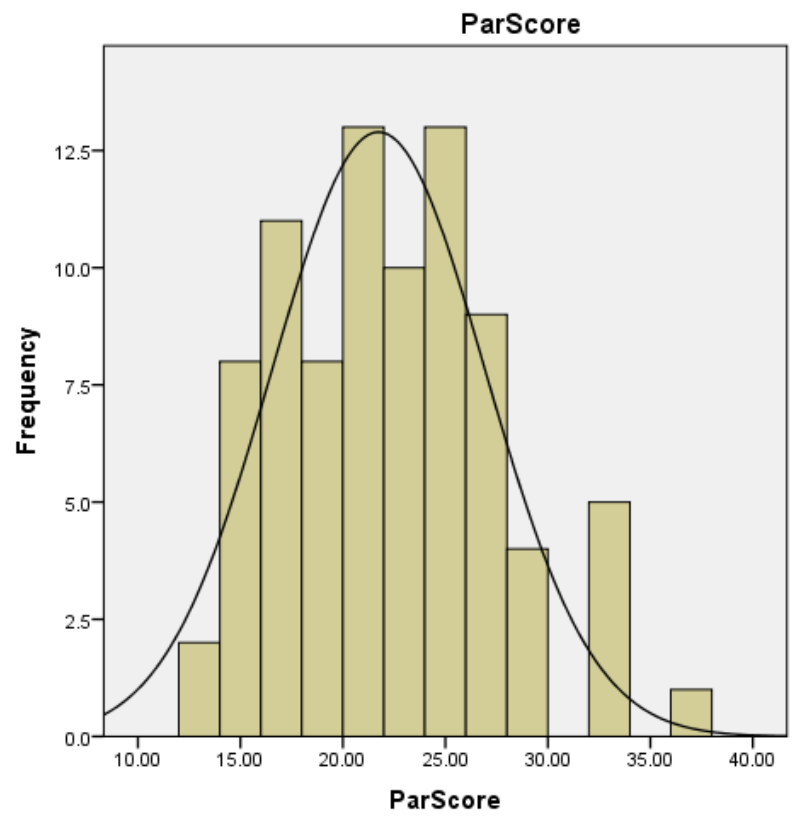

Histogram appears to be normally skewed from inspection

\begin{tabular}{rrrrr}
\hline $\mathrm{N}$ & Mean & SD & Minimum & Maximum \\
\hline 84 & 21.74 & 5.20 & 13.00 & 36.00
\end{tabular}

Figure 4. Paranoia.

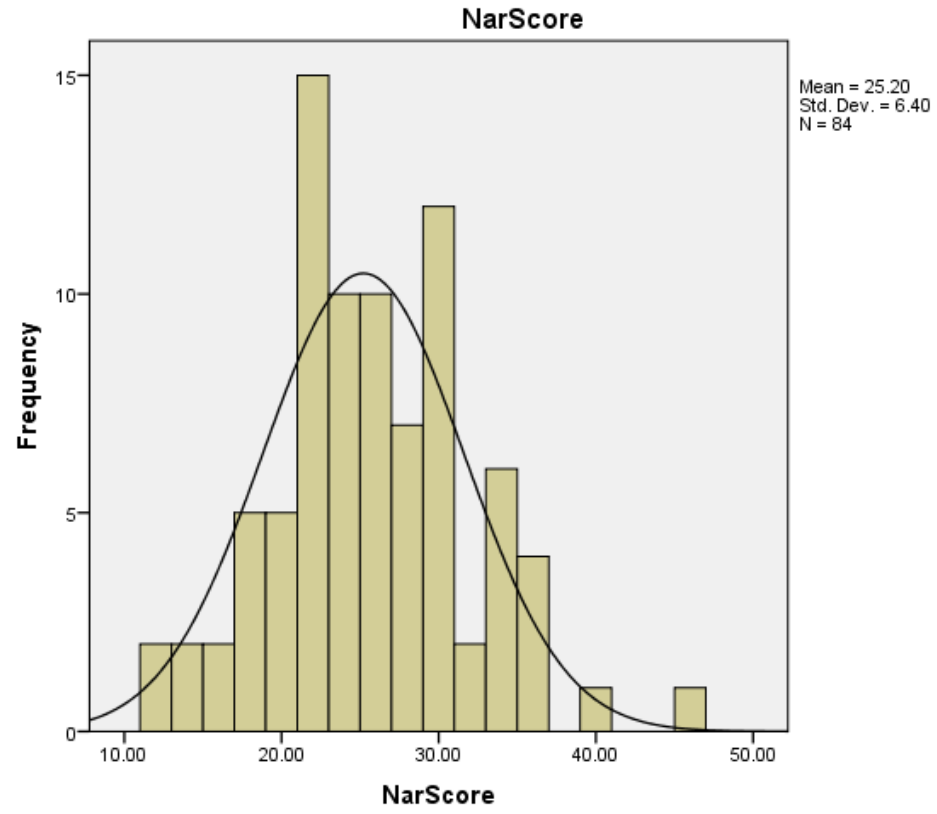

Histogram appears to be normally skewed from inspection

\begin{tabular}{rrrrr}
\hline $\mathrm{N}$ & Mean & SD & Minimum & Maximum \\
\hline 84 & 25.20 & 6.40 & 12.00 & 46.00
\end{tabular}

Figure 5. Narcissism. 


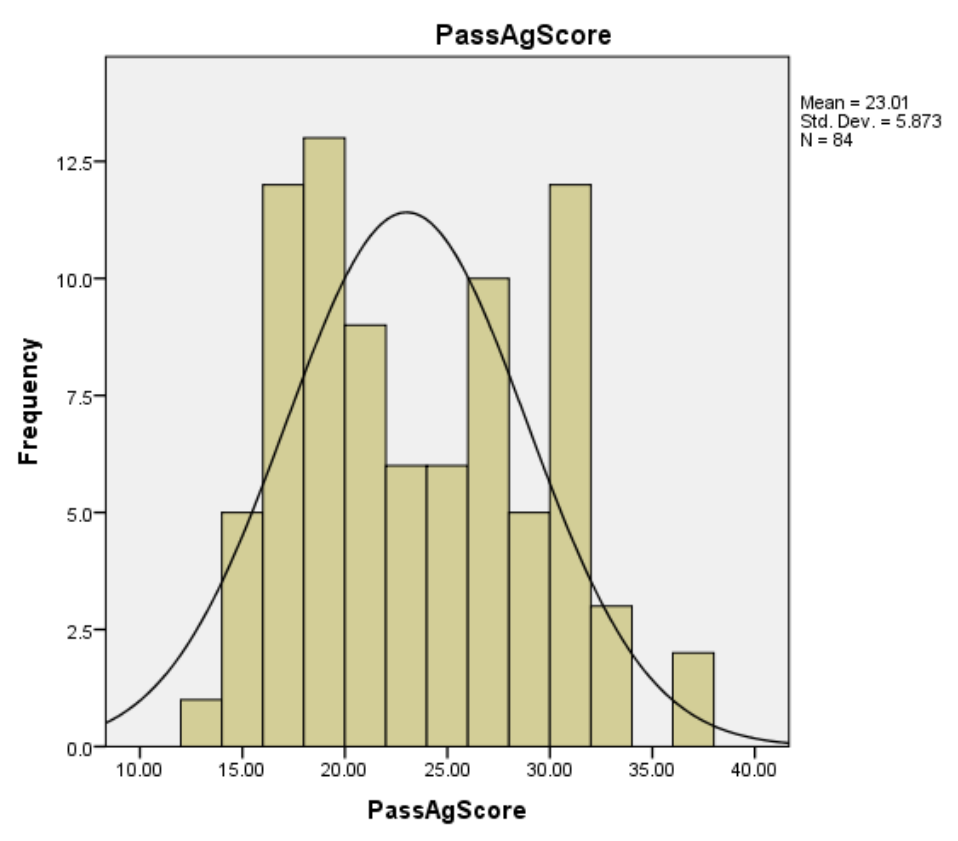

Histogram appears to be normally skewed from inspection

\begin{tabular}{rrrrr}
\hline $\mathrm{N}$ & Mean & SD & Minimum & Maximum \\
\hline 84 & 23.01 & 5.87 & 13.00 & 37.00
\end{tabular}

Figure 6. Passive-aggression.

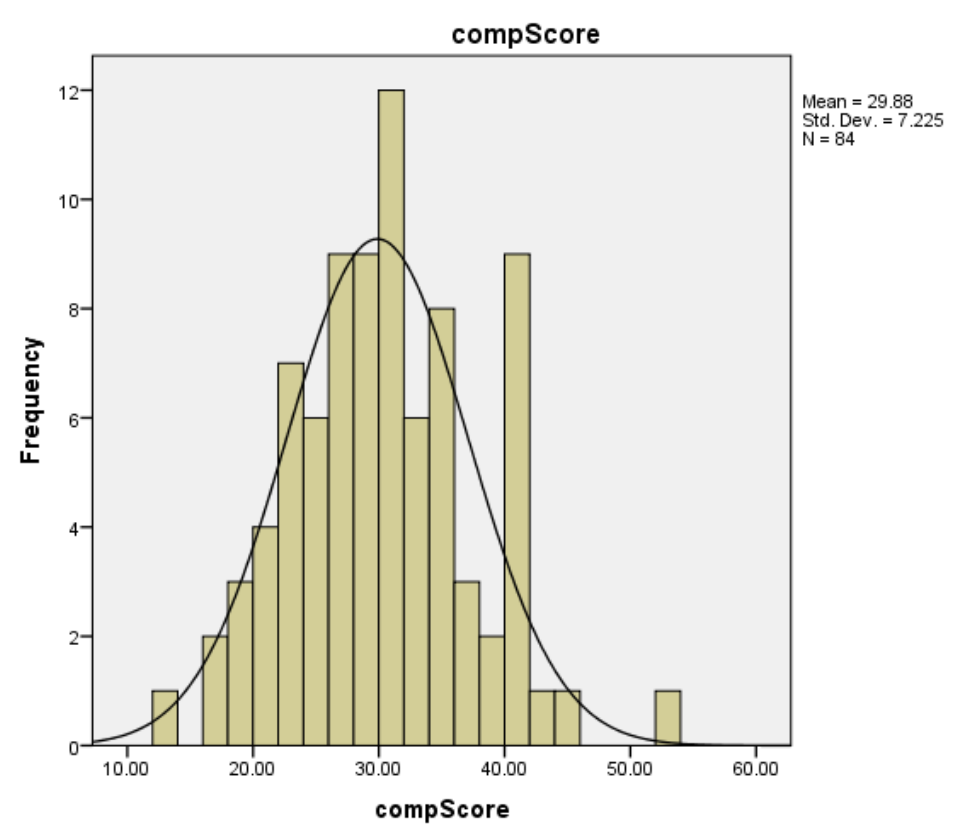

Histogram appears to be normally skewed from inspection

\begin{tabular}{lccrr}
\hline $\mathrm{N}$ & Mean & SD & Minimum & Maximum \\
\hline 84 & 29.88 & 7.23 & 13.00 & 53.00
\end{tabular}

Figure 7. Compulsion. 


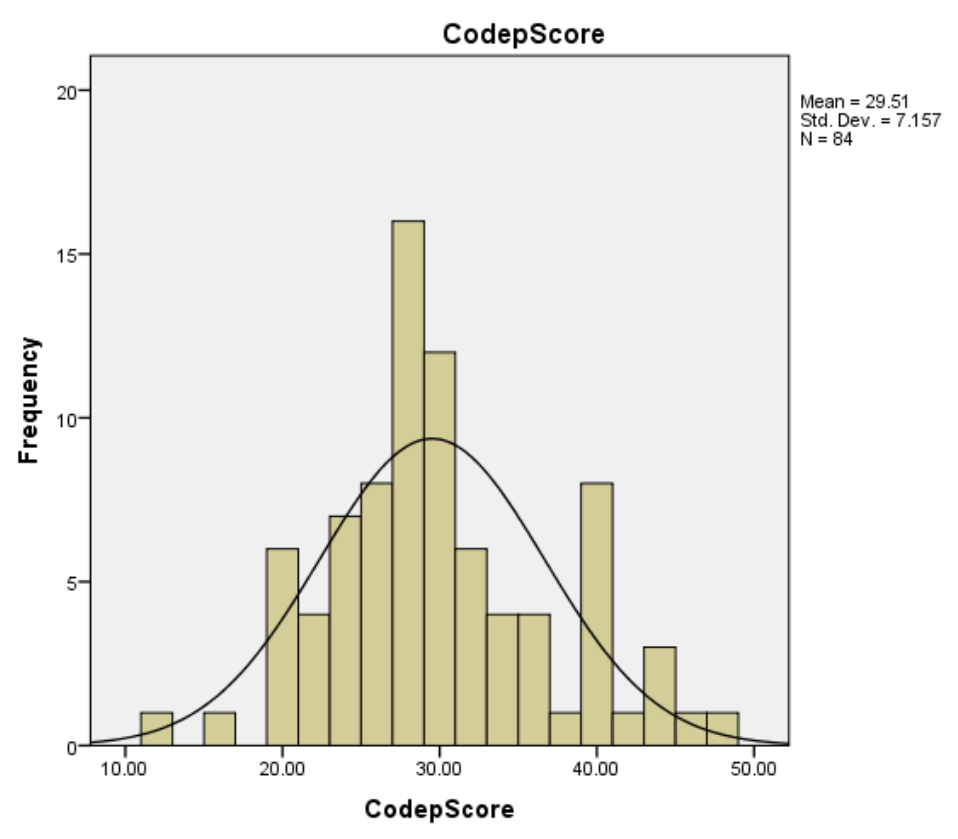

Histogram appears to be normally skewed from inspection

\begin{tabular}{cccrr}
\hline $\mathrm{N}$ & Mean & SD & Minimum & Maximum \\
\hline 84 & 29.51 & 7.16 & 12.00 & 48.00
\end{tabular}

Figure 8. Codependence.

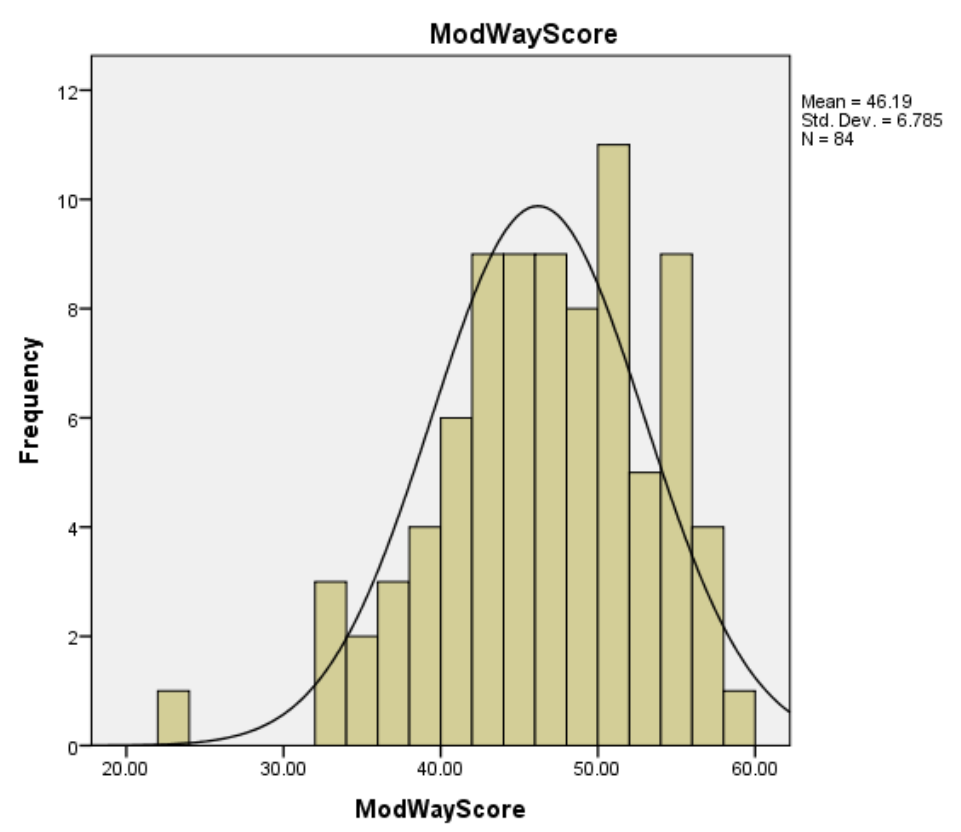

Histogram appears to be normally skewed from inspection

\begin{tabular}{cccrr}
\hline $\mathrm{N}$ & Mean & SD & Minimum & Maximum \\
\hline 84 & 46.19 & 6.78 & 23.00 & 58.00
\end{tabular}

Figure 9. Modeling-the-Way. 
APPENDIX H

SCATTER PLOTS 


\section{APPENDIX H}

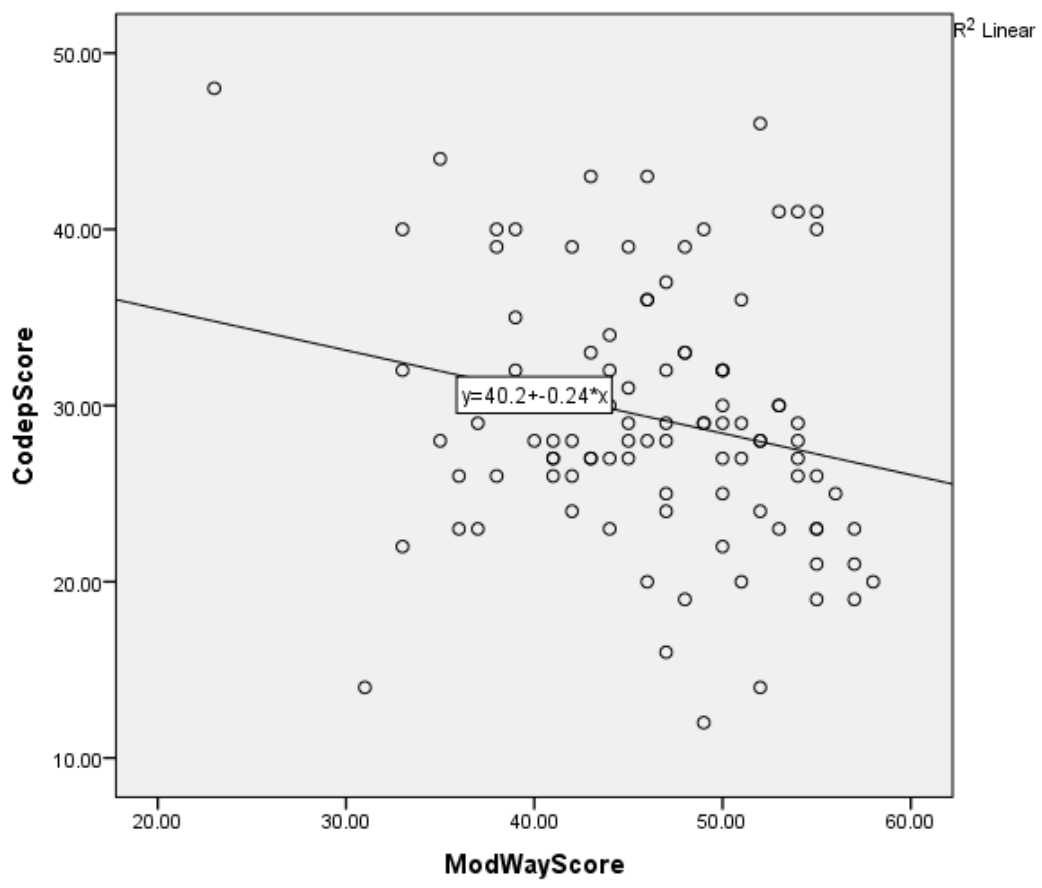

Figure 10. Codependence.

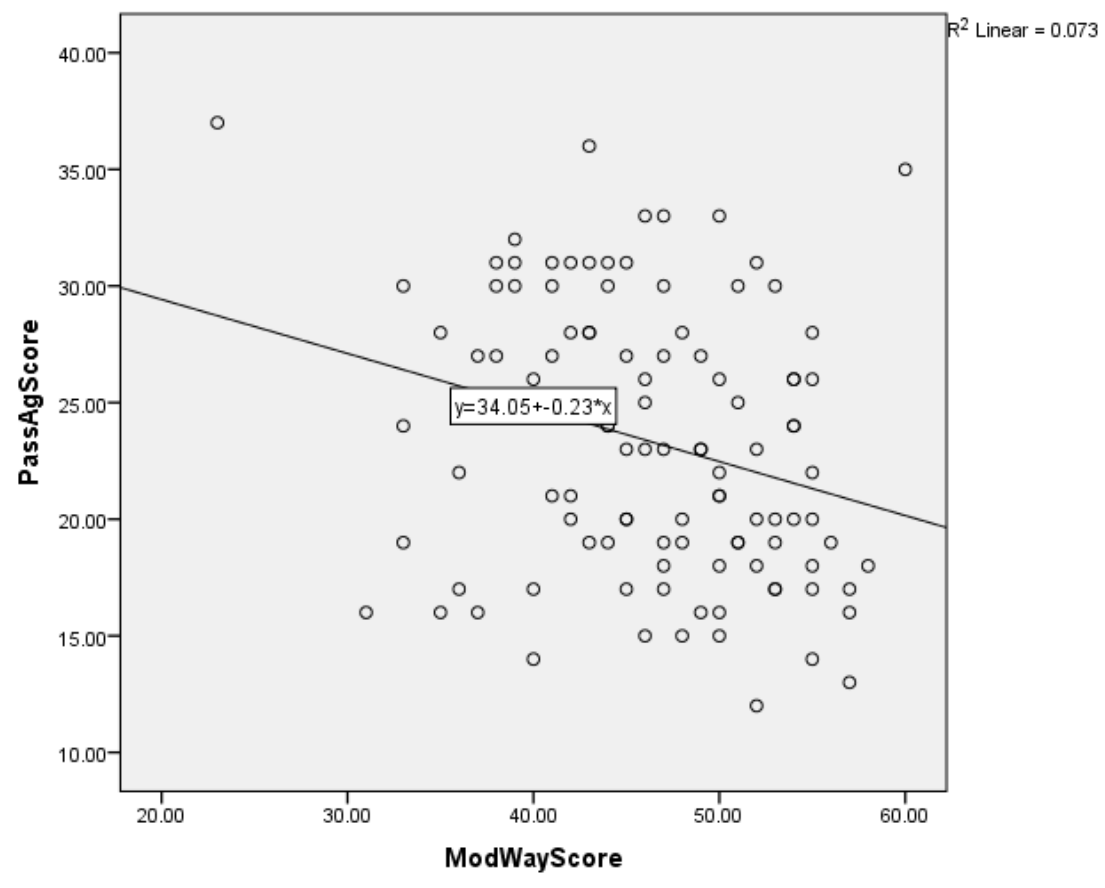

Figure 11. Passive-aggression. 


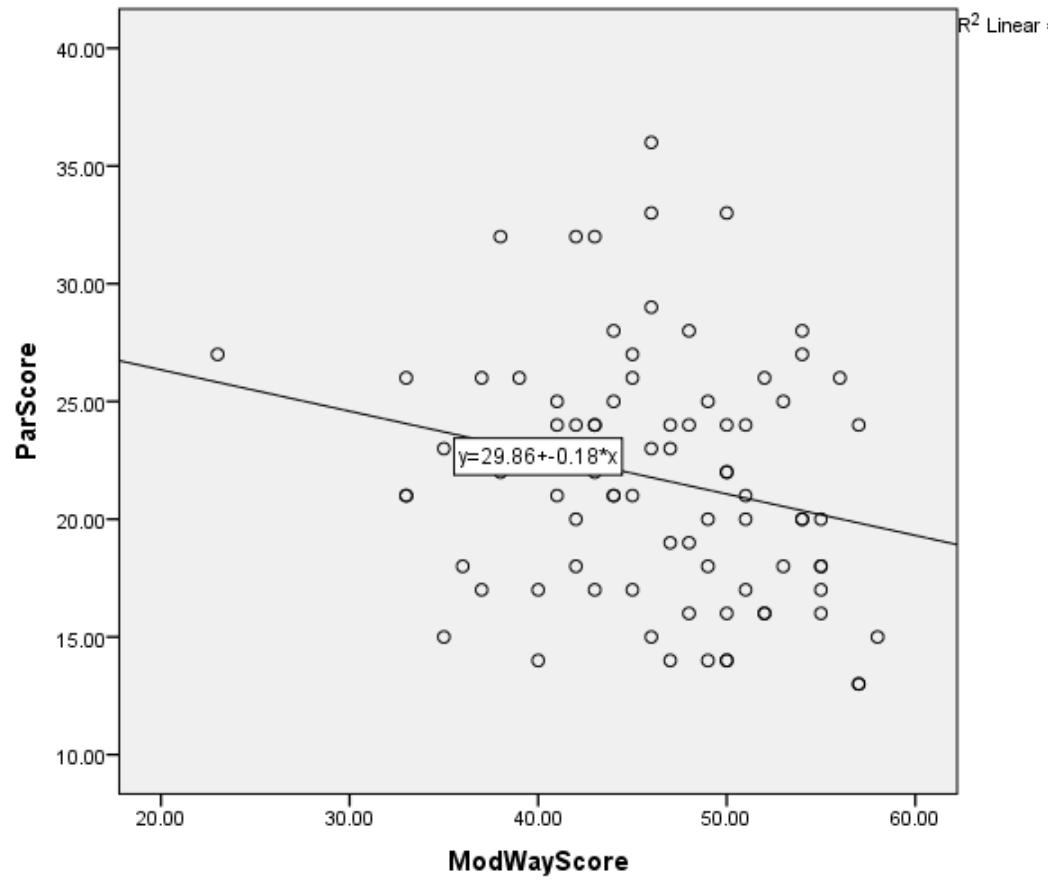

Figure 12. Paranoia.

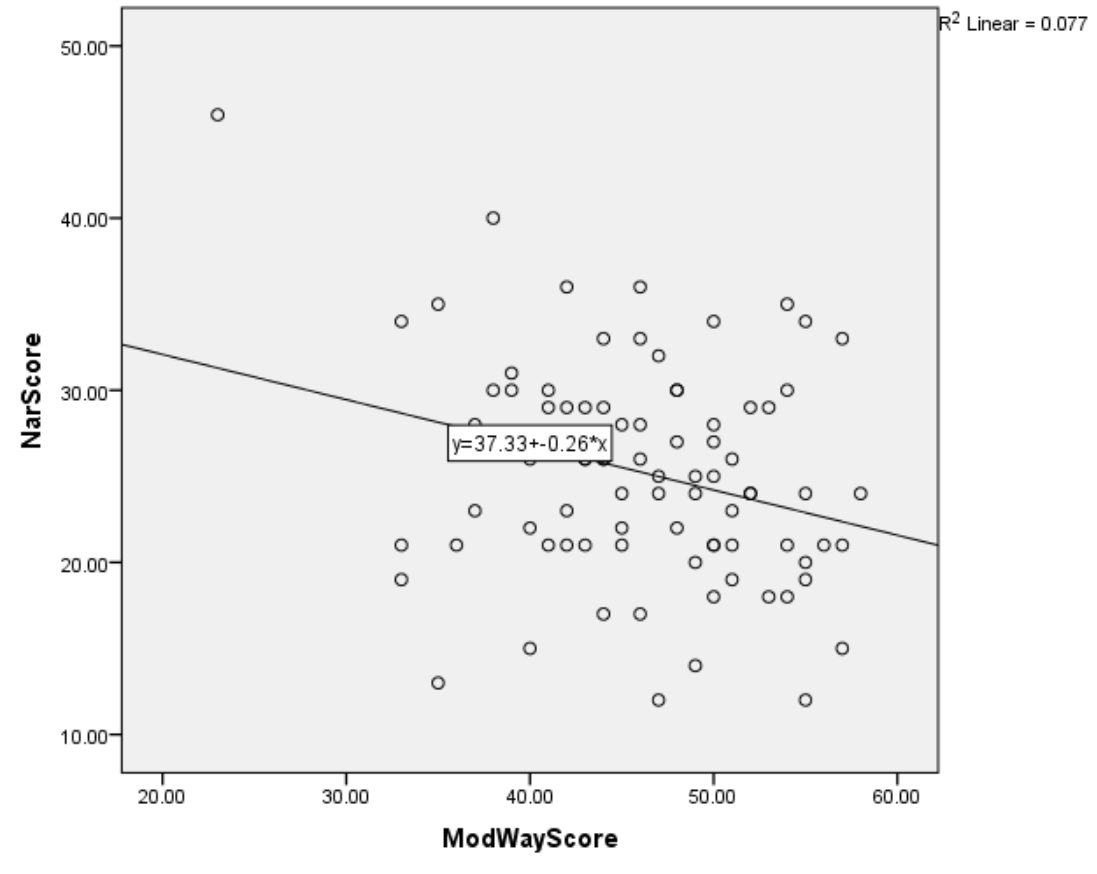

Figure 13. Narcissism. 


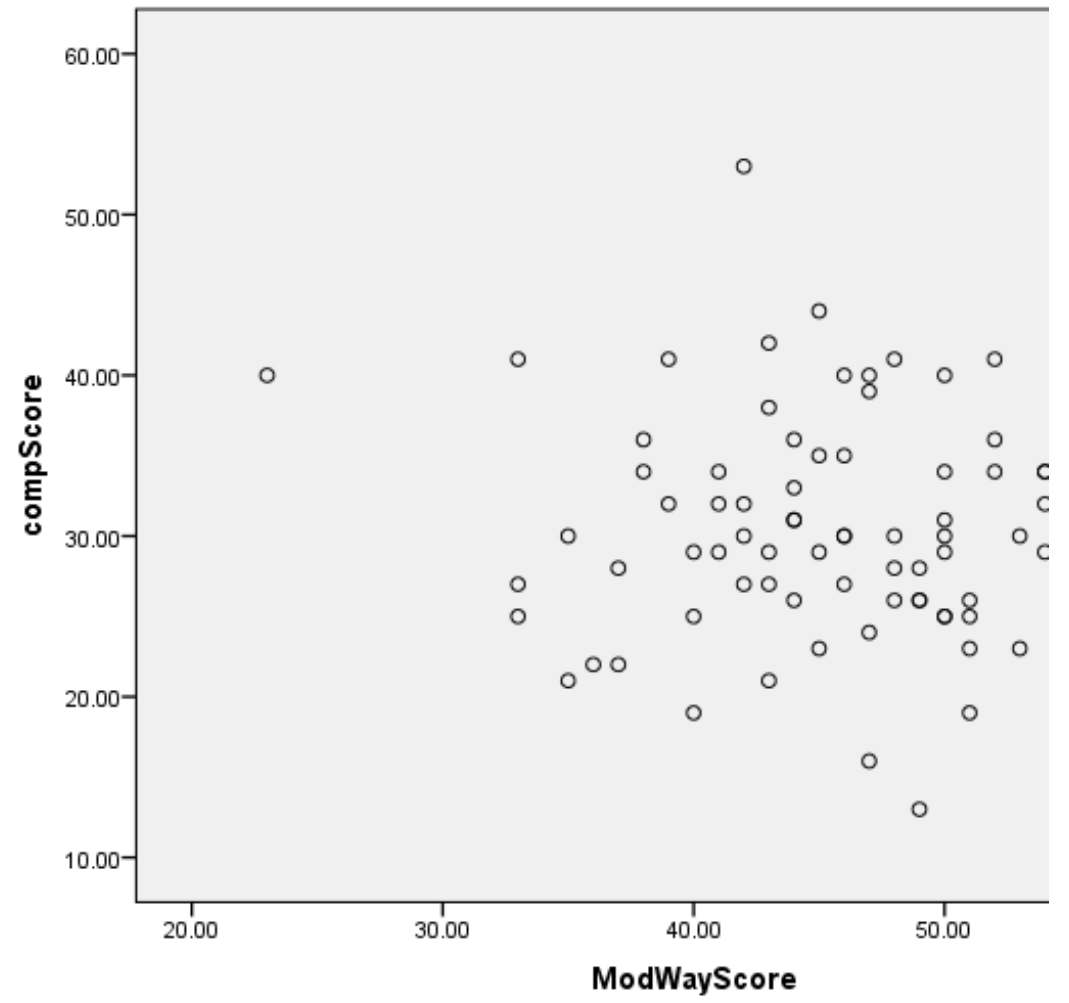

Figure 14. Compulsion.

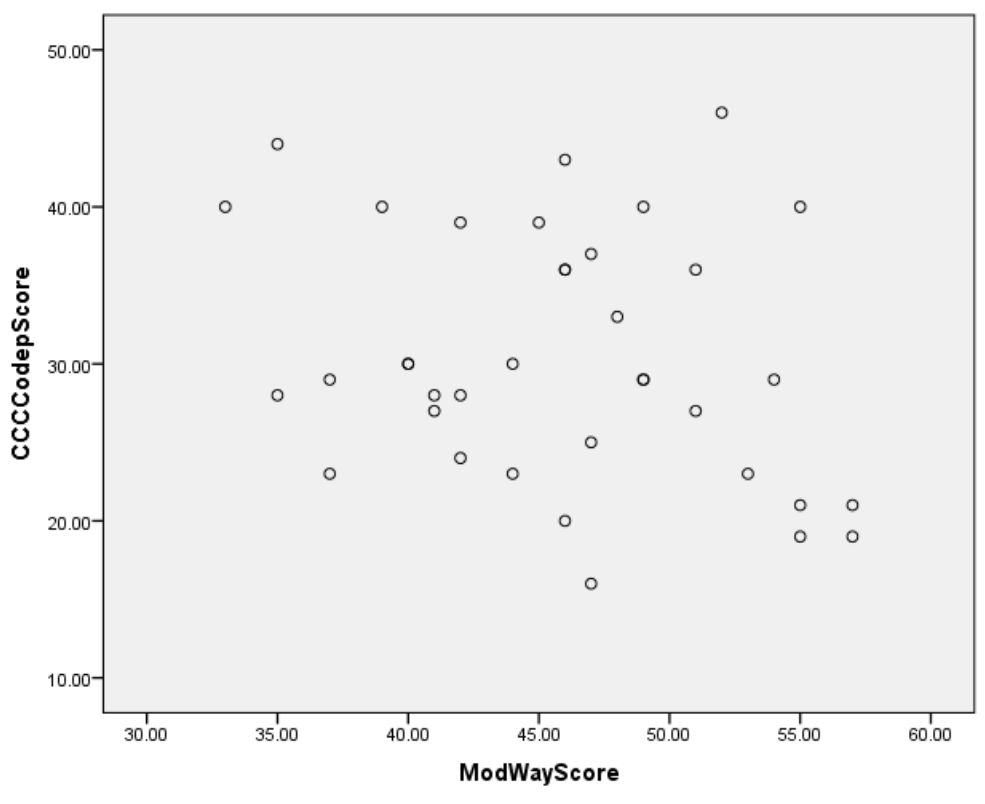

Figure 15. Codependence (CCC). 


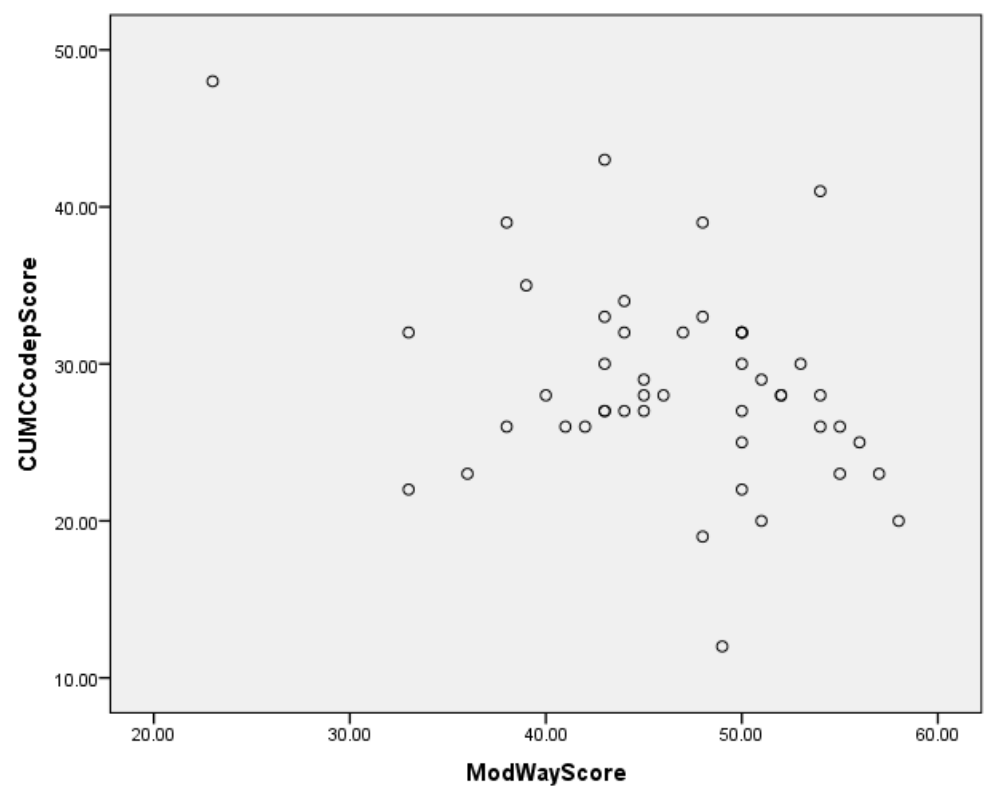

Figure 16. Codependence (CUM). 
APPENDIX I

\section{GENDER CORRELATION TABLES}




\section{APPENDIX I}

\section{GENDER CORRELATION TABLES}

Correlations Between Modeling-the-Way and the

Dysfunctions Among Male Participants

Correlations Between Modeling-the-Way and the Dysfunctions Among Male Participants

\begin{tabular}{lcccccccc}
\hline & $\mathrm{N}$ & $\mathrm{M}$ & $\mathrm{SD}$ & 2 & 3 & 4 & 5 & 6 \\
\hline 1. ModWayScore & 38 & 46.42 & 6.43 & -.271 & -.084 & -.104 & -.220 & -.284 \\
2. CodepScore & 38 & 29.18 & 6.71 & & $.728^{* *}$ & $.593^{* *}$ & $.462^{* *}$ & $.441^{* *}$ \\
3. CompScore & 38 & 30.13 & 7.12 & & & $.699^{* *}$ & $.575^{* *}$ & $.627^{* *}$ \\
4. NarScore & 38 & 25.58 & 6.00 & & & & $.739^{* *}$ & $.574^{* *}$ \\
5. ParScore & 38 & 22.00 & 4.82 & & & & & $.744^{* *}$ \\
6. PassAgScore & 38 & 24.68 & 5.36 & & & & & \\
\hline
\end{tabular}

*p $<0.05 * * \mathrm{p}<0.01$

Correlations Between Modeling-the-Way and the Dysfunctions Among Female Participants

\begin{tabular}{lcccccccc}
\hline & $N$ & $M$ & $S D$ & 2 & 3 & 4 & 5 & 6 \\
\hline 1. ModWayScore & 46 & 46.00 & 7.13 & $-.340^{*}$ & -.238 & $-.397^{* * *}$ & -.239 & $-.500^{* *}$ \\
2. CodepScore & 46 & 29.78 & 7.57 & & $.568^{* *}$ & $.709^{* *}$ & $.605^{* *}$ & $.690^{* *}$ \\
3. CompScore & 46 & 29.67 & 7.38 & & & $.738^{* *}$ & $.678^{* *}$ & $.562^{* *}$ \\
4. NarScore & 46 & 24.89 & 6.76 & & & & $.692^{* *}$ & $.727^{* *}$ \\
5. ParScore & 46 & 21.52 & 5.53 & & & & & $.774^{* *}$ \\
6. PassAgScore & 46 & 21.63 & 5.97 & & & & & \\
\hline *p $<0.05 * * \mathrm{p}<0.01$ & & & & & & & &
\end{tabular}


APPENDIX $\mathbf{J}$

DSLP MEAN SCORES BY DEMOGRAPHIC CATEGORY 


\section{APPENDIX J}

\section{DSLP MEAN SCORES BY DEMOGRAPHIC CATEGORY}

Average Scores for Dysfunctions and Modeling-the-Way by Church and Gender

\begin{tabular}{|c|c|c|c|c|c|c|c|c|c|c|c|c|}
\hline & \multicolumn{2}{|c|}{$\begin{array}{c}\text { Codependence } \\
(n=84)\end{array}$} & \multicolumn{2}{|c|}{$\begin{array}{l}\text { Compulsion } \\
\quad(n=84)\end{array}$} & \multicolumn{2}{|c|}{$\begin{array}{l}\text { Narcissism } \\
\quad(n=84)\end{array}$} & \multicolumn{2}{|c|}{$\begin{array}{c}\text { Paranoia } \\
(n=84)\end{array}$} & \multicolumn{2}{|c|}{$\begin{array}{l}\text { Passive- } \\
\text { aggression } \\
(n=84)\end{array}$} & \multicolumn{2}{|c|}{$\begin{array}{c}\text { Modeling-the- } \\
\text { Way } \\
(n=84)\end{array}$} \\
\hline & $M$ & $S D$ & $M$ & $S D$ & $M$ & $S D$ & $M$ & $S D$ & $M$ & $S D$ & $M$ & $S D$ \\
\hline Total & 29.51 & 7.16 & 29.88 & 7.23 & 25.20 & 6.40 & 21.74 & 5.20 & 23.01 & 5.87 & 46.19 & 6.78 \\
\hline $\begin{array}{l}\text { Collegedale } \\
\text { Community Church } \\
\text { Christ United }\end{array}$ & 30.46 & 7.96 & 29.32 & 7.67 & 24.62 & 6.39 & 21.54 & 5.27 & 23.19 & 5.87 & 45.86 & 6.49 \\
\hline Methodist Church & 28.77 & 6.44 & 30.32 & 6.91 & 25.66 & 6.44 & 21.89 & 5.19 & 22.87 & 5.94 & 46.45 & 7.06 \\
\hline Male $(n=38)$ & 29.18 & 6.71 & 30.13 & 7.12 & 25.58 & 6.00 & 22.00 & 4.82 & 24.68 & 5.36 & 46.42 & 6.43 \\
\hline Female $(n=46)$ & 29.78 & 7.57 & 29.67 & 7.38 & 24.89 & 6.76 & 21.52 & 5.53 & 21.63 & 5.97 & 46.00 & 7.13 \\
\hline
\end{tabular}


Average Scores for Dysfunctions and Modeling-the-Way by Tenure as a Church Member and Lay Leader

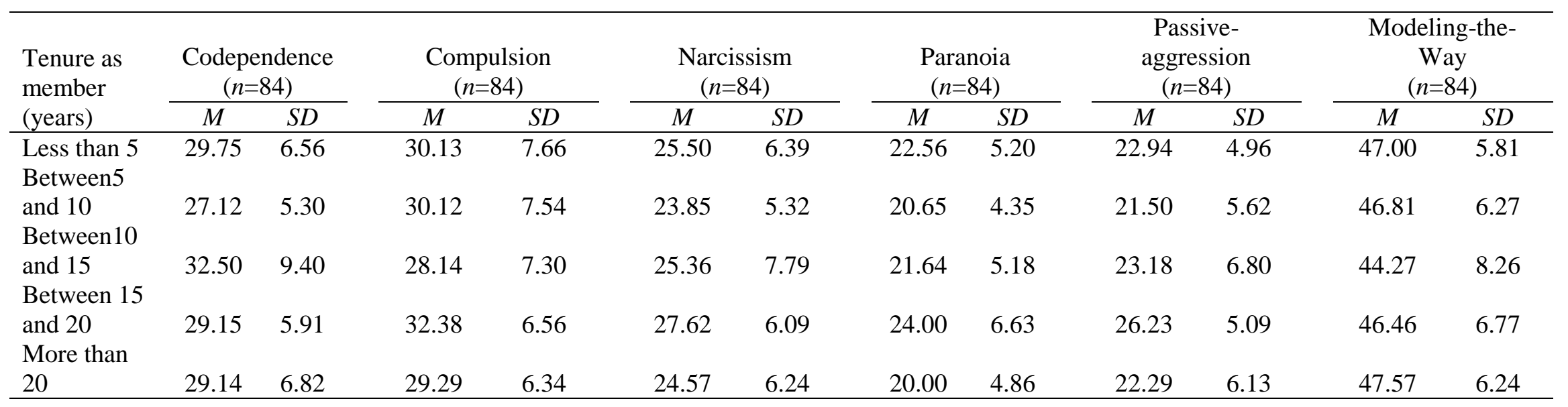

\begin{tabular}{|c|c|c|c|c|c|c|c|c|c|c|c|c|}
\hline \multirow{2}{*}{$\begin{array}{l}\text { Tenure as a } \\
\text { lay leader } \\
\text { (years) }\end{array}$} & \multicolumn{2}{|c|}{$\begin{array}{l}\text { Codep } \\
(n=84)\end{array}$} & \multicolumn{2}{|c|}{$\begin{array}{l}\text { Comp } \\
(n=84)\end{array}$} & \multicolumn{2}{|c|}{$\begin{array}{l}\text { Narc } \\
(n=84)\end{array}$} & \multicolumn{2}{|c|}{$\begin{array}{r}\text { Par } \\
(n=84)\end{array}$} & \multicolumn{2}{|c|}{$\begin{array}{l}\text { Pass-ag } \\
(n=84)\end{array}$} & \multicolumn{2}{|c|}{$\begin{array}{l}\text { Mod the Way } \\
(n=84)\end{array}$} \\
\hline & $M$ & $S D$ & $M$ & $S D$ & $M$ & $S D$ & $M$ & $S D$ & $M$ & $S D$ & $M$ & $S D$ \\
\hline Less than 1 & 27.00 & 8.73 & 25.78 & 7.98 & 23.89 & 6.64 & 19.78 & 6.94 & 20.89 & 5.84 & 48.89 & 4.46 \\
\hline and 5 & 30.84 & 7.97 & 28.42 & 6.17 & 25.16 & 6.91 & 20.79 & 4.37 & 22.89 & 5.70 & 45.37 & 7.06 \\
\hline
\end{tabular}

${ }^{*} p<0.05, * * p<0.01$ 


\section{REFERENCE LIST}

ABC Eyewitness News (2013, January 31). 4 out of previous 7 Illinois governors went to prison. ABC Eyewitness News. Chicago, IL. Retrieved from abc7chicago.com/archive/8973798/.

Aiken, L. R. (1997). Psychological testing and assessment (9th ed.). Needham Heights, MA: Allyn \& Bacon.

American Psychological Association. (1994). Diagnostic and statistical manual of mental disorders (4th. ed.). Washington, DC: Author.

American Psychological Association. (2000). Diagnostic and statistical manual of mental disorders (rev. 4th ed.). Washington, DC: Author.

Anderson, R. D. (2009). An analysis of attitudes, values, and beliefs of congregants and leaders of small churches towards church planting (Unpublished doctoral dissertation). Southern Baptist Theological Seminary, Ft. Worth, TX.

Austin, M. J., Regan, K., Gothard, S., \& Carnochan, S. (2013). Becoming a manager in nonprofit human serviceorganization: Making the transition from specialist to generalist. Administration in Social Work, 37(4), 372-385.

Avolio, B. J., Bass, B. M., \& Jung, D. I. (1999). Re-examining the components of transformational and transactional leadership using the Multifactor Leadership Questionnaire. Journal of Occupational \& Organizational Psychology, 72(4), 441-462.

Baloglu, N. (2012). Relations between value-based leadership and distributed leadership: A casual research on school principles' behaviors. Educational Sciences: Theory \& Practice, 12(2), 1375-1378.

Bass, B. M. (1985). Leadership and performance beyond expectations. New York, NY: Free Press.

Bass, B. M. (1990). Bass and Stodgill's handbook of leadership. New York, NY: Free Press.

Baumgartner, E. (1990). Towards a model of pastoral leadership for church growth in German-speaking Europe (Doctoral dissertation). Fuller Theological Seminary, Pasadena, CA. Available from ProQuest Dissertation \& Theses database. (AAT No. 9028136) 
Beattie, M. (1987). Codependent no more: How to stop controlling others and start caring for yourself. San Francisco, CA: Harper.

Bell, C. R. (2000). The mentor as a partner. Training \& Development, 54(2), 52-57.

Bennis, W. (1989). On becoming a leader. Reading, MA: Addison-Wesley.

Blake, R., \& Mouton, J. (1969). The managerial grid: Key orientations for achieving production through people. Houston, TX: Gulf.

Boeckmann, M. E., \& Dickinson, G. B. (2001). Leadership: Values and performance. Education, 121(3), 494-497.

Boyd, B. E. (2007). Improving leadership effectiveness in the nonprofit sector: A quantitative study on the impact of clarification ov values and expression of beliefs on codependency in religious orgainizations (Unpublished doctoral dissertation). Capella University, Minneapolis, MN.

Brown, A. D. (1997). Narcissism, identity, and legitimacy. Academy of Management Review, 22(3), 643-686.

Bruinsma, R. (2009). The body of Christ: A biblical understanding of the church. Hagerstown, MD: Review \& Herald.

Bruno, L. C., \& Lay, E. G. (2008). Personal values and leadership effectiveness. Journal of Business Research, 61(6), 678-683.

Bryant, F. B., \& Yarnold, P. R. (1995). Principal-components analysis and exploratory and confirmatory factor analysis. In L. G. Grimm \& P. R. Yarnold (Eds.), Reading and understanding multivariate statitics (pp. 99-136). Washington, DC: American Psychological Association.

Buford, B. (Ed.). (2008). Halftime: Changing your game plan from success to significance. Grand Rapids, MI: Zondervan. (Original work published 1994)

Burns, J. M. (1978). Leadership. New York: Harper \& Row.

Casson, R., \& Franzco, P. (2014). Understanding and checking the assumptions of linear regression: A primer for medical research. Clinical \& Experimental Ophthalmology, 42(6), 590-596. doi: 10.1111/ceo.12358

Clements, C., \& Washburn, J. B. (1999). The two faces of leadership: Considering the dark side of leader-follower dynamics. Journal of Workplace Learning, 11(5), 170-177.

Collins, J. (2000, June). Aligning actions and values. Forum. Retrieved from jimcollins.com/article_topics/articles/aligning-action.html 
Collins, J. (2005). Good to great in the social sectors. Chicago, IL: Author.

Conger, J. A. (1990). The dark side of leadership. Organizational Dynamics, 19(2), 4455.

Creswell, J. (2003). Research design: Qualitative, quantitative, and mixed methods approaches (2nd ed.). Thousand Oaks, CA: Sage.

Creswell, J. (2012). Educational research: Planning, conducting, and evaluating quantitative and qualitative research (4th ed.). Boston, MA: Pearson Education.

Cummings, T. G., \& Worley, C. G. (Eds.). (2009). Organizational development and change (9th ed.). Mason, OH: Cengage Learning.

Daboub, A., Rasheed, A., Priem, R., \& Gray, D. (1995). Top management team characteristics and corporate illegal activity. Academy of Management Review, 20(1), 138-170.

Dhar, U., \& Mishra, P. (2001). Leadership effectiveness: A study of constituent factors. Journal of Management Research, 1(4), 254-266.

Dinh, J. E., \& Lord, L. G. (2012). Implications of dispositional and process views of traits for individual difference research in leadership. Leadership Quarterly, 23(4), 651-669. doi: 10.1016/j.leaqua.2012.03.003

Dorfman, P. W., \& Howell, J. P. (1988). Dimensions of national culture and effective leadership patterns: Hofstede revisited. Advances in International Comparative Management Journal, 3, 127-150.

Drucker, P. (1999, March-April). Managing oneself. Harvard Business Review 77(2), 6474.

Field, A. (2009). Discovering statistics using SPSS (3rd ed.). London, UK: Sage.

Fiorina, C. (2006). Tough choices: A memoir. New York: Penguin Group.

Francis, C. A. (2012). The mediating force of "face:" Supervisor character and status related to perceived organizational support and work outcomes. Journal of Leadership \& Organizational Studies, 19(1), 58-67.

Franklin, F., \& Fong, R. (Eds.). (2011). The church leaders counceling resource handbook: A guide to mental health and social problems. New York: Oxford University Press.

Frost, R. (2013, May 30). Regression analysis: How do I interpret R-squared and assess the goodness-of-fit. Retrieved from blog.minitab.com/blog /adventures-instatistics/regression-analysis-how-do-i-interpret-r-squared-and-assess-thegoodness-of-fit 
Fullan, M. (2008). The six secrets of change. San Francisco, CA: Jossey-Bass.

General Conference of Seventh-day Adventists. (2000). Seventh-day Adventist church manual (16th ed.). Hagerstown, MD: Review \& Herald.

George, B., \& Sims, P. (2007). True north: Discover your authentic leadership. San Francisco, CA: Jossey-Bass.

Gilkeson, N. (2007). For-profit scandal in the nonprofit world: Should states force Sarbanes-Oxley provisions onto nonprofit corporations? Georgetown Law Journal, 95, 832-854.

Gonzalez, R. A. (2009). Ellen G. White's view on church order: The early years 18491854. Journal of Asia Adventist Seminary, 12(1), 51-72.

Groves, K. S., \& LaRocca, M. A. (2012). Does transformational leadership facilitate follower beliefs in corporate responsibility? A field study of leaders personal values and follower outcomes. Journal of Leadership \& Organizational Studies, 19(2), 215-229.

Guder, D. L. (2005). The church as missional community. In M. Husbands \& D. J. Treier (Eds.), The community of the world: Toward an evangelical ecclesiology (pp. 114-128). Downers Grove, IL: InterVarsity Press.

Gupta, P. (2011). Leading innovation change: The Kotter way. International Journal of Innovation Science, 3(3), 141-150.

Haaken, J. (1993). From Al-Anon to ACOA: Codependence and the reconstruction of caregiving. Signs: Journal of Women in Culture \& Society, 18(2), 321-345.

Heitzenrater, R. P. (1995). Wesley and the people called Methodists. Nashville, NT: Abingdon Press.

Hepworth, M., Simonds, L. M., \& Marsh, R. (2010). Catholic priests' conceptualisation of scrupulosity: A grounded theory analysis. Mental Health, Religion, \& Culture, 13(1), 1-16.

Hersey, K., \& Blanchard, K. (1969). Changing patterns of leadership: 3-D leadership effectiveness theory. West Point, NY: U.S. Military Academy.

Hersey, K., \& Blanchard, K. (1974). What's missing in MBO. Management Review, 63(10), 25-32.

Hersey, K., Blanchard, K., \& Johnson, D. (1996). Management of organizational behavior: Utilizing human resources (7th ed.). Englewood Cliffs, NJ: Prentice Hall. 
Hogan, R. (1983). A socioanalytic theory of personality. In M. M. Page (Ed.), 1982 Nebraska Symposium on Motivation (pp. 327-396). Lincoln, NB: University of Nebraska Press.

Hogan, R. (1996). A socioanalytic perspective on the five-factor model. In J. S. Wiggins (Ed.), The five-factor model of personality (pp. 163-179). New York: Guilford Press.

Hogg, M. A. (2001). A social identity theory of leadership. Personality \& Social Psychology Review, 5(3), 184-200.

Hopwood, C. J., Morey, L. C., NMarkowitz, J. C., Pinto, A., Skodol, A. E., Gunderson, J., . . Sanislow, C. A. (2009). A construct validity of passive-aggressive personality disorder. Psychiatry, 72(3), 256-268.

House, R. J., Spangler, W. D., \& Woycke, J. (1991). Personality and charisma in the U.S. presidency: A psychological theory of leader effectiveness. Administrative Science Quarterly, 36(3), 364-396.

Howell, D. (2013). Statistical methods for psychology (8th ed.). Belmont, CA: Wadsworth, Cengage Learning.

Hucks, J. (2003). John Wesley and the eighteenth century Methodist movement: A model for effective leadership. (Unpublished doctoral dissertation). Regent University, Virginia Beach, VA.

Hughes, R. L., Ginnett, R. C., \& Curphy, G. J. (2006). Leadership: Enhancing the lessons of experience (5th ed.). New York: McGraw-Hill.

Hughes, R. L., Ginnett, R. C., \& Curphy, G. J. (2012). Leadership: Enhancing the lessons of experience (7th ed.). New York: McGraw-Hill.

Hybels, B. (2002). Courageous leadership. Grand Rapids, MI: Zondervan.

Irving, J. A. (1994). Evaluating the reliability and validity of the dark side of leadership profile. In conference proceeding, International Leadership Studies Conference (pp. 1-12), Virginia Beach, VA: Regent University.

Johnson, C. (2007). Ethics in the workplace: Tools and tactics for organizational transformation. Thousand Oaks, CA: Sage.

Johnson, C. (2012). Meeting the ethical challenge of leadership: Casting light or shadow (4th ed.). Thousand Oaks, CA: Sage.

Johnson, S. E. (2002). The relationship of personal values and leadership behavior among first level supervisors. (Unpublished doctoral dissertation). University of Phoenix, Phoenix, AZ. 
Judge, T. A., Bono, J. E., \& Gerhardt, M. (2002). Personaility and leadership: A qualitative and quantitative review. Journal of Applied Psychology, 87(4), 765780 .

Judge, T. A., Piccolo, R. F., \& Kosalka, T. (2009). The bright and dark side of leader traits: A review and theoretical extension of the leader trait paradigm. Leadership Quarterly, 20(6), 855-875.

Kellerman, B. (2012). The end of leadership (1st ed.). New York: Harper Collins.

Knight, G. (2006). Philosophy \& education: An introduction in Christian perspective (4th ed.). Berrien Springs, MI: Andrews University Press.

Knudsen, T. M., \& Terrell, H. K. (2012). Codependency, perceived interparental conflict, and substance abuse in the family of origin. American Journal of Family Therapy, 40(3), 245-257. doi: 10.1080/01926187.2011.610725

Kouzes, J. M., \& Posner, B. Z. (2001). Leadership practices inventory (2nd ed.). San Fransisco, CA: Jossey-Bass Pfeiffer.

Kouzes, J. M., \& Posner, B. Z. (2002). The leadership practices inventory: Theory and evidence behind the five practices of exemplary leaders. Retrieved from media.wiley.com/assets/463/74/lc_jb_appendix.pdf

Kouzes, J. M., \& Posner, B. Z. (Eds.). (2003). The leadership challenge (3rd ed.). San Fransisco, CA: Jossey-Bass Pfeiffer.

Kouzes, J. M., \& Posner, B. Z. (2012a). The leadership challenge: How to make extraordinary things happen in organizations (5th ed.). San Francisco, CA: Jossey-Bass.

Kouzes, J. M., \& Posner, B. Z. (2012b). The leadership challenge workbook (3rd ed.). San Francisco, CA: Jossey-Bass.

Mancheno-Smoak, L., Endres, G. M., Polak, R., \& Athanasaw, Y. (2009). The individual cultural values and job satisfaction of the transformational leader. Organization Development Journal, 27(3), 9-21.

Martin, R. L. (2007). The opposable mind: How successful leaders win through integrative thinking. Boston, MA: Harvard Business School.

Martin, R. L. (2009). The opposable mind: Winning through integrative thinking. Boston, MA: Harvard Business School.

McIntosh, G., \& Rima, A. (1997). Overcoming the dark side of leadership: The paradox of personnal dysfunction. Cambridge, MA: Baker Book House. 
McIntosh, G., \& Rima, A. (2007). Overcoming the dark side of leadership: How to become an effective leader by confronting potential failures (Rev. ed.). Grand Rapids, MI: Baker Books.

McKlesky, J. (2012). The dark side of leadership: Measurement, assessment, and intervention. Business Renaissance Quarterly: Enhancing the Quality of Life at Work, 8(2), 35-53.

Mead, J. (2008). Confidence in the nonprofit sector through Sarbanes-Oxley reforms. Michigan Law Review, 106(5), 881-900.

Million, T., Grossman, S., Millon, C., Meagher, S., \& Ramnath, R. (2004). Personaility disorders in modern life (2nd ed.). Hoboken, NJ: John Wiley.

Morgan, G. A., \& Harmon, M. D. (2000). Research questions and hypothesis. Child \& Adolescent Psychiatry, 36(2), 261-263.

Morin, W. (1995). Silent sabotage: Mending the crisis in corporate values. Management Review, 84(7), 10-14.

Northouse, P. G. (2004). Leadership: Theory and practice (3rd ed.). Thousand Oaks, CA: Sage.

Northouse, P. G. (2013). Leadership: Theory and practice (6th ed.). Thousand Oaks, CA: Sage.

O’Toole, J. (1996). Leading change: An argument for value based leadership. New York: Jossey-Bass.

Palmer, P. (1994). Leading from within: Out of the shadow into the light. In J. A. Conger (Ed.), Spirit at work: Discovering the spirituality of leadership (pp. 19-40). San Francisco, CA: Jossey-Bass.

Phillips, D. T. (1992). Lincoln on leadership: Executive strategies for tough times. New York, NY: Warner.

Pierro, A., Cicero, L., \& Higgins, E. T. (2009). Followers' satisfaction from working with group-prototypic leaders: Promotion focus as moderator. Journal of Experimental Social Psychology, 45(5), 1105-1110. doi: 10.1016/j.jesp.2009.06.020

Pierson, R. (1996). So you want to be a leader. Silver Spring, MD: Ministerial Association, General Conference of Seventh-day Adventists.

Plante, T., \& Apodaca, C. (2011). Episcopal applicants to ordained ministry: Are they psychologocally healthy? Pastoral Psychology, 60(2), 279-289. 
Plass, R. E. (2002). A theological and empirical assessment of narcissism in theological students: A pilot study (Unpublished doctoral disserttation). Southern Baptist Theologocal Seminary, Louisville, KY.

Rokeach, M. (1979). Understanding human values: Individual and social. New York: Free Press.

Rosenzweig, P. (2007). The halo effect. New York: Free Press.

Rowntree, D. (1981). Statistics without tears: A primer for non-mathematicians. Needham Heights, MA: Allyn \& Bacon.

Rozbicki, M. (2011). Culture and liberty in the age of the American revolution. Charlottesville, VA: University of Virginia Press.

Rubio, D. M., Birkenmaier, J. M., \& Berg-Weger, M. (2000). Social welfare policy changes and social work practice. Advances in Social Work, 1(2), 177-186.

Sarantopoulos, N. D. (2008). The relationship between values and leadership styles of nonprofit leaders (Unpublished doctoral dissertation). University of Phoenix, Phoenix, AZ.

Savage, G. T., Dunkin, J. W., \& Ford, D. M. (2004). Responding to a crisis: A stakeholder analysis of community health organizations. Journal of Health \& Human Services Administration, 26(4), 383-414.

Schmid, H. (2013). Nonprofit human services: Between identity blurring and adaption to changing environments. Administration in Social Work, 37(3), 242-256.

Schwartz, S. H. (2012). An overview of the Schwartz theory of basic values. Online Readings in Psychology \& Culture, 2(1). Retrieved fom http://dx:doi.org/10.970712307-0919.116.

Schweitzer, C. (2011). The church leader's counseling and resource book: A guide to mental health and social problems. New York: Oxford University Press.

Shoemaker, M. E. (2003). Leadership behaviors in sales managers: A level analysis. Journal of Marketing Theory \& Practice, 11(2), 17-29.

Smith, P. C., Kendall, L. M., \& Hulin, C. L. (1969). The measurement of satisfaction in work and retirement. Chicago, IL: Rand McNally.

Smith, W. (2008, December 6). The big picture: Speech by Win Smith (as in Merrill Lynch, Pierce, Fenner, and Smith). Paper presented at the annual meeting of Merrill Lynch, Princeton, NJ. Retrieved from ritholtz.com/blog/2008/12/winsmith-as-in-merrill-lynch-pierce-fenner-smith/

Sorkin, A. R. (2009). Too big to fail. New York: Penguin Group. 
Strack, J. G. (2001). The relationship of healthcare managers' spirituality to their selfperceived effective leadership practices (Unpublished doctoral dissertation). University of South Carolina, Columbia.

Stubbs, P. A. (2011). St. Michaels Methodist Church spiritual and strategic planning: A congregation's movement into (increased) wholeness (Unpublished doctoral dissertation). Garrett Evangelical Theological Seminary, Evanston, IL.

Toates, F., \& Coschug-Toates, O. (2005). Obsessive compulsive disorder: Practical, tried-and-tersted strategies to overcome OCD (2nd ed.). London, UK: Class.

Torrenzano, R. (2008, October 1). The Torrenzano group: Financial crisis a result of leadership and communications failures. Retrieved from reuters.com/article /2008/10/01/idUS195895+01-Oct-2008+BW20081001\#58EtT9PG1GhRpkQz.97

Trochim, M. K. (2006). Types of reliability. Retrieved from socialresearchmethods.net/kb /reltypes.php

Turak, A. (2013). Business secrets of the Trappist monks: One CEO'squest for meaning and authenticity. New York: Columbia University Press.

United Methodist Publishing House. (2012). The book of discipline of the United Methodist Church. Nashville, TN: Author.

Van Knippenberg, D. (2011). Embodying who we are: Leader group prototypically and leadership effectiveness. Leadership Quarterly, 22, 1078-1091. doi: 10.1016/j.leaqua.2011.09.004

Veenker, R. R. (2000). A theraputeic strategy addressing three developmental issues in the person of pastor (Unpublished doctoral dissertation). Fuller Theological Seminary, Pasadena, CA.

Vogt, W. P. (1999). Dictionary of statistics and methodology: A nontechnical guide for the social sciences (2nd ed.). Thousand Oaks, CA: Sage.

Watson, D., Clark, L., \& Tellegen, A. (1988). Development and validation of brief measures of positive and negative affect: The PANAS Scales. Journal of Personality \& Social Psychology, 54(6), 1063-1070.

Webster, J. (2005). The visible attests the invisible. In M. Husbands \& D. J. Treier (Eds.), The community of the world: Toward an evangelical ecclesiology (pp. 96-113). Downers Grove, IL: InterVarsity Press.

Weinfurt, K. P. (Ed.). (1995). Multivariate analysis of variance. Washington, DC: American Psychological Association. 
Wheeler, W., \& Csoka, L. (1975). Leader behavior: Theory and study. In U. S. Military Academy Associates in Military Leadership (Ed.), The study of organizational leadership (1st ed.. pp. 361-370). West Point, NY: Author.

Wiehl, J. G. (2004). Roles and responsibilities of nonprofit health care board members in the post-Enron era. Journal of Legal Medicine, 25(4), 411-439.

Wolf, T. (2012). Social change and development: A research template. New Delhi: University Institute.

Zaidman, N., Goldstein-Gidoni, O., \& Nehemya, I. (2009). From temples to organization: The introduction and packaging of spirituality. Organization, 16(4), 597-621. doi: $10.1177 / 1350508409104510$ 
VITA 
VITA

\section{John Cosgrove \\ jfc1953@gmail.com}

John Cosgrove started his leadership career back in high school being president of his high school student body along with being captain of several athletic teams. In 1971 he was admitted to the United States Military Academy at West Point, where he graduated in 1975 as a Cadet Captain. His military career included serving as a Commander in the Presidential Honor Guard in Washington, DC. He attended the United States Army Ranger School becoming its valedictorian and teaching Leadership at the University of Wisconsin, where while teaching he earned a Masters of Science. He departed the service in 1987 as an Infantry, Airborne-Ranger, Major after 12 years of service.

Upon departing the service, John entered the financial industry eventually becoming a Director for Merrill Lynch (leading a Central part of the country) in 1996, followed by being appointed President of Mellon Bank Financial Advisors in 2003, and finally advancing to becoming a Senior Vice-President for UBS Investment Bank in 2004. He departed the corporate financial industry in 2003 and started his own financial firm.

Since 2006 John continues to be a community leader in the nonprofit community to include having been president of his church and being of the Board of Directors for local nonprofit organizations. He still owns a financial business, is the CEO and founder 
of the Leadership Workshop, LLC, and has spoken all over the world on values-based leadership. $\mathrm{He}$ is presently seeking a $\mathrm{PhD}$ in Leadership from Andrews University. 